Flora Maria Barbosa da Silva

\title{
TRANSFERÊNCIAS MATERNAS DE UMA CASA DE PARTO PARA O HOSPITAL: ESTUDO CASO-CONTROLE
}

\author{
Tese apresentada ao Programa \\ de Pós-Graduação em \\ Enfermagem da Escola de \\ Enfermagem da Universidade de \\ São Paulo para obtenção do título \\ de Doutor em Ciências.
}

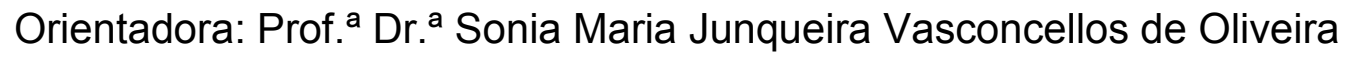

São Paulo 
AUTORIZO A REPRODUÇÃO E DIVULGAÇÃO TOTAL OU PARCIAL DESTE TRABALHO, POR QUALQUER MEIO CONVENCIONAL OU ELETRÔNICO, PARA FINS DE ESTUDO E PESQUISA, DESDE QUE CITADA A FONTE.

Assinatura:

Data:

Silva, Flora Maria Barbosa da

Transferências maternas de uma casa de parto para o hospital: estudo caso-controle / Flora Maria Barbosa da Silva. -- São Paulo, 2011.

$100 \mathrm{p}$.

Tese (Doutorado) - Escola de Enfermagem da Universidade de São Paulo.

Orientadora: Prof ${ }^{a}$ Dra $^{a}$ Sonia Maria Junqueira Vasconcellos de Oliveira

1. Centros independentes de assistência à gravidez e ao parto 2. Parto normal 3. Enfermagem obstétrica 4. Estudos de casos e controles I. Título. 


\section{FOLHA DE APROVAÇÃO}

Flora Maria Barbosa da Silva

Transferências maternas de uma casa de parto para o hospital: estudo casocontrole.

Tese apresentada ao Programa de PósGraduação em Enfermagem da Escola de Enfermagem da Universidade de São Paulo para obtenção do título de Doutor em Ciências.

Aprovado em: de novembro de 2011.

Profa $^{a}$ Dra

\section{Banca Examinadora}

Instituição:

Assinatura:

Profa $^{a} \cdot r^{a}$

Instituição:

Assinatura:

Profa $^{a} \cdot \mathrm{Dr}^{\mathrm{a}}$

Instituição:

Assinatura:

Prof. Dr.

Instituição:

Assinatura:

Profa $^{a}$ Dra $^{a}$

Instituição:

Assinatura: 


\section{DEDICATÓRIA}

A meus pais, João e Jessy, por tudo A minhas irmãs, Patrícia e Denise, por nossa união Com amor 


\section{AGRADECIMENTOS}

À professora Doutora Sonia Maria Junqueira Vasconcellos de Oliveira, orientadora desta tese, por ter conduzido esta aventura do saber e por nossa convivência.

Às professoras do Departamento de Enfermagem Materno-Infantil e Psiquiátrica, pela amizade e acolhimento.

À professora Doutora Ruth Hitomi Osava, pela amizade e inspiração na luta pela humanização do parto e nascimento.

À professora Doutora Debra Bick, da Florence Nightingale School of Midwifery do King's College London, pela orientação durante o estágio de doutorado sanduíche.

À CAPES, pelo estágio de doutorado sanduíche .

Ao CNPq, pela bolsa de doutorado.

Às colegas da Casa do Parto de Sapopemba, pelo apoio na realização deste trabalho.

Aos profissionais do Hospital Estadual de Vila Alpina, pela colaboração na coleta de dados desta pesquisa.

À professora Ivone Borelli, pela revisão de língua portuguesa.

À professora Maria do Rosário Dias de Oliveira Latorre, da Faculdade de Saúde Pública da USP, pela análise estatística.

Ao professor Moacyr Roberto Cuce Nobre, do Departamento de Epidemiologia do Instituto do Coração (Incor), pelas sugestões no desenho do estudo. 
SILVA FMB. Transferências maternas de uma casa de parto para o hospital: estudo caso-controle [tese]. São Paulo: Escola de Enfermagem, Universidade de São Paulo; 2011.

\section{RESUMO}

Centros de parto normal (CPN) têm como finalidade a assistência à mulher no parto normal sem complicações. Podem ter localização intra-hospitalar, peri-hospitalar ou extra-hospitalar (autônomo). Os objetivos foram: identificar os fatores de risco para transferência materna de um CPN para o hospital; elaborar um modelo de risco para transferência intraparto baseado nos fatores identificados e analisar os desfechos maternos e neonatais das transferências. Estudo do tipo caso-controle, com coleta de dados retrospectiva, em um centro de parto extra-hospitalar (Casa do Parto de Sapopemba - CPS) e no Hospital Estadual de Vila Alpina (HEVA), na cidade de São Paulo. Os casos foram todas as mulheres transferidas da CPS para o HEVA, de março de 2002 a dezembro de 2009. Os controles foram mulheres não transferidas que deram à luz na CPS no mesmo período, selecionadas aleatoriamente, sendo quatro controles para cada caso. Os fatores de risco para transferências maternas intraparto foram analisados primeiro pelo teste QuiQuadrado. Na análise múltipla, incluíram-se as variáveis com $p<0,20$. Elaborou-se a seguir o modelo de regressão logística múltiplo pelo processo stepwise forward selection; variáveis com $p<0,05$ foram fatores independentes associados às transferências maternas. Transferências maternas pós-parto tiveram análise descritiva, em razão do reduzido número (13). Variáveis identificadas como fatores de risco independentes para transferência intraparto: nuliparidade (OR 5,6; IC 95\% 2,9-10,9), idade materna $\geq 35$ anos (OR 5,0; IC 95\% 2,0-12,7), não ter companheiro (OR 2,7; IC 95\% 1,4-5,1), ser admitida na CPS com cervicodilatação $\leq 3 \mathrm{~cm}$ (OR 2,0; IC 95\% 1,1-3,4), realizar 5-12 consultas na CPS (OR 3,3; IC 95\% 1,6-6,7) e peso do RN de 4.000-4.600 g (OR 3,5; IC 95\% 1,1-11,2). Adequação entre altura uterina e idade gestacional baixa (OR 0,3; IC 95\% 0,2-0,6) foi fator de proteção para a transferência. Apresentou-se modelo de risco para transferência intraparto, com probabilidade de transferência estimada de acordo com as variáveis identificadas como fatores de risco. Nos desfechos das transferências maternas: taxa de transferência intraparto: $4,1 \%$; pós-parto: $0,5 \%$; não houve óbitos entre as mulheres que deram à luz na CPS ou no HEVA e entre os RN da CPS; houve óbito de dois RN do HEVA (taxa de mortalidade perinatal: 0,73/1.000 nascidos vivos). Causas de transferência intraparto: maternas $(57,6 \%$ falha no progresso do trabalho de parto); fetais (28\% líquido amniótico meconial e traçado cardiotocográfico alterado); outras (14,4\%); via de parto das mulheres transferidas: $49,5 \%$ parto normal; $44,1 \%$ cesariana; $4,5 \%$ fórceps e 1,8\% vácuo extrator. Entre os $\mathrm{RN}$ de mães transferidas: $25,2 \%$ e $4,5 \%$ tiveram Apgar $<7$ nos $1^{\circ}$ e $5^{\circ}$ minutos, respectivamente; unidade de internação: $10,8 \%$ na UTI neonatal, $9,0 \%$ unidade de cuidados intermediários, $0,9 \%$ setor de observação e $79,3 \%$ alojamento conjunto. Causas de transferência no pós-parto: retenção placentária $(38,5 \%)$; outros problemas $(30,8 \%)$; sangramento vaginal aumentado $(15,4 \%)$ e febre materna $(15,4 \%) ; 46,1 \%$ necessitaram de curetagem e $38,4 \%$ de transfusão sanguínea. Concluiu-se que identificar os fatores de risco para transferência materna contribui para refinar os critérios de admissão de mulheres atendidas em CPN, ao auxiliar na identificação de casos que podem resultar em complicações.

PALAVRAS-CHAVE: centros independentes de assistência à gravidez e ao parto; parto; parto normal; enfermagem obstétrica; estudos de casos e controles. 
SILVA FMB. Maternal transfers from a freestanding birth center to the hospital: a case control study [thesis]. São Paulo (SP): Nursing School, University of São Paulo, 2011.

\begin{abstract}
Birth centers (BC) aim to provide care to women in normal birth without complications. They may have in-hospital, alongside or freestanding (autonomous) locations. The objectives were to identify risk factors for maternal transfer from a BC to the hospital, to develop a risk model for intrapartum transfers using the identified factors and to analyze the maternal and neonatal outcomes of transfers. It was a case-control study, with retrospective data collection in a freestanding birth center (Sapopemba Birth Center - SBP) and the State Hospital Vila Alpina (HEVA), in São Paulo. The cases were all women transferred from SBP to HEVA, from March 2002 to December 2009. The controls were not transferred women who gave birth in CPS in the same period, randomly selected, four controls for each case. Risk factors for maternal intrapartum transfers were primarily analized by the Chi-square test. In the multivariate analysis, the variables with $p<0.20$ were included. The multiple logistic regression model was build by stepwise forward selection process; variables with $p$ $<0.05$ were factors independently associated with maternal transfers. Postpartum maternal transfers had descriptive analysis, due to the small number (13). Variables identified as independent risk factors for intrapartum transfer: nulliparity (OR 5.6, $95 \% \mathrm{Cl} 2.9$ to 10.9 ), maternal age $\geq 35$ years (OR $5.0,95 \% \mathrm{Cl} 2.0$ to 12 . 7 ), no partner (OR 2.7, 95\% Cl 1.4 to 5.1 ), admission to the CPS with cervical dilation $\leq 3$ $\mathrm{cm}$ (OR 2.0, 95\% Cl 1.1-3.4), number of appointments on SBC 5-12 CPS (OR 3.3, $95 \% \mathrm{Cl} 1.6$ to 6.7 ) and newborn weight $4000-4600 \mathrm{~g}$ (OR 3.5, 95\% $\mathrm{Cl} 1.1$ to 11.2 ). The low result for fitting uterine height and gestational age (OR $0.3,95 \% \mathrm{Cl} 0.2-0.6$ ) was a protective factor for transfer. A model of risk for intrapartum transfer was presented, to estimate the probability of transfer according to the variables identified as risk factors. The outcomes of maternal transfers were: intrapartum transfer rate: $4.1 \%$; postpartum transfer rate: $0.5 \%$; there were no deaths among women who gave birth in SBC or HEVA or between the newborns who were born on SBC; there were two deaths of newborns born in HEVA (perinatal mortality rate: 0.73 / 1,000 live births). Causes of intrapartum transfer: maternal (57.6\% failure to progress in labor), fetal (28\% meconium stained amniotic fluid and cardiotocographic trace changes), others (14.4\%); mode of delivery of the transferred women: $49,5 \%$ normal delivery, cesarean section $44.1 \%, 4.5 \%$ forceps and $1.8 \%$ vacuum extractor. Among infants of mothers transferred: $25.2 \%$ and $4.5 \%$ had Apgar score $<7$ at 1 st and 5th minutes, respectively; unit admission of newborns: $10.8 \%$ in the neonatal intensive care unity, $9.0 \%$ intermediate care unit, $0,9 \%$ observation rooms and $79.3 \%$ rooming-in unity. Causes of postpartum transfer: retained placenta (38.5\%), other problems $(30.8 \%)$, increased vaginal bleeding $(15.4 \%)$ and maternal fever $(15.4 \%) ; 46.1 \%$ required curettage and $38.4 \%$ blood transfusion. It was concluded that identifying risk factors for maternal transfer contributes to refine the criteria for admission of women attending $\mathrm{BC}$, as it can be useful in identifying cases that may lead to complications.
\end{abstract}

Keywords: Birthing centers, parturition, natural childbirth, obstetrical nursing, case control studies. 


\section{SILVA FMB. Transferencias maternas de una casa de parto para el hospital: estudio caso-control [tesis doctoral]. São Paulo: Escuela de Enfermería, Universidade de São Paulo, 2011.}

\section{RESUMEN}

Centros de parto normal (CPN) se destinan a la atención a la mujer en el parto normal sin complicaciones. Pueden tener localización intra-hospitalaria, perihospitalaria o extra-hospitalaria (independiente). Los objetivos fueron: identificar los factores de riesgo para la transferencia materna de un CPN para el hospital, elaborar un modelo de riesgo para la transferencia intra-parto con base en los factores identificados y analizar los resultados maternos y neonatales de las transferencias. Estudio de tipo caso-control, con recolección de datos retrospectiva en un CPN extra-hospitalario (Casa de Parto Sapopemba-CPS) y en el Hospital Estadual de Vila Alpina (HEVA), en São Paulo. Los casos fueron todas las mujeres transferidas de la CPS para el HEVA, desde Marzo del 2002 a Diciembre del 2009. Los controles fueron mujeres no transferidas que dieron a luz en la CPS en el mismo período, seleccionados al azar, con cuatro controles para cada caso. Se analizaron los factores de riesgo para la transferencia materna intra-parto, primeramente por el test chi-cuadrado. En el análisis multivariado, se incluyeron las variables con $p<0,20$. A seguir, se elaboró un modelo de regresión logística múltiple por el proceso de stepwise forward selection; variables con $p<0,05$ fueron factores independientemente asociados con las transferencias maternas. Las transferencias maternas post-parto fueron analizadas de modo descriptivo, debido a su pequeño número (13). Variables identificadas como factores de riesgo independientes para la transferencia intra-parto: nuliparidad (OR 5,6; IC 95\%: 2,9 a 10,9); edad materna $\geq 35$ años (OR 5,0; IC 95\%: 2,0 a 12, 7); no tener pareja (OR 2,7; IC 95\%: 1,4 a 5,1); admisión en la CPS con dilatación del cuello uterino $\leq 3 \mathrm{~cm}$ (OR 2,0; IC 95\%: 1,1 a 3,4 ); realizar de 5 a 12 consultas en la CPS (OR 3,3; IC 95\%: 1,6 a 6,7) y peso del recién nacido de 4000 a 4600 g (OR 3,5; IC 95\%: 1,1 a 11,2). La adecuación entre altura uterina y edad gestacional pequeña (OR 0,3; IC 95\% 0,2-0,6) fue un factor de protector para la transferencia. Se presentó un modelo de riesgo para la transferencia intra-parto, con una probabilidad estimada de acuerdo con las variables identificadas como factores de riesgo. Resultados de las transferencias maternas: tasa de transferencia intra-parto: $4,1 \%$; post-parto: $0,5 \%$; no hubo muertes de mujeres que dieron a luz en la CPS o en el HEVA y ni tampoco entre los recién nacidos de la CPS; se registraron muertes de dos recién nacidos el HEVA (tasa de mortalidad perinatal: 0,73/1.000 nacidos vivos). Causas de transferencia intra-parto: maternas (57,6\% de fracaso para avanzar en el trabajo); fetales (28\% líquido amniótico meconial y cardiotocografía alterada); otras (14,4\%); vía de parto de las mujeres transferidas: $49,5 \%$ parto normal; $44,1 \%$ cesariana; $4,5 \%$ fórceps y $1,8 \%$ ventosa. Entre los recién nacidos de madres transferidas: $25,2 \%$ y $4,5 \%$ tuvieron puntaje de Apgar $<7$ en el $1^{\text {er }}$ y $5^{\circ}$ minutos, respectivamente; internación hospitalaria: $10,8 \%$ en la unidad de cuidados intensivos neonatales; $9,0 \%$ en la unidad de cuidados intermedios; $0,9 \%$ en el sector de observación y $79,3 \%$ en el alojamiento conjunto. Causas de transferencia post-parto: placenta retenida $(38,5 \%)$, otros problemas $(30,8 \%)$, aumento del sangrado vaginal $(15,4 \%)$ y fiebre materna $(15,4 \%) ; 46,1 \%$ necesitaron raspado y $38,4 \%$ transfusión de sangre. Se concluyó que la identificación de factores de riesgo para la transferencia materna contribuye a perfeccionar los criterios para la admisión de mujeres atendidas en el CPN, al ayudar a identificar los casos que pueden resultar en complicaciones.

Palabras-clave: Centros Independientes de Asistencia al Embarazo y al Parto. Parto. Parto Normal. Enfermería Obstétrica. Estudios de casos y controles. 


\section{LISTA DE ILUSTRAÇÕES}

Figura 1. Fluxograma da seleção de casos e controles 36

Figura 2. Taxas de transferência intraparto e número anual de partos na Casa do Parto de Sapopemba. São Paulo, 2002 a 2009 48 


\section{LISTA DE TABELAS}

Tabela 1 - Distribuição do número e porcentagem de mulheres transferidas e não transferidas, conforme características sócio-demográficas. São Paulo, 2002 a 2009

Tabela 2 - Distribuição do número e porcentagem de mulheres transferidas e não transferidas, segundo variáveis da assistência pré-natal, história obstétrica e admissão na CPS. São Paulo, 2002 a 2009

Tabela 3 - Distribuição do número e porcentagem de mulheres transferidas e não transferidas, segundo variáveis da assistência durante o trabalho de parto e do recém-nascido. São Paulo, 2002 a 2009

Tabela 4 - Odds ratio (OR) brutas e ajustadas para transferência materna intraparto. São Paulo, 2002 a 2009

Tabela 5 - Modelo de risco para transferência materna no período intraparto - CPS, São Paulo, 2011

Tabela 6 - Número e frequência dos motivos para transferência materna intraparto. São Paulo, 2002 a 2009.

Tabela 7 - Número e frequência das indicações de partos cirúrgicos entre as mulheres transferidas. São Paulo, 2002 a 2009

Tabela 8 - Número e frequência dos motivos para transferência materna pós-parto. São Paulo, 2002 a 2009 


\section{SUMÁRIO}

Resumo

Abstract

Resumen

Lista de Figuras

Lista de Tabelas

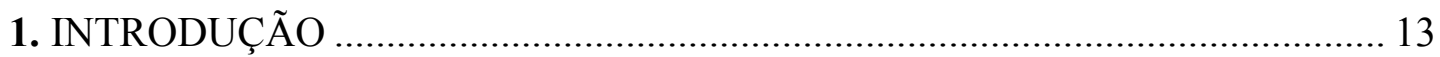

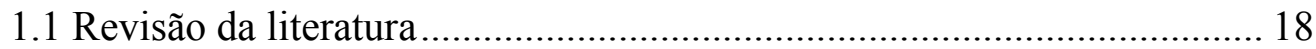

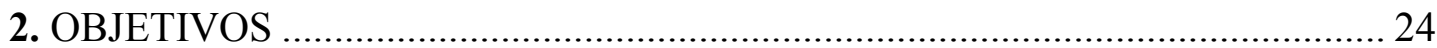

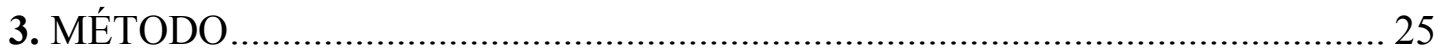

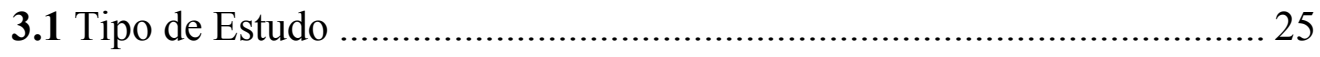

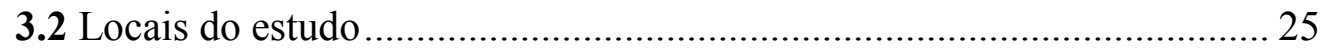

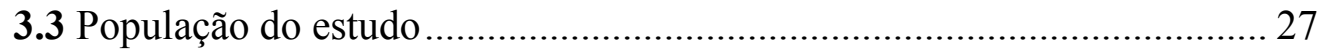

3.3.1 Definição e seleção de casos ..................................................... 28

3.3.2 Definição e seleção de controles ............................................... 28

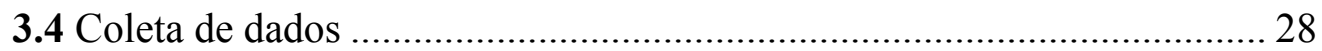

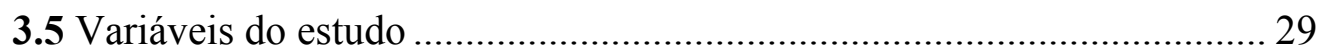

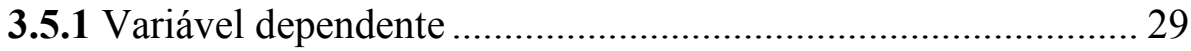

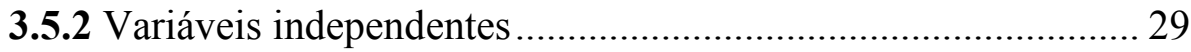

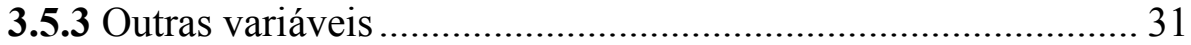

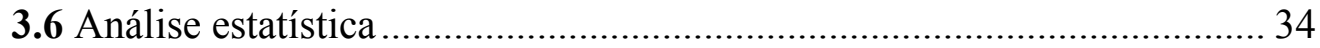

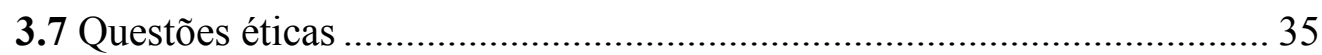

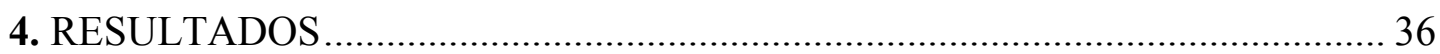

4.1 Fatores de risco para transferência materna .......................................... 36

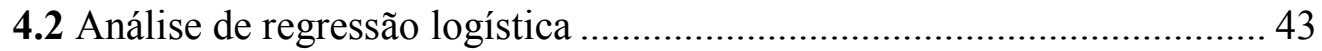

4.3 Modelo de risco para transferência materna no período intraparto.......... 45

4.4 Análise dos desfechos das transferências maternas ............................... 47

4.4.1 Desfechos das transferências no período intraparto .................. 47 
6. CONCLUSÃO 72

7. CONSIDERAÇÕES FINAIS 74

8. REFERÊNCIAS 76

\section{ANEXOS}

1. Protocolos assistenciais da Casa do Parto de Sapopemba. 84

2. Parecer do Comitê de Ética em Pesquisa - SMS/SP .................................. 90

3. Parecer do Comitê de Ética em Pesquisa - IEPAC/SECONCI .................. 92

\section{APÊNDICES}

1. Formulário de coleta de dados - grupo controle 93

2. Formulário de coleta de dados - transferência intraparto 95

3. Formulário de coleta de dados - transferência pós-parto 98 
Centros de parto normal (CPN) são instituições cujo objetivo é prestar assistência à mulher no parto normal sem complicações. A definição do Grupo Nacional de Epidemiologia Perinatal inglês é a seguinte:

\footnotetext{
Um centro de parto é uma instituição que oferece cuidado a mulheres com gravidez fisiológica e onde obstetrizes têm a responsabilidade profissional primária pelo cuidado. Os serviços médicos, incluindo cuidado obstétrico, neonatal e anestésico estão disponíveis durante o trabalho de parto e o parto, se necessário, porém eles podem estar em um local separado ou um prédio separado, o que pode envolver transferência por carro ou ambulância. (Stewart et al., 2005, p.8).
}

Esses serviços recebem diversas denominações, tanto no Brasil quanto como no exterior. O termo mais conhecido é birth center ou birth centre, que pode ser traduzido como "centro de parto". No Brasil, a expressão "Casa de Parto" está associada a centros de parto extrahospitalares e peri-hospitalares. O termo "centro de parto normal" tem sido usado para designar centros de parto localizados dentro das instalações do hospital, porém fora do ambiente cirúrgico denominado centro obstétrico.

Os CPN podem ter localização dentro (intra-hospitalar), ao lado (peri-hospitalar) ou distante do hospital (extra-hospitalar ou autônomo). Nesses locais, a assistência à mulher é feita geralmente por enfermeiras obstétricas e obstetrizes. A Organização Mundial de Saúde (OMS) reconhece estas profissionais, além de médicos, como habilitados para prestar assistência à mulher no parto (WHO, 2004) e recomenda que as mulheres possam escolher dar à luz no nível mais periférico no qual o cuidado é acessível e seguro. (WHO, 1996).

Embora a filosofia do cuidado no CPN possa variar entre os serviços, de maneira geral, nesses locais há estímulo à normalidade do parto e nascimento, à continuidade do cuidado e à assistência centrada na mulher, com apoio às suas escolhas (Laws et al., 2009). Em caso de problemas durante o parto ou com o recém-nascido, a parturiente deve ser transferida para uma unidade de saúde devidamente equipada, e os 
profissionais deverão trabalhar de maneira conjunta, caso surjam problemas durante o parto (WHO, 2007).

Em razão dessa eventual necessidade de transferência, a assistência ao parto em ambiente fora do hospital, tanto em centros de parto como nos domicílios é um tópico controverso entre profissionais, sobretudo com relação à questão de segurança das mulheres e dos recém-nascidos. Eventos adversos podem surgir no período intraparto ou pós-parto, a despeito da cuidadosa avaliação das mulheres candidatas a dar à luz nesses locais. O tempo necessário para a transferência poderia protelar a adoção de medidas urgentes, como cesarianas de emergência ou manobras de reanimação neonatal (Overgaard et al., 2011). A situação pode ser complicada pela falta de cooperação ou comunicação deficiente entre o centro de parto e o hospital (David et al., 2006). A assistência ao parto no domicílio tem sido objeto de maiores questionamentos, pois parece trazer benefícios à mãe, mas pode aumentar os riscos ao recém-nascido (Tuffnell, 2010)

Entre diversas organizações profissionais, não há consenso quanto ao melhor local para o parto e nascimento. O American College of Nurse Midwives (ACNM, 2005) e a American Public Health Association (APHA, 2001), o Royal College of Midwives (RCM) e o Royal College of Obstetricians and Gynaecologists (RCOG) apoiam o parto domiciliar para mulheres com gestações não complicadas (RCOG, RCM., 2007). A International Federation of Gynecology and Obstetrics (FIGO) e a Organização Mundial de Saúde recomendam que a mulher possa dar à luz em um serviço no nível mais periférico onde a assistência for viável e segura (WHO, 1996) (FIGO, 1992). O American College of Obstetricians and Gynecologists apoia a assistência ao parto em CPN (sem especificar sua localização), mas não partos domiciliares (ACOG, 2011). A Federação Brasileira da Associação de Ginecologistas e Obstetras (FEBRASGO) tem posicionamento formal contrário aos centros de parto extra-hospitalares (FEBRASGO, 2009).

Neste contexto, a designação do hospital como local de escolha para dar à luz foi acompanhada pelo aumento de intervenções no 
processo de nascimento. Estas práticas foram inseridas na assistência ao parto normal, usualmente sem avaliação científica de sua eficácia e segurança. Neste sentido, o parto é abordado como um evento de alto risco que deve ser adequado à rotina hospitalar. Entre tais práticas, incluem-se: aumento do número de partos cirúrgicos, aceleramento do processo do parto pelo manejo ativo (amniotomia precoce, uso de ocitocina), realização rotineira de episiotomia e não participação de acompanhantes no processo da parturição (Davis-Floyd, 2001). Essas intervenções, quando utilizadas para corrigir desvios de normalidade no processo do nascimento e parto, contribuem para a melhoria dos indicadores maternos e perinatais. No entanto, intervenções inoportunas em mulheres com gestações fisiológicas podem resultar em iatrogenias e consumirem recursos do sistema de saúde de maneira desnecessária.

Com o advento da medicina baseada em evidências pautada em dados de pesquisas obtidas em colaborações internacionais, apoiadas pela OMS, procurou-se verificar a eficácia e a segurança das práticas na assistência à gravidez, parto e pós-parto. Constatou-se, então, que muitos dos procedimentos utilizados na assistência obstétrica e supostamente benéficos à mulher, após revisões sistemáticas, demonstraram-se danosos e desnecessários (Moore, 1985).

A assistência ao parto em um serviço extra-hospitalar foi uma das estratégias para oferecer uma assistência que minimizasse essas intervenções no cuidado às mulheres com gestações de baixo risco. Iniciouse nos Estados Unidos da América (EUA), e o primeiro centro de parto independente foi aberto pela Maternity Center Association of New York em 1975. Na Europa, o primeiro centro de parto iniciou suas atividades, em 1987, em Berlim (David et al., 1999). Nos EUA, a expansão dos CPN, como unidades integradas ao hospital e com rápido acesso ao atendimento médico, ocorreu aparentemente sem dificuldades, ao contrário dos CPN autônomos (Walsh e Downe, 2004). No Brasil, a regulamentação dos CPN começou com a Portaria n985/1998 do Ministério da Saúde (Brasil, 1999).

Em nosso País, a institucionalização do parto, durante a década de 1940, foi provavelmente a primeira ação de saúde pública 
destinada à mulher. Este modelo de assistência tomou corpo com a criação de maternidades e a elevação do percentual de partos cirúrgicos. Embora a hospitalização do parto tenha contribuído para a diminuição da mortalidade materna e neonatal, o ambiente de nascimento tornou-se pouco acolhedor para a mulher e sua família (Diniz, 2005). Paradoxalmente, o abuso da tecnologia pode ser responsável pelo aumento da morbidade e mortalidade materna e perinatal, como demonstrado em um estudo de coorte realizado no Sul do Brasil (Barros et al., 2005). Observa-se que a condição das mulheres melhorou com relação à nutrição, educação e serviços de saúde, mas as taxas de mortalidade neonatal permanecem estáveis desde 1990. Isto tem sido atribuído ao aumento das taxas de cesariana e indução do parto, associadas à interrupção da gestação, antes do início espontâneo do trabalho de parto (Barros et al., 2005).

As altas taxas de cesariana são comuns a quase todos os países do mundo, pois os avanços da medicina, a industrialização e o modelo biomédico fizeram com que houvesse aumento da incidência desse tipo de parto. No entanto, foram raros os países que atingiram níveis de cesariana tão altos como o Brasil onde, em serviços particulares, as taxas podem chegar próximas a 90\% (Brasil, 2008). Estes índices tornaram-se emblemáticos da interferência sobre o corpo e a dinâmica femininos em nosso País (Moraes e Goldenberg, 2001) (Barbosa et al., 2003).

A partir de 1970, houve experiências em diversos estados brasileiros que buscaram promover a humanização e as práticas alternativas na assistência ao parto. Desse modo, no final da década de 1980, surgiu um movimento dos profissionais da Medicina Sanitária que questionou o modelo de assistência ao parto vigente no Brasil (Diniz, 2005). Entre as iniciativas governamentais que procuravam estimular a assistência apropriada ao nascimento, destaca-se a Portaria assinada pelo então ministro da saúde José Serra, que viabilizou a criação dos centros de parto normal extrahospitalares, com o nome de Casas de Parto (Brasil, 1999). Assim, a Casa do Parto de Sapopemba foi inaugurada em 1998, e sua experiência diária forneceu parâmetros para a regulamentação desse tipo de serviço. Tinha como objetivo oferecer uma vivência humanizada de parto e nascimento às 
gestantes de baixo risco da região de Sapopemba, local carente de leitos obstétricos.

Os resultados maternos e neonatais dos centros de parto são de modo geral favoráveis, porém as mulheres atendidas nesses serviços e que precisam de transferência constituem um grupo de risco (Fullerton et al., 1997; David et al., 2006; Nguyen et al., 2009; Laws et al., 2011). Essas parturientes, embora sejam avaliadas como de baixo risco obstétrico durante a gestação e na admissão nos centros de parto, apresentam complicações no decorrer do trabalho de parto que demandam assistência hospitalar. Existem poucos estudos que investigaram os resultados dessas transferências maternas. Além disso, há necessidade de produzir evidências locais sobre CPN no Brasil, visto que a oferta desses serviços no âmbito do SUS é bastante recente e ainda limitada. Neste contexto, esta pesquisa teve como objetivo investigar os fatores de risco e os resultados maternos e neonatais das transferências maternas de centro de parto autônomo para o hospital. 


\section{Revisão da Literatura}

A assistência ao parto em CPN tem sido objeto de investigação em diversos estudos internacionais. Como indicadores clínicos da qualidade da assistência prestada nesses locais, as seguintes variáveis têm sido investigadas: morbidade e mortalidade materna e neonatal, taxas de transferência materna e neonatal e suas causas, taxas de parto cesariana e de parto vaginal assistido, taxas de intervenções nos partos assistidos nos CPN e nos partos das mulheres transferidas (uso de ocitocina, episiotomia, cesariana, parto vaginal assistido), escores de Apgar nos $1 .^{\circ}$ e $5 .^{\circ}$ minutos de vida e taxas de admissão em unidade neonatal (Albers e Katz, 1991). Outros estudos vêm investigando outras variáveis como a satisfação das mulheres e o custo da assistência. Estudo de coorte com coleta de dados prospectiva está sendo conduzido no Reino Unido para avaliar os resultados maternos e perinatais de acordo com os locais planejados para dar à luz. Os locais são: domicílio, centros de parto autônomos e peri-hospitalares e unidades obstétricas hospitalares ${ }^{1}$. O ambiente dos centros de parto parece ter um efeito positivo na experiência de dar à luz (Esposito, 1999; Borquez, Wiegers, 2006).

Os estudos foram identificados pela busca bibliográfica com os seguintes termos: centro de parto, casa de parto, birth center, birthing center, birth centre, birthing centre, maternity center, maternity centre, maternity home, maternity unit, birth unit, birthing unit, midwifery-led birthing units. As bases de dados nas quais realizou a busca foram: Biblioteca Cochrane, Ebsco Host, Emerald, Embase, Gale Cengage Academic OneFile, Medline, Scopus, Web of Knowledge (ISI), e, nos anos de 1980 a 2011.

$\mathrm{O}$ efeito do local de parto em resultados maternos e neonatais foi investigado em revisão da Biblioteca Cochrane que incluiu nove ensaios randomizados e quasi-randomizados, totalizando 10.684 mulheres. Este estudo comparou os resultados maternos e neonatais de dois tipos de ambientes de parto no hospital: convencional e alternativo (ambiente semelhante ao domicílio) (Hodnett et al., 2010). Na busca bibliográfica desta

\footnotetext{
${ }^{1}$ www.npeu.ox.ac.uk/birthplace
} 
revisão, não foram encontrados estudos relativos a centros de nascimento autônomos. A alocação das mulheres para ambientes alternativos aumentou significantemente a probabilidade de terem parto vaginal espontâneo (oito ensaios; $n=10.818$; risco relativo (RR) 1,04 ; intervalo de confiança (IC) $95 \%$ 1,02 a 1,06), não fazerem uso de analgesia ou anestesia no período intraparto (cinco ensaios; $n=7.842$; RR: 1,17; IC 95\% 1,01 a 1,35), estarem amamentando 6 a 8 semanas após o parto (um ensaio, n=1147; RR 1,04, IC $95 \%$ 1,02 a 1,06) e terem opinião positiva sobre o atendimento (dois ensaios, $n=1.207$; RR 1,96; IC 95\% 1,78 a 2,15). A mulher, ao ser designada para o grupo de cuidado em ambientes alternativos, teve diminuída a probabilidade de usar analgesia (sete ensaios, $n=9.820$; RR 0,82, IC 95\%: 0,75 a 0,89 ); de receber ocitocina durante o trabalho de parto (sete ensaios, $\mathrm{n}=10.020$; RR 0,78; IC 95\% 0,66 a 0,91) e ter episiotomia (sete ensaios, n=9.944; RR 0,83; IC 95\% IC 0,77 a 0,90). Não houve diferenças entre os grupos com relação à morbidade e mortalidade materna, resultados neonatais adversos e hemorragia pós-parto. Nesta análise, não foi possível separar os efeitos do ambiente daqueles efeitos dos modelos de cuidado, pois em diversos ensaios o ambiente diferenciado envolvia outra estrutura de equipe e maior continuidade da assistência.

Revisão estruturada analisou cinco artigos que relatam os resultados de CPN autônomos, liderados por obstetrizes, comparados a unidades obstétricas localizadas em hospitais (Walsh e Downe, 2004). Não foi feita revisão sistemática, pois não foram encontrados ensaios clínicos randomizados. Os desfechos verificados no grupo de centros de nascimentos foram: maiores taxas de parto normal (aumento da percentagem de parto normal de $4,8 \%$ a $13,3 \%$ em quatro estudos); períneo intacto (aumento de $3,4 \%$ a $18,7 \%$ em quatro estudos) e permanência dos bebês com suas mães (acima de $90 \%$ em ambos os grupos, com um aumento de 0,8 a $3,6 \%$ nos $\mathrm{CPN}$ ). Houve diminuição de taxas de cesariana (de $1,0 \%$ a $8,0 \%$ em quatro estudos) e de episiotomia (de $13,9 \%$ a $39,1 \%$ ). A mortalidade perinatal apresentou números muito pequenos e, de maneira geral, não foi relatada nos estudos, conforme relato dos autores. Os dados de um dos ensaios clínicos indicaram que a taxa de óbitos fetais poderia ser 
de, quase, 2/1.000 partos em centros de nascimento, versus 4/1.000, em partos hospitalares.

O estudo pioneiro sobre CPN, "The National Birth Center Study (NBCS)", mostra os resultados de 11.814 mulheres admitidas para o trabalho de parto e parto em 84 CPN nos Estados Unidos da América (EUA), entre 1985 e 1987. Trata-se de um estudo descritivo com coleta de dados prospectiva, cuja finalidade foi oferecer subsídios aos questionamentos do Instituto de Medicina Americano, Academia Americana de Pediatria e Colégio Americano de Obstetrícia e Ginecologia a respeito da segurança desse modelo de atendimento (Rooks et al., 1989). O estudo foi publicado em três artigos, que descrevem como sujeitos do NBCS todas as mulheres que deram à luz nos EUA, em 1996. Aponta quais são os cuidados no prénatal e as práticas de orientação durante a gravidez dos centros de nascimento no estudo. Descreve também as características das mulheres admitidas nos centros de nascimento para cuidado intraparto, com relação ao risco perinatal. Relata os cuidados e as complicações intraparto, pósparto imediato e neonatal e, por fim, as transferências e a satisfação da cliente.

Os resultados desta pesquisa mostraram que $76 \%$ das mulheres tiveram complicações leves e $21 \%$ nenhuma complicação durante o parto e pós-parto, de acordo com o score de risco adotado no estudo. Mãe e recém-nascido apresentaram complicações graves em $7,9 \%$ dos casos. A mortalidade perinatal foi $1,3 / 1.000$ nascidos vivos, sem mortes maternas. $O$ estudo concluiu que os CPN são uma alternativa segura, sobretudo, às mulheres com partos anteriores, além de apresentarem uma taxa muito baixa de cesarianas. No entanto, merece comentar que este estudo não incluiu resultados de CPN integrados ao hospital ou autônomos.

David et al. (1999) realizaram estudo comparativo retrospectivo entre 801 partos de CPN autônomos e 3.271 partos hospitalares em Berlim; observaram que o grupo do centro de nascimento teve significativamente menos intervenções, com uma taxa similar de cesariana (3,0\% versus $4,6 \%$, $p=0,057)$ e ocorrência de lesões perineais de $3^{\circ}$ e $4^{\circ}$ graus $(0,9$ versus $1,1 \%$, $p=0,240$. A taxa de episiotomia foi de modo significativo maior nos hospitais, 
tanto para nulíparas $(21,1$ versus $69,9 \%, p<0,001)$ como para multíparas $(3,6$ versus $37,2 \%, p<0,001)$. Número maior de RN teve escores de Apgar menores que 7 , no $1^{\circ}$ minuto de vida no grupo dos centros de nascimento $(1,9$ versus $3,6 \%, p=0,002)$, porém sem diferenças entre os grupos nos $5^{\circ} \mathrm{e}$ $10^{\circ}$ minutos de vida. Não houve óbitos de mães ou bebês nos grupos de CPN e hospitais.

No Brasil, algumas pesquisas vêm analisando os resultados de centros de parto, tais como o estudo conduzido na Casa do Parto de Juiz de Fora, Minas Gerais (Fernandes, 2004). A pesquisadora elaborou um perfil da assistência correlacionado com a percepção das usuárias, com procedimento de investigação de natureza quantitativa e qualitativa, em um centro de parto normal extra-hospitalar. A taxa de transferência neonatal foi de $3,6 \%$, sem nenhum óbito neonatal. A percepção das usuárias mostrou que a satisfação em relação ao atendimento baseia-se, sobretudo, nas relações interpessoais de confiança, tratamento individualizado, acolhimento, ambiente agradável, manejo da dor por métodos não medicamentosos e protagonismo da mulher no parto.

Campos e Lana (2007), em um estudo descritivo e retrospectivo de 2.117 partos ocorridos entre janeiro de 2002 e julho de 2003, no CPN Dr. David Capistrano da Costa Filho, um centro de parto perihospitalar em Belo Horizonte, observaram que a taxa de transferência materna foi de 11,4\%; a de cesárea 2,2\%; a de admissão em Centro de Tratamento Intensivo (CTI) neonatal de 1,25\%; e a de escore Apgar inferior a 7 no $5 .^{\circ}$ minuto de $1 \%$. Distocias de trabalho de parto e o desejo por analgesia peridural foram as maiores causas para a transferência materna, enquanto o distúrbio de desconforto respiratório foi a causa principal para admissão dos RN no CTI. A mortalidade neonatal corrigida foi de 2/1.000 nascidos vivos.

Em um estudo caso-controle realizado na Casa do Parto de Sapopemba (CPS), instituição onde se realizou a presente pesquisa, Koiffman et al. (2010) analisaram todas as remoções de recém-nascido de setembro de 1998 a agosto de 2005, com 32 casos no total. A taxa de remoções foi de $1,1 \%$, e a mortalidade neonatal corrigida (óbitos com 
relação direta ao acompanhamento pré-natal ou à assistência durante o parto na CPS) foi de 1/1.000 nascidos vivos, inferior às taxas encontradas em centros de nascimento extra-hospitalares dos países desenvolvidos.

Schneck e Riesco (2006) realizaram um estudo transversal e analisaram a assistência prestada por enfermeiras obstétricas no Centro de Parto Normal do Hospital Geral de Itapecerica da Serra - SECONCI/OSS (CPN-HGIS), um CPN intra-hospitalar. A amostra probabilística foi de 830 prontuários de mulheres com parto normal, gestação única e apresentação cefálica, atendidas entre janeiro e dezembro de 2001. Constataram que a episiotomia foi realizada em $26,5 \%$ dos partos, associada à nuliparidade, posição litotômica, parto ocorrido na sala de parto e líquido amniótico meconial, após a internação. Outros resultados da assistência foram uso da posição lateral $(52,0 \%)$, parto realizado no quarto $(67,3 \%)$, presença de acompanhante $(78,9 \%)$ e contato precoce mãe-recém-nascido $(96,9 \%)$. A integridade perineal ocorreu em 25,5\%, e o índice de Apgar foi maior que 7 no $5^{\circ}$ minuto em $99,6 \%$; a idade gestacional entre 38 e 42 semanas foi encontrada em $87,8 \%$ dos casos, e o peso médio dos RN foi de 3.125 gramas. As intervenções obstétricas no CPN-HGIS apresentaram proporções superiores a de outros serviços, porém estiveram associadas às condições maternas e fetais, daí sua adoção não rotineira. Nesse serviço, foi observado o uso criterioso de intervenções no processo de parto e nascimento, além do estímulo à presença do acompanhante.

David et al. (2006) realizaram uma análise prospectiva de todas as mulheres que deram à luz em Berlim e na Bavária, no período de 1 de setembro de 1999 a 31 de agosto de 2001, que foram transferidas no período intraparto de um centro de nascimento para um hospital. Os grupos de comparação foram formados por todos os partos ocorridos em centros de nascimento de Berlim e da Bavária 1999/2000 ( $n=3.060)$, e os partos hospitalares de Berlim e da Bavária em 1998/1999 (dados selecionados, $\mathrm{n}=89.696$ nascimentos). Trezentos e sessenta casos de transferência foram avaliados, sendo a maioria de nulíparas. As razões mais frequentes para a transferência foram rotura precoce das membranas ovulares e falha no progresso do trabalho de parto. Cinquenta e sete por cento das mulheres 
transferidas deram à luz espontaneamente, com uma taxa de episiotomia de quase $30 \%$. Índices de Apgar de $1^{\circ}$ e $5^{\circ}$ minuto menores que 7 foram mais frequentes no grupo de transferência que nos grupos de mulheres não transferidas, principalmente para nulíparas. Valores de $\mathrm{pH}$ inferior a 7 no sangue de cordão umbilical também foram verificados mais frequentemente no grupo de mulheres transferidas. A hospitalização de neonatos do grupo de transferência e, sobretudo, nas nulíparas foi significantemente mais frequente. As mulheres que foram admitidas nos centros de nascimento representaram, em geral, um grupo de baixo risco em razão de uma préseleção cuidadosa. Entretanto, dados neonatais sobre a morbidade e a mortalidade neonatais e a alta taxa de partos operatórios (cesarianas, fórceps e extração a vácuo) indicam que mulheres transferidas no período intraparto, em particular, quando nulíparas representaram um grupo de alto risco.

Embora os resultados de estudos sobre CPN apresentem de maneira geral resultados positivos, a metodologia destas pesquisas tem sido criticada em razão da ausência de randomização e de amostras pequenas (Albers e Katz, 1991), que podem excluir complicações raras, usualmente pouco frequentes entre mulheres saudáveis e com gestações fisiológicas. Assim, são necessários estudos para avaliar os resultados das transferências maternas, visto que estas são as mulheres que apresentam complicações em um grupo de baixo risco. Isto poderia contribuir para 0 aprimoramento dos critérios de admissão nos CPN. 
1. Identificar os fatores de risco para transferência materna de uma casa de parto para o hospital.

2. Elaborar um modelo de risco para transferência materna no período intraparto, com base nos fatores identificados.

3. Analisar os desfechos maternos e neonatais das transferências de uma casa de parto para o hospital. 


\subsection{Tipo de estudo}

Este é um estudo do tipo caso-controle, com coleta de dados retrospectiva, sobre as transferências maternas em um centro de parto extra-hospitalar (casa de parto) para o hospital de referência, de março de 2002 a dezembro de 2009. A escolha deste tipo de pesquisa foi feita em função de ser conveniente para investigar eventos de rara prevalência, como as transferências maternas da CPS. Estudos caso-controle têm também particular utilidade na investigação de múltiplos fatores de risco (Hennekens, Buring, 1987).

A existência de uma população definida para a seleção de casos e controles, ou seja, as mulheres atendidas na CPS permitiu minimizar o viés de seleção, que é inerente a esse tipo de estudo.

\subsection{Locais de estudo}

O estudo foi desenvolvido em duas instituições: a instituição de origem das transferências foi a Casa do Parto de Sapopemba, estabelecimento de saúde que funciona no âmbito do SUS, integrado ao Programa de Saúde da Família (PSF) da Secretaria Municipal de Saúde de São Paulo, em parceria com a Sociedade Paulista para o Desenvolvimento da Medicina - UNIFESP e o hospital de referência para as remoções maternas e neonatais da CPS: Hospital Estadual de Vila Alpina (HEVA).

A CPS está localizada na região sudeste da cidade de São Paulo, suas atividades iniciaram-se em setembro de 1998. A filosofia que norteou sua implantação foi a do modelo de atenção comunitária durante o ciclo gravídico-puerperal, incluindo a resolutividade do parto normal no nível da atenção básica.

A população atendida na CPS é composta por mulheres com gestação de baixo risco, encaminhadas pelas Unidades Básicas de Saúde (UBS) da região e por gestantes provenientes fora da área de abrangência. Estas mulheres são atraídas pelo modelo de atenção oferecido na CPS e do qual têm conhecimento por meio da mídia impressa, televisiva e Internet.

A gestante e seus familiares podem visitar a CPS, para obterem informações sobre o serviço, em qualquer período gestacional. $O$ 
acompanhamento na CPS inicia-se a partir da $37^{\mathrm{a}}$ semana de gestação, com uma consulta na qual se verificam as condições clínicas da gestante, de acordo com os critérios estabelecidos pelo protocolo do serviço (Anexo 1). Em linhas gerais, são atendidas mulheres com gestação fisiológica, sem intercorrências clínicas ou obstétricas que possam gerar complicações no parto ou pós-parto; entre estas incluem-se hipertensão arterial, diabetes, cardiopatias, iteratividade e gestações de fetos gemelares ou em apresentação pélvica.

Na primeira consulta, é aberto um Plano de Parto, que consiste em um resumo da história clínica, obstétrica e de amamentação da gestante. São agendadas consultas semanais até a $40^{a}$ semana de gestação e a 2 a 3 dias até a $41^{\text {a }}$ semana, sendo que após esta idade gestacional a gestante é encaminhada ao hospital mais próximo de sua casa para uma avaliação médica. A mulher pode retornar à CPS ou realizar contato telefônico a qualquer momento, caso apresente sinais de alarme, de trabalho de parto ou queira esclarecer dúvidas. Em todos os atendimentos, a avaliação do risco é feita, de maneira que a mulher seja admitida na CPS quando não apresentar quaisquer complicações clínicas ou obstétricas.

Nas consultas subsequentes, o acompanhamento clínico é realizado e são fornecidas orientações sobre o processo fisiológico do nascimento, reconhecimento dos sinais e sintomas do início do trabalho de parto, práticas que favorecem a boa evolução do parto, preparo para a amamentação e cuidados com o recém-nascido. Em caso de intercorrências que necessitem de atenção médica, a gestante é encaminhada à UBS ou ao hospital, de acordo com a urgência do atendimento. Este acompanhamento não substitui o cuidado pré-natal que deve continuar a ser realizado pela gestante na UBS ou em consultório médico particular ou de convênio.

As gestantes que não passaram por esse atendimento inicial, podem dar à luz na CPS, desde que tenham realizado o acompanhamento pré-natal adequado e atenderem aos critérios estabelecidos para admissão de parturientes no serviço (Anexo 1).

Vale ressaltar que a assistência obstétrica e neonatal na CPS é prestada exclusivamente por enfermeiras obstétricas e obstetrizes com o 
apoio de auxiliares de enfermagem. As remoções maternas e neonatais são realizadas em ambulância própria da CPS destinada somente para esta finalidade.

Durante os primeiros anos de funcionamento (setembro de 1998 a fevereiro de 2002), os hospitais de referência para a CPS foram o Amparo Maternal, a Clínica Infantil do Ipiranga e o Hospital Cândido Fontoura. Não havia acordo formal com essas instituições para esta retaguarda, que se efetuava pelo contato direto das enfermeiras obstétricas da CPS com os profissionais desses hospitais.

A partir de março de 2002, o Hospital Estadual de Vila Alpina (HEVA) passou a ser a referência para as transferências maternas e neonatais. A distância entre a CPS e o HEVA é cerca de $4 \mathrm{~km}$. Há quase 10 anos vem existindo essa colaboração entre os dois serviços, mas ainda não foi firmado o termo oficial que garanta $\mathrm{o}$ atendimento das mulheres removidas da CPS para essa instituição.

De acordo com o Programa Mãe Paulistana, iniciativa da Prefeitura de São Paulo, que procura estabelecer um hospital de referência às mulheres atendidas em determinada área, o HEVA é o hospital de referência às gestantes da região de Vila Prudente e Sapopemba onde está localizada a CPS. Trata-se de um hospital credenciado ao SUS, sob a gestão do Serviço Social da Indústria e do Mobiliário de São Paulo (SECONCI-OSS). Sua complexidade é terciária, sendo referência para atendimento às gestações de alto risco na região, além de partos de baixo risco. Dispõe de um centro de parto normal intra-hospitalar, de uma unidade de terapia intensiva neonatal e de adulto e uma agência transfusional, para o fornecimento de sangue e hemoderivados.

\subsection{População do estudo}

Fizeram parte da pesquisa todas as parturientes e puérperas atendidas na CPS e transferidas durante o trabalho de parto e o pós-parto para o serviço de referência, de março de 2002 até dezembro de 2009, que totalizaram 2.736 mulheres. Nesse período, foram assistidos 2.625 partos neste serviço e houve 111 transferências maternas no período intraparto e 
13 transferências no pós-parto. Quatro controles para cada caso foram coletados, resultando em 455 controles.

\subsubsection{Definição e seleção de casos}

Os casos foram todas as mulheres transferidas para o HEVA após a internação na CPS, durante o trabalho de parto ou após o parto, de março de 2002 a dezembro de 2009. Para este estudo, definiu-se como transferência intraparto, o caso em que a mulher foi removida para o hospital em trabalho de parto; ela poderia ou não ter feito o acompanhamento prévio na CPS, após a $37^{a}$ semana de gravidez. No entanto, na admissão seu exame deveria estar de acordo com os critérios de gestação de baixo risco e com o protocolo de internação do serviço.

\subsubsection{Definição e seleção de controles}

Os números de controles definidos para cada caso foram quatro, visto que um número superior de controles não aumentaria o poder estatístico do estudo para detectar diferenças entre os grupos caso e controle (Gail et al., 1976). Os quatro controles foram sorteados dentro do mesmo ano em que ocorreu a transferência intraparto (caso), totalizando, assim, 455 controles.

Os controles foram mulheres provenientes da mesma população dos casos (ou seja, internadas em trabalho de parto para assistência ao parto na CPS), mas, que não foram removidas para o HEVA durante ou após o parto e cujo recém-nascido também não tenha sido removido.

\subsection{Coleta de dados}

Os dados foram obtidos nos livros de registro das transferências e nos prontuários da CPS e do HEVA. A coleta foi realizada nos seguintes períodos: de 10 de janeiro a 30 de março de 2010 na CPS, e de 15 de junho a 27 de setembro de 2010 no HEVA. Para a coleta, foi feita revisão manual dos registros, com a aplicação de um formulário desenvolvido para esta pesquisa (Apêndice 1), pela pesquisadora e uma 
aluna do Curso de Graduação da Escola de Enfermagem da USP (TCRP). Os casos de transferência materna foram identificados nos livros de registro da CPS, que são preenchidos pela enfermeira ou obstetriz que realizou a transferência. Os dados coletados foram armazenados, em dupla entrada, pela pesquisadora e pela aluna TCRP em um banco de dados elaborado no software Epi-Data ${ }^{2}$. Este banco de dados foi validado para assegurar sua consistência.

\subsection{Variáveis do estudo}

\subsubsection{Variável dependente}

- Transferência materna: da CPS para o HEVA, categorizada como sim ou não.

3.5.2 Variáveis independentes - variáveis analisadas no estudo casocontrole para identificação dos fatores de risco

Variáveis sociodemográficas

- Idade materna: categorizada nas seguintes faixas etárias: 14 a 19 anos, 20 a 34 anos e 35 a 42 anos

- Escolaridade materna: obtida por meio de dados da Declaração de Nascido Vivo (DNV), categorizada como de 1 a 3 anos, 4 a 7 anos, 8 a 11 anos, mais que 11 anos;

- Estado marital: categorizada como ter ou não ter companheiro;

- Ocupação materna: tipo de atividade relatada pela mulher e registrada em seu prontuário como: estudante, do lar, sem ocupação e trabalho remunerado. Para a análise estatística, esta variável foi categorizada como ocupação remunerada ou não remunerada;

- Área de abrangência: variável classificada em sim ou não, de acordo a localização da moradia da parturiente (pertencente ou não à área de abrangência da CPS).

\footnotetext{
${ }^{2}$ www.epidata.dk
} 
- Sistema de saúde: variável categorizada, de acordo com a assistência recebida na unidade do pré-natal de origem: SUS, convênio ou privado;

- Tabagismo: variável classificada como sim ou não. A mulher que relatou tabagismo na gestação, mesmo que referisse ter parado de fumar na gravidez, foi classificada como tabagista.

Variáveis da assistência pré-natal, história obstétrica e da admissão na CPS:

- Nuliparidade: classificada como sim ou não;

- Idade gestacional: categorizada em semanas completas, de 37 a 40 semanas ou de 41 a 42 semanas, calculada pela data da última menstruação (DUM) quando conhecida ou pelo primeiro ultrassom, quando a DUM era desconhecida;

- Número de consultas no período pré-natal: realizadas na unidade de origem e obtidas pelos dados da DNV, sendo classificadas como de uma a três consultas, de quatro a seis e sete ou mais;

- Número de consultas realizadas na CPS: classificadas como nenhuma, uma a quatro e 5 a 12 consultas;

- Problema na gestação: categorizado como sim ou não; sim inclui intercorrências menores que foram tratadas durante a gestação que aparentemente não afetaram o desfecho do parto, tais como: infecção do trato urinário, corrimento vaginal, sangramento vaginal discreto, RN com dilatação pielo calicial (diagnosticada por exame ultrassom);

- Dilatação cervical na admissão na CPS: dilatação cervical que a parturiente apresentava ao ser internada e categorizada como de 1 a $3 \mathrm{~cm}$, de 4 a $6 \mathrm{~cm}$ e de 7 a $10 \mathrm{~cm}$;

- Condição das membranas amnióticas na admissão na CPS: categorizada como membranas rotas ou íntegras;

- Adequação entre altura uterina e idade gestacional: obtida conforme parâmetros estabelecidos pela medida da curva de altura uterina em função da idade gestacional de Martinelli (Martinelli et al., 2001). Os dados utilizados para este cálculo foram obtidos das anotações, referentes ao exame de admissão da parturiente nos prontuários e 
analisados pela própria pesquisadora, para avaliar a relação entre altura uterina e idade gestacional. Esta variável foi categorizada como normal (entre os percentis 10 e 90 da curva), baixa (abaixo do percentil 10) e alta (acima do percentil 90).

Variáveis da assistência durante o trabalho de parto

- Tipo de rotura das membranas: classificado como artificial ou espontânea;

- Uso de ocitocina no período de dilatação: classificado como sim ou não;

- Uso de ocitocina no período de expulsão: classificado como sim ou não;

- Peso do recém-nascido: categorizado como 1.500 a 2.499 g, de 2.500 a $3.999 \mathrm{~g}$, de 4.000 a $4.600 \mathrm{~g}$.

\subsubsection{Outras variáveis}

A seguir, as variáveis descritas foram utilizadas na análise dos desfechos das transferências maternas nos períodos intraparto e pós-parto. Transferências intraparto

- Motivo da transferência - Os motivos da transferência materna intraparto foram coletados, mantendo-se os mesmos termos registrados nos prontuários pelas enfermeiras obstétricas e obstetrizes da CPS e foram agrupados em 13 categorias, descritas a seguir:

1) Fase latente prolongada: dilatação cervical de até $4 \mathrm{~cm}$ no momento da transferência, associada à: dinâmica uterina fraca, trabalho de parto lento, parada de progressão, parada de progressão da dilatação, trabalho de parto prolongado, sem progressão da cervicodilatação, distocia de progressão, distocia funcional, amniorrexe prematura, sem evolução do trabalho de parto, sem progressão da dilatação após indução; 
2) Fase ativa prolongada: dilatação cervical de 5 a $9 \mathrm{~cm}$ no momento da transferência associada aos motivos mencionados na categoria anterior ou sem progressão da descida;

3) Fase pélvica prolongada: motivo registrado foi período expulsivo prolongado;

4) Índice de Bishop desfavorável: motivo registrado foi colo desfavorável ou espástico;

5) Anormalidades do trajeto ou feto: motivo registrado foi bossa, suspeita de desproporção cefalopélvica, desproporção cefalopélvica, distocia de rotação, macrossomia fetal, edema de colo, apresentação alta e móvel e promontório atingível, polidrâmnio;

6) Traçado cardiotocográfico alterado: registro de alteração na frequência dos batimentos cardiofetais por meio da cardiotocografia, tais como: desaceleração do tipo I ou II, taquicardia, bradicardia, variabilidade comprometida;

7) Presença de mecônio no líquido amniótico: visualização ou suspeita de mecônio;

8) Estresse materno: mulher agitada ou pouco colaborativa, parturiente com tontura e fraqueza;

10) Taquissistolia e hipertonia uterina;

11) Prolapso de cordão umbilical: foi utilizado o próprio motivo registrado nos prontuários pelas enfermeiras obstétricas;

12) Apresentação pélvica; $e$

13) Outros: motivos relativos à condição clínica desfavorável ou não prevista no protocolo de admissão na CPS e decisão da própria mulher, febre, polidrâmnio, varizes vulvares e de membros inferiores em grande proporção, líquido amniótico sanguinolento, human papilloma virus (HPV) e neoplasia intra-epitelial cervical (NIC) III.

- Dilatação cervical no momento da transferência - em centímetros;

- Condição das membranas ovulares - classificadas como íntegras ou rotas;

- Batimentos cardiofetais no momento da transferência - presente ou ausente; 
- Alteração na cardiotocografia anterior à transferência - sim ou não; se sim, qual; e

- Alterações no estado materno - descrever.

Desfecho da transferência no período intraparto (assistência hospitalar)

- Monitorização eletrônica fetal durante o trabalho de parto - sim ou não;

- Presença do acompanhante - sim ou não;

- Uso de ocitocina - sim ou não;

- Tipo de parto - classificado em normal, cesariana, fórceps ou vácuo extrator;

- Condição perineal - períneo íntegro, lacerações de primeiro, segundo, terceiro ou quarto graus, episiotomia médio-lateral direita (EMLD) e mediana;

- Intercorrências durante o trabalho de parto, parto e pós-parto imediato - classificadas como sim ou não; se sim, qual;

- Unidade de internação materna - descrever; e

- Intercorrências maternas no período da internação hospitalar descrever

Desfecho da assistência ao recém-nascido no hospital

- Condições de nascimento - classificadas como vivo ou morto. Se óbito descrever a causa e com quantas horas de vida;

- Índice de Apgar - avaliado nos $1^{\circ}$ e $5^{\circ}$ minutos de vida;

- Peso ao nascer - em gramas;

- Manobras de reanimação - sim ou não, se sim, descrever;

- Administração de medicamentos durante a reanimação - sim ou não, se sim, descrever quais;

- Intercorrências neonatais - descrever; e

- Óbitos neonatais: foi realizada uma descrição sumária dos casos de óbitos neonatais (ocorridos de zero a 27 dias de vida), ocorridos no período do estudo (WHO, 2006). 
A mortalidade neonatal na CPS foi calculada conforme a fórmula:

Óbitos neonatais entre as mulheres admitidas na CPS $=\frac{\text { Número de óbitos neonatais na CPS e no hospital }}{\text { Número de nascimentos na CPS e no hospital }} \times 1.000$

- Unidade de internação neonatal - unidade neonatal (unidade de observação, unidade de cuidados intermediários e unidade de terapia intensiva), alojamento conjunto;

Remoções pós-parto

- Motivo da transferência - Os motivos da transferência materna intraparto foram coletados, utilizando-se a mesma terminologia registrada nos prontuários que foram agrupados em quatro categorias e estão descritas a seguir:

1) retenção placentária;

2) sangramento vaginal aumentado;

3) febre materna; e

4) outros motivos (relativos à condição clínica desfavorável ou não prevista no protocolo de admissão na CPS, como ausência de colostro, loquiação fétida e tontura).

Desfecho da transferência no período pós-parto (assistência hospitalar)

- Unidade de internação materna - descrever;

- Intercorrências maternas no período da internação hospitalar descrever; e

- Intervenção realizada no hospital - classificada como observação, curagem, curetagem, transfusão sanguínea, administração de medicamentos ou outra (descrever). 
Desfecho da assistência ao recém-nascido de mulher transferida no período pós-parto (assistência hospitalar)

- Índice de Apgar - avaliado nos $1^{\circ}$ e $5^{\circ}$ minutos de vida;

- Peso ao nascer - em gramas;

- Unidade de internação; e

- Intercorrências neonatais.

\subsection{Análise estatística}

A análise das características e dos desfechos das transferências maternas foi realizada por meio do cálculo de proporções para variáveis categóricas e de medidas de tendência central e dispersão média, mediana, desvio-padrão, valores mínimo e máximo - para variáveis contínuas. Esta análise foi desenvolvida no programa SPSS versão 17.0 e apresentada na forma descritiva.

A análise dos fatores de risco para transferências maternas intraparto foi feita, primeiramente, pelo teste de associação do QuiQuadrado. Para a análise múltipla, foram selecionadas todas as variáveis que apresentaram $p<0,20$ neste teste.

A seguir, foi elaborado o modelo de regressão logística múltiplo pelo processo stepwise forward selection. Nessa etapa, consideraram-se como fatores independentemente associados às transferências maternas as variáveis que apresentaram $p<0,05$. O ajuste do modelo foi avaliado pelo teste de Hosmer-Lemeshow (Hosmer-Lemeshow, 2000). A análise dos dados possibilitou a construção de um modelo de risco para transferência materna.

Com relação às transferências maternas pós-parto, foi feita apenas análise descritiva em razão do reduzido número de casos (13 mulheres).

\subsection{Questões éticas}

Em observância às determinações da Resolução 196/96, do Conselho Nacional de Saúde, o projeto do estudo foi aprovado pelo Comitê de Ética em Pesquisa da Secretaria Municipal de Saúde de São Paulo 
(Parecer n. 223/2006/CEP/SMS) (Anexo 2), para coleta de dados na CPS e pelo Comitê de Ética em Pesquisa do IEPAC/SECONCI (Protocolo CEP $n^{\circ}$ 03/2010), para coleta de dados no HEVA (Anexo 3).

A pesquisadora comprometeu-se a manter sigilo quanto à identificação das mães e neonatos cujos dados foram coletados. Os resultados obtidos serão divulgados em publicações e eventos científicos e utilizados para melhorar a assistência oferecida às mulheres e RN. 
Este estudo, do tipo caso-controle, investigou as remoções maternas intraparto e pós-parto de um centro de parto extra-hospitalar, no período de 2002 a 2009.

A amostra foi composta da seguinte maneira:

- Transferências maternas no período intraparto: 111 mulheres;

- Transferências maternas no período pós-parto: 13 mulheres;

- Controles: 456 mulheres que deram à luz no mesmo período na CPS e não foram transferidas. Entre os controles, houve a exclusão de um controle no qual uma mulher com idade gestacional de 36 semanas deu à luz na CPS, porém esta foi admitida em período expulsivo. Restaram, portanto, 455 mulheres como controles (Figura 1).

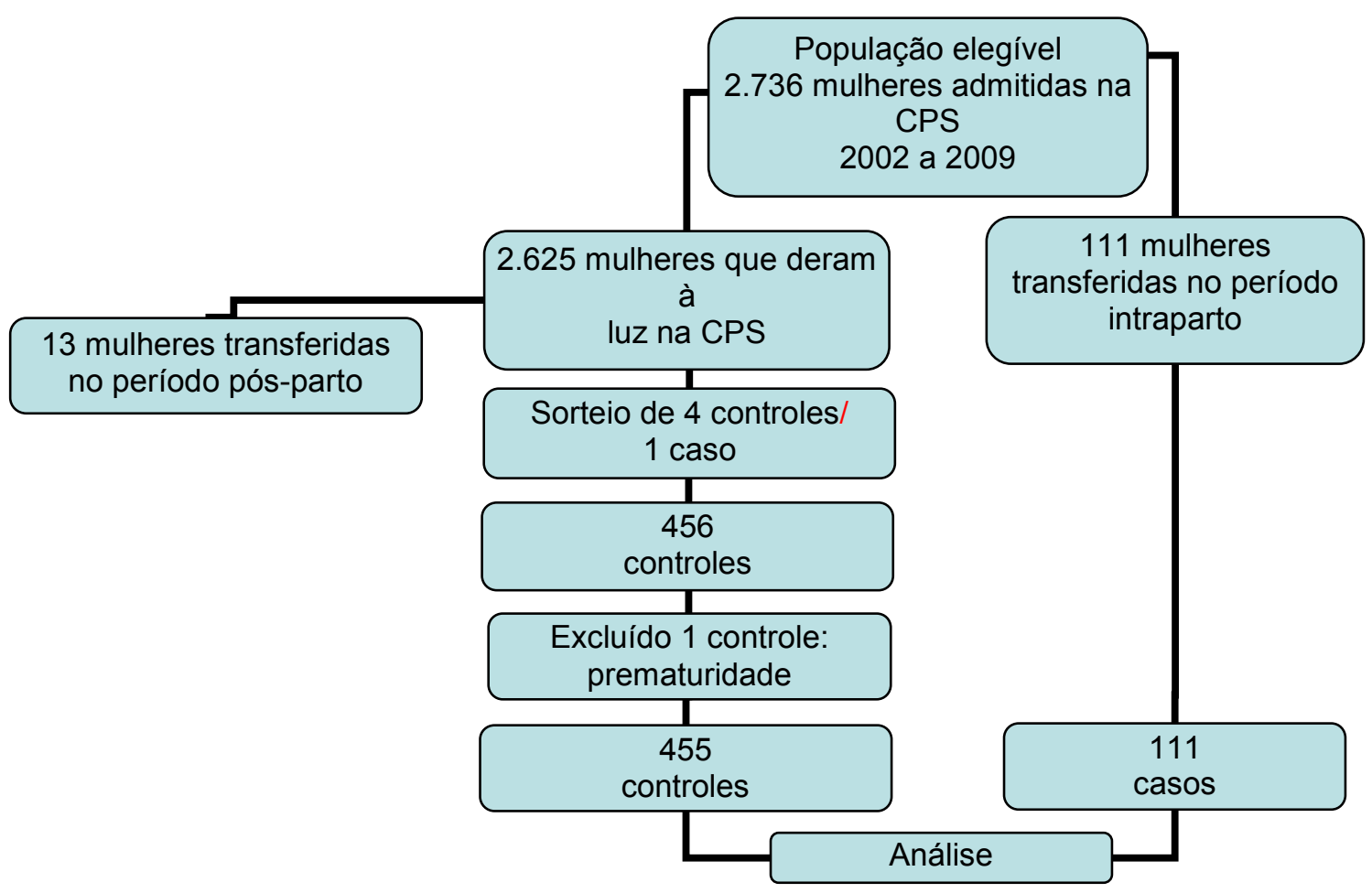

Figura 1. Fluxograma da seleção de casos e controles.

\subsection{Fatores de risco para transferência materna}

A análise univariada foi realizada entre as mulheres transferidas no período intraparto $(n=111)$ e as não removidas $(n=455)$, distribuídas em tabelas, de acordo com as características 
sociodemográficas, variáveis da assistência pré-natal, história obstétrica e admissão na CPS e variáveis da assistência durante o trabalho de parto.

Os resultados da análise univariada que explorou as relações entre as variáveis independentes e a variável dependente (transferência) estão organizadas em três tabelas, que são: variáveis referentes às características sociodemográficas (Tabela 1), variáveis referentes à assistência pré-natal, história obstétrica e admissão (Tabela 2) e variáveis da assistência durante o trabalho de parto e do recém-nascido (Tabela 3).

A análise dos fatores de risco para transferências maternas intraparto foi feita, primeiramente, pelo teste de associação do QuiQuadrado. $\mathrm{Na}$ análise múltipla, foram incluídas as variáveis que apresentaram $p<0,20$ neste teste. 
Tabela 1 - Distribuição do número e porcentagem de mulheres transferidas e não transferidas, conforme as características sociodemográficas. São Paulo, 2002 a 2009.

\begin{tabular}{|c|c|c|c|c|c|c|c|}
\hline Variável & \multicolumn{2}{|c|}{ Controle } & \multicolumn{2}{|c|}{ Caso } & \multicolumn{2}{|c|}{ Total } & $\mathbf{P}$ \\
\hline \multicolumn{8}{|l|}{ Idade (anos) } \\
\hline 14 a 19 & 102 & $(22,4)$ & 27 & $(24,3)$ & 129 & $(22,8)$ & \\
\hline 20 a 34 & 333 & $(73,2)$ & 72 & $(64,9)$ & 405 & $(71,6)$ & \\
\hline 35 a 42 & 20 & $(4,4)$ & 12 & $(10,8)$ & 32 & $(5,7)$ & \\
\hline Total & 455 & (100) & 111 & $(100)$ & 566 & $(100)$ & 0,024 \\
\hline \multicolumn{8}{|l|}{ Escolaridade (anos) } \\
\hline 1 a 3 & 18 & $(4,0)$ & 3 & $(2,8)$ & 21 & $(3,7)$ & \\
\hline 4 a 7 & 130 & $(28,6)$ & 26 & $(24,3)$ & 156 & $(27,8)$ & \\
\hline 8 a 11 & 286 & $(62,9)$ & 68 & $(63,6)$ & 354 & $(63,0)$ & \\
\hline Mais que 11 & 21 & $(4,6)$ & 10 & $(9,3)$ & 31 & $(5,5)$ & \\
\hline Total & 455 & (100) & 107 & $(100)$ & 562 & $(100)$ & 0,222 \\
\hline \multicolumn{8}{|l|}{ Estado marital } \\
\hline Com companheiro & 392 & $(86,2)$ & 79 & $(71,2)$ & 471 & $(83,2)$ & \\
\hline Sem companheiro & 63 & $(13,8)$ & 32 & $(28,8)$ & 95 & $(16,8)$ & \\
\hline Total & 455 & $(100)$ & 111 & $(100)$ & 566 & $(100)$ & $<0,001$ \\
\hline \multicolumn{8}{|l|}{ Ocupação } \\
\hline Não remunerada & 337 & $(74,6)$ & 68 & $(61,8)$ & 405 & $(72,1)$ & \\
\hline Remunerada & 115 & $(25,4)$ & 42 & $(38,2)$ & 157 & $(27,9)$ & \\
\hline Total & 452 & $(100)$ & 110 & $(100)$ & 562 & $(100)$ & 0,008 \\
\hline \multicolumn{8}{|l|}{ Área de abrangência } \\
\hline Sim & 350 & $(76,9)$ & 80 & $(72,1)$ & 430 & $(76,0)$ & \\
\hline Não & 105 & $(23,1)$ & 31 & $(27,9)$ & 136 & $(24,0)$ & \\
\hline Total & 455 & $(100)$ & 111 & $(100)$ & 566 & $(100)$ & 0,283 \\
\hline \multicolumn{8}{|l|}{ Sistema de saúde } \\
\hline SUS & 427 & $(94,1)$ & 98 & $(90,7)$ & 525 & $(93,4)$ & \\
\hline Convênio ou privado & 27 & $(5,9)$ & 10 & $(9,3)$ & 37 & $(6,6)$ & \\
\hline Total & 454 & (100) & 108 & $(100)$ & 562 & $(100)$ & 0,212 \\
\hline \multicolumn{8}{|l|}{ Tabagismo } \\
\hline Não & 363 & $(80,3)$ & 90 & $(82,6)$ & 453 & $(80,7)$ & \\
\hline Sim & 89 & $(19,7)$ & 19 & $(17,4)$ & 108 & $(19,3)$ & \\
\hline Total & 452 & $(100)$ & 109 & (100) & 561 & (100) & 0,685 \\
\hline
\end{tabular}

Teste Qui-quadrado

Entre as características sociodemográficas, observou-se que a idade, o estado marital e a ocupação associaram-se estatisticamente à transferência intraparto $(p<0,05)$. Cerca de $23,0 \%$ das mulheres eram adolescentes e quase $70,0 \%$ haviam tido 8 anos ou mais de educação formal.

Quanto ao estado civil, 429 (75,8\%) eram solteiras, 132 $(23,3 \%)$ casadas e $5(0,9 \%)$ separadas ou divorciadas (dados não constam 
em Tabela). Como mais de $80,0 \%$ das mulheres possuíam companheiro, observa-se o grande número de união informal nesta amostra.

Aproximadamente, um quarto das mulheres era proveniente de regiões localizadas fora da área de abrangência da CPS. Entre estas, 83,1\% vinham da zona leste da cidade de São Paulo e o restante das zonas norte, sul e oeste da cidade.

Mais de $90,0 \%$ das mulheres eram usuárias do SUS e, aproximadamente, $20,0 \%$ eram tabagistas. 
Tabela 2 - Distribuição do número e porcentagem de mulheres transferidas e não transferidas, conforme as variáveis da assistência pré-natal, história obstétrica e admissão na CPS. São Paulo, 2002 a 2009.

\begin{tabular}{lrrrrrrr}
\hline Variável & \multicolumn{2}{c}{ Controle } & \multicolumn{2}{c}{ Caso } & \multicolumn{2}{c}{ Total } & $\mathbf{P}^{\mathbf{a}}$ \\
& $\mathrm{N}$ & $(\%)$ & $\mathrm{N}$ & $(\%)$ & $\mathrm{N}$ & $(\%)$ & \\
Nuliparidade & & & & & & & \\
Não & & & & & & & \\
Sim & 267 & $(58,7)$ & 26 & $(23,4)$ & 293 & $(51,8)$ & \\
Total & 188 & $(41.3)$ & 85 & $(76,6)$ & 273 & $(48,2)$ & \\
& 455 & $(100)$ & 111 & $(100)$ & 566 & $(100)$ & $<0,001$ \\
Idade gestacional & & & & & & & \\
$37-40$ & 414 & $(91,8)$ & 99 & $(91,7)$ & 513 & $(91,8)$ & \\
$41-42$ & 37 & $(8,2)$ & 9 & $(8,3)$ & 46 & $(8,2)$ & \\
Total & 451 & $(100)$ & 108 & $(100)$ & 559 & $(100)$ & 0,965 \\
& & & & & & & \\
Consultas de pré-natal & & & & & & & \\
Até 6 & 14 & $(3,1)$ & 6 & $(5,9)$ & 20 & $(3,6)$ & \\
7 ou mais & 440 & $(96,9)$ & 95 & $(94,1)$ & 535 & $(96,4)$ & \\
Total & 454 & $(100)$ & 101 & $(100)$ & 555 & $(100)$ & 0,231 \\
& & & & & & & \\
Consultas na CPS & & & & & & & \\
0 & 99 & $(21,8)$ & 25 & $(23,4)$ & 124 & $(22,1)$ & \\
1-4 & 317 & $(69,7)$ & 57 & $(53,3)$ & 374 & $(66,5)$ & \\
5-12 & 39 & $(8,6)$ & 25 & $(23,4)$ & 64 & $(11,4)$ & \\
Total & 455 & $(100)$ & 107 & $(100)$ & 562 & $(100)$ & $<0,001$ \\
& & & & & & & \\
Problema na gestação & & & & & & & \\
Não & 382 & $(84,0)$ & 88 & $(79,3)$ & 470 & $(83,0)$ & \\
Sim & 73 & $(16,0)$ & 23 & $(20,7)$ & 96 & $(17,0)$ & \\
Total & 455 & $(100)$ & 111 & $(100)$ & 566 & $(100)$ & 0,259 \\
& & & & & & &
\end{tabular}

Dilatação cervical na admissão

$1-3$

4-6

$7-10$

Total

$\begin{array}{rrrrrrr}121 & (26,7) & 58 & (53,7) & 179 & (31,9) & \\ 245 & (54,0) & 47 & (43,5) & 292 & (52,0) & \\ 88 & (19,4) & 3 & (2,8) & 91 & (16,2) & \\ 454 & (100) & 108 & (100) & 562 & (100) & <0,001\end{array}$

Membranas amnióticas na admissão

Íntegras

Rotas

Total

$\begin{array}{lrrrrrr}342 & (77,0) & 75 & (68,2) & 417 & (75,3) & \\ 102 & (23,0) & 35 & (31,8) & 137 & (24,7) & \\ 444 & (100) & 110 & (100) & 554 & (100) & 0,064\end{array}$

Adequação entre $\mathrm{AU}$ e

IG

Normal

$\begin{array}{llllll}229 & (54,7) & 73 & (74,5) & 302 & (58,4)\end{array}$

Baixa

Alta

181

$(43,2)$

19

$(19,4) \quad 200 \quad(38,7)$

Total

$419 \quad(100)$

$98 \quad(100)$

$517 \quad(100)<0,001$

${ }^{a}$ Teste Qui-quadrado

AU: altura uterina

IG: dade gestacional

Entre as variáveis da assistência pré-natal, história obstétrica e condições de admissão no serviço, a nuliparidade, o número de consultas na 
CPS, dilatação cervical na admissão e adequação da altura uterina e idade gestacional apresentaram associação estatisticamente significante com a transferência intraparto $(p<0,05)$.

Entre as 566 mulheres da amostra, 17\% (96/566) tiveram problemas menores na gestação, estes foram: infecção urinária (ITU) (54/566; 9,5\%), corrimento vaginal (14/566; 2,5\%), ITU associado a corrimento vaginal $(12 / 566 ; 2,12 \%)$, ameaça de trabalho de parto prematuro $(3 / 566 ; 0,5 \%)$, problemas fetais como dilatação pielocalicial detectada pelo exame de ultrassonografia (USG) e líquido amniótico ligeiramente aumentado (2/566; 0,3\%) e outros problemas clínicos (bronquite, depressão, NIC III) (11/566; 1,9\%).

Verificou-se que quase $70,0 \%$ das mulheres tinham dilatação cervical de 4 ou mais centímetros e três quartos do total de mulheres admitidas apresentavam membranas amnióticas intactas ao serem admitidas na CPS.

Tabela 3 - Distribuição do número e porcentagem de mulheres transferidas e não transferidas, conforme as variáveis da assistência durante o trabalho de parto e do recémnascido. São Paulo, 2002 a 2009.

\begin{tabular}{|c|c|c|c|c|c|c|c|}
\hline Variável & $\begin{array}{c}\text { Controle } \\
\mathrm{N}\end{array}$ & $(\%)$ & $\begin{array}{c}\text { Caso } \\
\mathrm{N}\end{array}$ & $(\%)$ & $\begin{array}{c}\text { Total } \\
\mathrm{N}\end{array}$ & $\%$ & $\mathbf{P}^{a}$ \\
\hline \multicolumn{8}{|c|}{ Rotura das membranas } \\
\hline Artificial & 247 & $(57,3)$ & 39 & $(41,5)$ & 286 & $(54,5)$ & \\
\hline Espontânea & 184 & $(42,7)$ & 55 & $(58,5)$ & 239 & $(45,5)$ & \\
\hline Total & 431 & $(100)^{\prime}$ & 94 & $(100)$ & 525 & $(100)$ & 0,006 \\
\hline \multicolumn{8}{|c|}{ Ocitocina na dilatação } \\
\hline Não & 321 & $(70,5)$ & 61 & $(55,5)$ & 382 & $(67,6)$ & \\
\hline Sim & 134 & $(29,5)$ & 49 & $(44,5)$ & 183 & $(32,4)$ & \\
\hline Total & 455 & $(100)^{\prime}$ & 110 & $(100)$ & 565 & $(100)$ & 0,002 \\
\hline \multicolumn{8}{|c|}{ Ocitocina na expulsão } \\
\hline Não & 317 & $(69,7)$ & 102 & $(92,7)$ & 419 & $(74,2)$ & \\
\hline Sim & 138 & $(30,3)$ & 8 & $(7,3)^{\prime}$ & 146 & $(25,8)$ & \\
\hline Total & 455 & $(100)$ & 110 & $(100)$ & 565 & $(100)$ & $<0,001$ \\
\hline \multicolumn{8}{|l|}{ Peso fetal } \\
\hline $1.500-2.499$ & 9 & $(2,0)$ & 2 & $(1,8)$ & 11 & $(1,9)$ & \\
\hline $2.500-4.000$ & 433 & $(95,2)$ & 100 & $(90,1)$ & 533 & $(94,2)$ & \\
\hline$>4.000$ & 13 & $(2,9)$ & 9 & $(8,1)$ & 22 & $(3,9)$ & \\
\hline Total & 455 & (100) & 111 & (100) & 566 & $(100)$ & 0,037 \\
\hline
\end{tabular}

${ }^{\mathrm{a}}$ Teste Qui-quadrado 
Quanto às variáveis da assistência durante o trabalho de parto, o tipo de rotura das membranas amnióticas, o uso de ocitocina nos períodos de dilatação e expulsão e o peso fetal estiveram estatisticamente associadas à transferência materna intraparto $(p<0,05)$.

Entre as mulheres que foram transferidas, maior número delas teve 7 ou mais horas de bolsa rota $(46,4 \%)$ comparadas com as não transferidas (9,0\%). Quanto ao uso de ocitocina no período de dilatação, cerca de $45,0 \%$ das mulheres transferidas receberam essa medicação, enquanto apenas um terço das não transferidas recebeu-a. No período expulsivo, o número de mulheres que recebeu ocitocina entre as que foram transferidas foi quatro vezes maior do que entre as não transferidas.

Quanto às intercorrências durante o trabalho de parto, 15,2\% (69/455) das mulheres que deram à luz na CPS e não foram transferidas após o parto apresentaram problemas, tais como: fase de dilatação prolongada $(10 / 69 ; 14,5 \%)$, remoção manual da placenta $(5 / 69 ; 7,2 \%)$, distocias óssea e fetal (4 casos de variedade de posição occiptossacra) (6/69; 8,7\%), líquido amniótico meconial (40/69; 58,0\%), circular de cordão umbilical justa $(4 / 69 ; 5,8 \%)$, apresentação pélvica $(1 / 69 ; 1,4 \%)$ e outros problemas $(3 / 69 ; 4,3 \%)$. Em outros problemas, incluem-se: apresentação defletida de terceiro grau, polidrâmnio e nó verdadeiro de cordão. No caso de apresentação pélvica, não houve tempo para transferir a parturiente para o hospital, porém tanto o RN como a mãe tiveram boas condições após o parto e receberam alta no tempo usual. A maioria das mulheres não transferidas recebeu alta da CPS em torno de 24 horas após o parto.

O peso médio dos $\mathrm{RN}$ das mulheres não transferidas foi 3.205,7 (peso mínimo $2.300 \mathrm{~g}$, máximo $4.600 \mathrm{~g}$, desvio-padrão $390 \mathrm{~g}$, mediana $3.180 \mathrm{~g}$ ) e o das mulheres transferidas para o hospital foi $3.365,5 \mathrm{~g}$, (peso mínimo $2.370 \mathrm{~g}$, máximo $4.690 \mathrm{~g}$, desvio-padrão 422,1 e mediana $3.340 \mathrm{~g}$ ). Em relação ao escore Apgar, entre as mulheres não transferidas esse índice foi menor que 7 nos $1^{\circ}$ e $5^{\circ}$ minutos de vida em $0,7 \%$ (3/456) e zero $(0 / 456)$ dos recém-nascidos, respectivamente. Merece comentar que entre os resultados do Apgar do $1^{\circ}$ minuto de vida, das três mulheres, duas eram nulíparas. Quanto às manobras de reanimação neonatal, 12,3\% dos 
bebês nascidos na CPS necessitaram de aspiração das vias aéreas superiores (56/455), 6,6\% de oxigênio inalatório (30/455) e 0,2\% de ventilação com pressão positiva (1/455).

Os resultados perinatais das transferências no período intraparto serão demonstrados posteriormente.

\subsection{Análise de regressão logística}

Conforme já descrito na seção de Métodos, foram selecionadas para a análise de regressão logística as variáveis que apresentaram $p<0,20$ pelo Qui-quadrado. Estas foram inseridas no modelo múltiplo na seguinte ordem: nuliparidade $(p<0,001)$, adequação altura uterina e idade gestacional $(p<0,001)$, dilatação cervical na admissão $(p<0,001)$, estado marital $(p<0,001)$, número de consultas na CPS $(p<0,001)$, uso de ocitocina no período de dilatação $(\mathrm{p}=0,002)$, uso de ocitocina no período expulsivo $(p<0,001)$, ocupação $(p<0,008)$, idade $(p<0,024)$, condição das membranas amnióticas na admissão na CPS $(p=0,054)$ e peso do recém-nascido $(p=0,037)$. Esta foi a ordem de entrada das variáveis no modelo. Optou-se por incluir a condição das membranas amnióticas na admissão e não a variável tipo de rotura das membranas (artificial ou espontânea), que também tinham $p<0,20$, pois as duas variáveis estão relacionadas.

A ordem de entrada das variáveis no modelo de regressão obedeceu aos critérios descritos a seguir. A variável nuliparidade foi a primeira a ser inserida por ser considerada em diversos trabalhos como fator de risco para transferência materna intraparto (David et al., 2006; Lindgren et al., 2008; Nguyen et al., 2009). Entre as variáveis que apresentaram mesmo valor de $p(p<0,001)$, optou-se por introduzir no modelo as variáveis clínicas (nuliparidade, adequação altura uterina e idade gestacional e dilatação cervical), antes da variável sociodemográfica (estado marital). A seguir, as variáveis foram introduzidas por ordem do menor valor de $p$ (idade materna, condição das membranas amnióticas na admissão e peso do recémnascido).

$\mathrm{Na}$ análise univariada, as seguintes variáveis foram fatores de risco para transferência intraparto $(p<0,05)$, com cálculo da Odds ratio bruta: 
ser nulípara, ser internada na CPS com cervicodilatação de até $3 \mathrm{~cm}$, não ter companheiro, ter realizado de 5 a 12 consultas na CPS, ter idade entre 35 e 42 anos e ter recém-nascido com peso entre 4.000 e $4.600 \mathrm{~g}$. As mesmas variáveis foram fatores de risco independentes para transferência materna no período intraparto, na análise de regressão logística múltipla, com cálculo da Odds ratio ajustada (Tabela 4).

Tabela 4 - Odds ratio (OR) brutas e ajustadas para transferência materna intraparto. São Paulo, 2002 a 2009.

\begin{tabular}{|c|c|c|c|c|c|c|}
\hline \multirow[t]{2}{*}{ Variável } & \multicolumn{3}{|c|}{ Análise univariada } & \multicolumn{2}{|c|}{ Análise múltipla } & \multirow[b]{2}{*}{$\begin{array}{l}\text { Valor } \\
\text { de } P^{a} \\
\end{array}$} \\
\hline & $\begin{array}{c}\text { OR } \\
\text { bruta }\end{array}$ & IC 95\% & $\mathrm{p}$ & $\begin{array}{c}\text { OR } \\
\text { ajustada }\end{array}$ & IC 95\% & \\
\hline \multicolumn{7}{|l|}{ Nulíparidade } \\
\hline Não & 1,0 & & & 1,0 & & \\
\hline Sim & 5,6 & $2,9-10,9$ & $<0,001$ & 5,6 & $2,9-10,9$ & $<0,001$ \\
\hline \multicolumn{7}{|l|}{ Idade materna } \\
\hline $14-19$ & 1,2 & $0,7-2,0$ & 0,423 & 0,6 & $0,3-1,2$ & 0,151 \\
\hline $20-34$ & 1,0 & & & 1,0 & & \\
\hline $35-42$ & 2,8 & $1,3-5,9$ & 0,008 & 5,0 & $2,0-12,7$ & 0,001 \\
\hline \multicolumn{7}{|l|}{ Ter companheiro } \\
\hline Sim & 1,0 & & & 1,0 & & \\
\hline Não & 2,5 & $1,5-4,1$ & $<0,001$ & 2,7 & $1,4-5,1$ & 0,002 \\
\hline \multicolumn{7}{|l|}{ Adequação AU/IG } \\
\hline Normal & 1,0 & & & 1,0 & & \\
\hline Baixa & 0,3 & $0,2-0,6$ & $<0,001$ & 0,3 & $0,2-0,6$ & $<0,001$ \\
\hline Alta & 2,1 & $0,7-6,1$ & 0,175 & 1,7 & $0,5-6,0$ & 0,384 \\
\hline $\begin{array}{l}\text { Dilatação } \\
\text { admissão na CPS }\end{array}$ & na & & & & & \\
\hline $1-3$ & 2,5 & $1,6-3,9$ & $<0,001$ & 2,0 & $1,1-3,4$ & 0,015 \\
\hline $4-6$ & 1,0 & & & 1,0 & & \\
\hline $7-10$ & 0,2 & $0,1-0,6$ & 0,005 & 0,4 & $0,1-1,5$ & 0,164 \\
\hline
\end{tabular}

Número de consultas na CPS

$\begin{array}{lllllll}0 & 1,4 & 0,8-2,4 & 0,202 & 1,9 & 0,9-3,7 & 0,060 \\ 1-4 & 1,0 & & & 1,0 & & \\ 5-12 & 3,6 & 2,0-6,3 & <0,001 & 3,3 & 1,6-6,7 & 0,001\end{array}$

Peso do RN

$1.500-2.499$

$2.500-3.999$

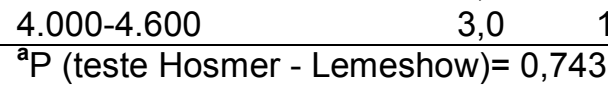

\begin{tabular}{llllll}
1,0 & $0,2-4,5$ & 0,961 & 1,5 & $0,3-8,5$ & 0,632 \\
1,0 & & & 1,0 & & \\
3,0 & $1,2-7,2$ & 0,014 & 3,5 & $1,1-11,2$ & 0,034 \\
\hline
\end{tabular}

O teste de Hosmer-Lemeshow para a adequação do modelo forneceu valor de associação pelo Qui-quadrado de 5,132; $p=0,743$ 
(hipótese nula: o modelo ajusta-se perfeitamente aos dados), o que implica a aceitação do modelo como adequado para determinado grupo de variáveis (Hosmer e Lemeshow, 2000). Estas variáveis foram utilizadas para a construção de um modelo de risco para transferência materna nesta população (Tabela 5).

Ser nulípara apresentou associação com a transferência materna intraparto, demonstrando um risco quase seis vezes maior de ser transferida. A idade materna acima de 35 anos esteve associada a um risco cinco vezes maior para a transferência. O fato de a adequação da altura uterina sugerir feto com restrição de crescimento intraútero foi fator de proteção para a transferência da mãe (diminuiu em $70 \%$ este risco), por outro lado, o fato dessa medida indicar feto grande para a idade gestacional não representou risco aumentado para transferência.

A admissão da parturiente com dilatação cervical de até 3 centímetros indicou um risco duas vezes maior de ser transferida para o hospital no período intraparto. Não ter companheiro representou um risco quase três vezes maior para esta transferência.

Ter um recém-nascido com peso superior a $4.000 \mathrm{~g}$ também, esteve associado a risco três vezes maior para a transferência, assim como a realização de 5 a 12 consultas na CPS.

\subsection{Modelo de risco para transferência materna no período intraparto}

Considerando os resultados da análise de regressão logística múltipla, definiu-se um modelo de probabilidade de transferências maternas intraparto, para o qual foi utilizada a seguinte fórmula:

$$
\operatorname{Prob}(\mathrm{Y}=1)=\frac{1}{1+\mathrm{e}^{\left(\begin{array}{l}
3,064-(0,641 \times \mathrm{A})-(1,195 \times \mathrm{B})-(1,731 \times \mathrm{C})-(0,421 \times \mathrm{xD}) \\
(1,254 \times \mathrm{xE})+(0,485 \times \mathrm{F})-(1,616 \times \mathrm{xG})+(1,117 \times \mathrm{xH})-(0,552 \times \mathrm{xI})-
\end{array}\right)}}
$$


$A=1$ se número de consultas $=0$ e 0 se não

$B=1$ se número de consultas $=5-12$ e 0 se não

$\mathrm{C}=1$ se for nulípara e 0 se for multípara

$\mathrm{D}=1$ se peso $=1.500-2.499 \mathrm{~g}$ e 0 se não

$\mathrm{E}=1$ se peso $>4.000 \mathrm{~g}$ e 0 se não

$F=1$ se idade $=14-19$ anos e 0 se não

$\mathrm{G}=1$ se idade $=35-42$ anos e 0 se não

$\mathrm{H}=1$ se adequação entre idade e altura uterina = baixa e 0 se não

$\mathrm{I}$ = 1 se adequação entre idade e altura uterina = alta e 0 se não

$\mathrm{J}=1$ se dilatação entre $1-3 \mathrm{~cm}$ e 0 se não

$K=1$ se dilatação entre $7-10 \mathrm{~cm}$ e 0 se não

$\mathrm{L}=1$ se gestante não tem companheiro e 0 se tem companheiro

Onde $\mathrm{Y}$ é a probabilidade de ocorrência de transferência em um determinado caso, considerando-se sim ou não para as variáveis que foram fatores de risco independentes para transferência materna no período intraparto.

A seguir, estão apresentados os resultados de algumas simulações de probabilidade de transferências.

Tabela 5 - Modelo de risco para transferência materna no período intraparto - CPS, São Paulo, 2011.

\begin{tabular}{lcccc}
\hline Variáveis & Probabilidade de transferência no período intraparto \\
& $99,3 \%$ & $37,0 \%$ & $18,2 \%$ & $5,0 \%$ \\
\hline Paridade & Nulipara & Nulipara & Nulipara & Multipara \\
Adequação entre AU/IG & Alta & Normal & Normal & Baixa \\
Dilatação na admissão na CPS & $1-3$ & $4-6$ & $4-6$ & $4-6$ \\
Ter companheiro & Não & Não & Sim & Sim \\
Número de consultas na CPS & $5-12$ & $1-4$ & $1-4$ & $1-4$ \\
Idade (anos) & $35-42$ & $20-34$ & $20-34$ & $20-34$ \\
Peso do RN $(\mathrm{g})$ & $>4000$ & $2-500-4000$ & $2500-4000$ & $2500-4000$ \\
\hline AU= altura uterina, IG= idade gestacional, RN= recém-nascido.
\end{tabular}

Na dados da Tabela 5, estão demonstradas as probabilidades de transferência para parturientes admitidas na CPS em determinadas condições. No primeiro exemplo, uma parturiente nulípara, com adequação entre altura uterina e idade gestacional sugestiva de feto macrossômico, admitida com cervicodilatação de até $3 \mathrm{~cm}$, sem companheiro, que realizou 
de cinco a 12 consultas na CPS, com 35 a 42 anos e feto com peso de 4.000 gramas ou mais tem probabilidade de 99,3\% de necessitar de transferência para o hospital. Esta mulher teria todos os fatores de risco para transferência intraparto.

No segundo exemplo, uma mulher nulípara que deu entrada na CPS com adequação entre altura uterina e idade gestacional normal, dilatação cervical de 4 a $6 \mathrm{~cm}$, sem companheiro, que realizou de uma a quatro consultas, com idade de 20 a 34 anos e feto com peso entre $2.500 \mathrm{~g}$ e $4.000 \mathrm{~g}$, teria probabilidade de $37,0 \%$ de ser transferida para o hospital. Ter companheiro, para uma mulher nas mesmas condições, representaria metade da chance de necessitar de transferência $(18,2 \%)$, o que está representado no terceiro exemplo.

No último exemplo, uma parturiente multípara, que apresenta adequação entre altura uterina e idade gestacional baixa, internada com dilatação de 4 a $6 \mathrm{~cm}$, com companheiro, que realizou entre uma e quatro consultas na CPS, com idade de 20 a 34 anos e feto com peso de 2.500 a $4.000 \mathrm{~g}$ teria probabilidade de 5,0\% de necessitar de transferência durante sua internação. Esta mulher não teria nenhum dos fatores de risco para transferência intraparto e ainda teria um fator de proteção para a transferência (adequação entre altura uterina e idade gestacional baixa).

\subsection{Análise dos desfechos das transferências maternas}

\subsubsection{Desfechos das transferências no período intraparto}

No período estudado (março de 2002 a dezembro de 2009), foram assistidos 2.625 nascimentos na CPS, sendo admitidas 2.736 mulheres, entre as quais 111 foram transferidas no período intraparto (taxa de transferência materna intraparto de 4,1\%). Não houve mortes maternas entre as mulheres assistidas na CPS ou no hospital, mas, dois óbitos entre os bebês que nasceram no hospital. Não ocorreu nenhum óbito entre os bebês que nasceram na CPS. 
Na Figura 2, observa-se o número de nascimentos e as taxas de transferência anuais. O cálculo destas taxas foi realizado por meio da seguinte fórmula:

Taxa de transferência anual $=\frac{\text { Total de mulheres transferidas no período intraparto durante } 0 \text { ano }}{\text { Total de mulheres admitidas durante } 0 \text { ano }} \times 100$

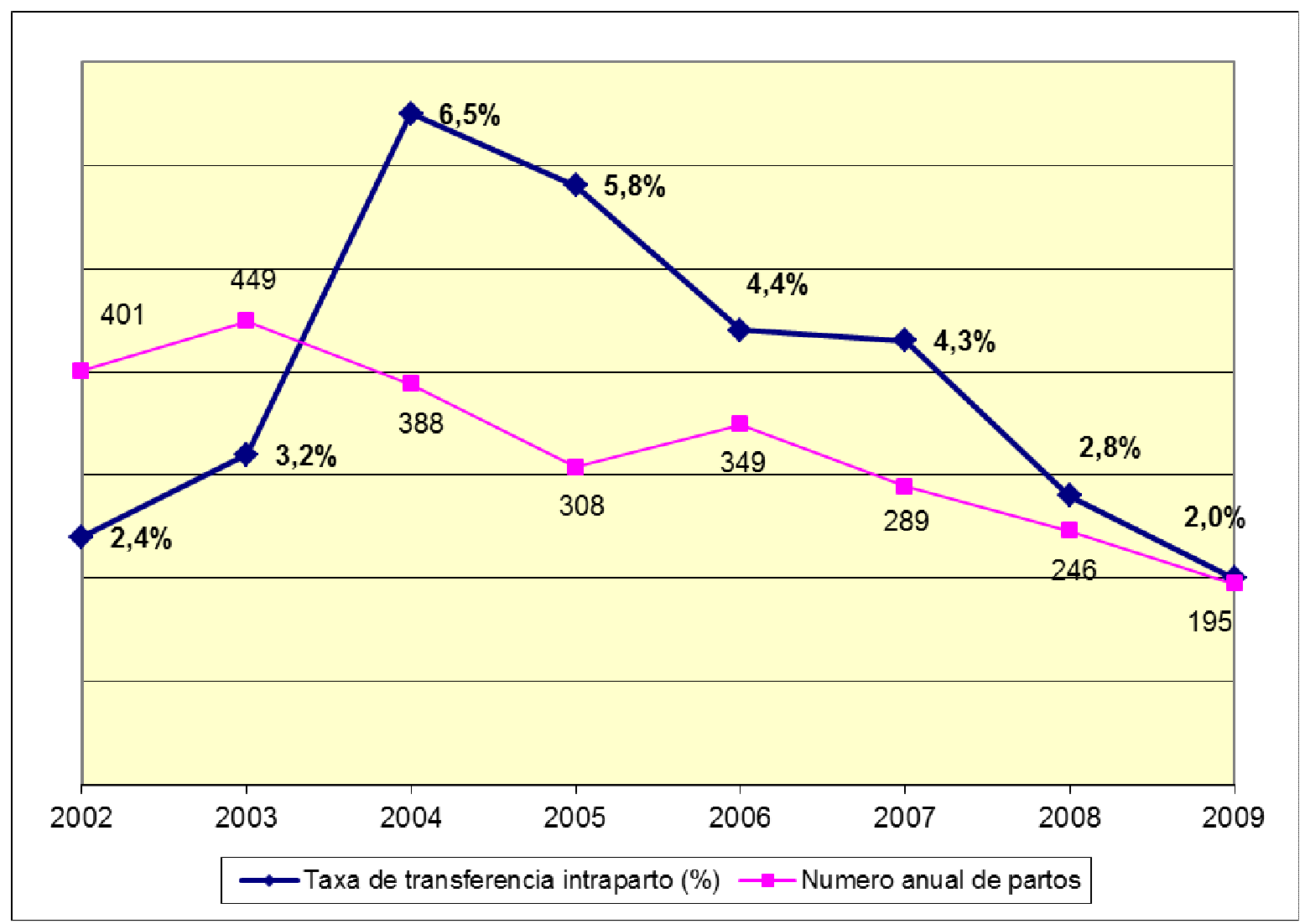

Figura 2. Taxas de transferência intraparto e número anual de partos na Casa do Parto de Sapopemba. São Paulo, 2002 a 2009.

Observa-se que, entre os anos 2002 e 2004, houve aumento nas taxas de transferência intraparto e, a partir de 2004, houve diminuição gradual e constante dessa taxa.

A seguir, os dados da Tabela 6 apresentam os motivos para a transferência materna intraparto. 
Tabela 6 - Número e frequência dos motivos para transferência materna intraparto. São Paulo, 2002 a 2009.

\begin{tabular}{lcc}
\hline Motivo de transferência materna intraparto & $\mathbf{N}$ & $\mathbf{\%}$ \\
\hline Fase ativa prolongada - de 5 a $9 \mathrm{~cm}$ & 35 & 31,5 \\
Líquido amniótico meconial & 20 & 18,0 \\
Fase pélvica prolongada (expulsivo) & 15 & 13,5 \\
Fase latente prolongada - até $4 \mathrm{~cm}$ & 14 & 12,6 \\
Traçado cardiotocográfico alterado & 11 & 9,9 \\
İndice de Bishop desfavorável & 4 & 3,6 \\
Outros motivos & 4 & 3,6 \\
Taquissistolia & 2 & 1,8 \\
Prolapso de cordão umbilical & 2 & 1,8 \\
Apresentação pélvica & 2 & 1,8 \\
Anormalidades fetais ou pélvicas & 1 & 0,9 \\
Estresse materno & 1 & 0,9 \\
\hline Total & $\mathbf{1 1 1}$ & $\mathbf{1 0 0}$
\end{tabular}

Observa-se que o número de casos em que houve falha no progresso do trabalho de parto (fase latente prolongada, fase ativa prolongada e fase pélvica prolongada) correspondeu à maioria das transferências $(64 / 111 ; 57,6 \%)$. Os motivos referentes ao feto, como líquido amniótico meconial e traçado cardiotocográfico alterado, corresponderam a $28 \%$ das transferências (31/111). Como outros motivos de transferência, estão incluídos hipertensão arterial, líquido amniótico sanguinolento, NIC III, HPV e febre materna.

Via de parto entre as mulheres transferidas da CPS para o hospital

Considerando o total das mulheres internadas na CPS, $1,8 \%$ (49/2.736) foram submetidas à cesariana.

Quanto às condições clínico-obstétricas das parturientes na transferência, a maioria tinha 6 ou mais centímetros de dilatação (74/111; $66,7 \%$ ), entre estas, $16,2 \%$ (18/111) estavam em período expulsivo. A maioria recebeu ocitocina durante o trabalho de parto $(74 / 111 ; 66,7 \%)$ e teve acompanhante de sua escolha no trabalho de parto no hospital (101/111; $91 \%)$.

Quanto à via de parto das mulheres transferidas, 49,5\% tiveram parto normal (55/111), 44,1\% cesariana (49/111), 4,5\% fórceps (5/111) e 1,8\% vácuo extrator (2/111). Entre as mulheres que deram à luz 
por via vaginal $(62 / 111 ; 55,9 \%), 17,7 \%$ (11/62) mantiveram o períneo íntegro, $17,7 \%$ (11/62) tiveram laceração de $1^{\circ}$ grau, 1,6\% (1/62) laceração de $2^{\circ}$ grau, $61,3 \%$ (38/62) episiotomia medio-lateral direita e 1,6\% (1/62) episiotomia mediana.

As análises de subgrupo que investigaram a paridade demonstraram que a maioria das mulheres transferidas era nulípara (85/111; $76,6 \%$ ), assim como a maioria das mulheres que foi submetida à cesariana (40/49; $81,6 \%)$ e a partos fórceps (3/5; 60,0\%). Quanto ao vácuo extrator, metade das mulheres era nulípara (1/2; 50,0\%).

Cerca de $10 \%$ das mulheres (11/111) apresentaram intercorrências durante o trabalho de parto e parto, tais como: amniorrexe prolongada (1), desprendimento fetal em posição occiptosacra (1), edema vulvar intenso (1), período expulsivo prolongado (1), fisometria (4), lesão vesical e cefaleia pós-raquianestesia depois da cesariana (1), parto cesariana após realização de episiotomia (1) e prolongamento do ângulo da histerotomia (1).

Após o parto, todas as mulheres foram internadas na unidade de alojamento conjunto. No período pós-parto, 4,5\% (5/111) das mulheres apresentam intercorrências, tais como edema perineal (1), equimose em episiotomia (1), infecção puerperal (1), necessidade de assistência psicológica (1) e retenção urinária prolongada (1).

As indicações dos partos cirúrgicos foram registradas, conforme a primeira indicação (no caso de haver mais de uma indicação) e foram agrupadas nas categorias a seguir (Tabela 7). 
Tabela 7 - Número e frequência das indicações de partos cirúrgicos entre as mulheres transferidas. São Paulo, 2002 a 2009.

\begin{tabular}{lcc}
\hline Tipo de Parto & N & $\%$ \\
\hline Cesarianas & 14 & 25,0 \\
Desproporção cefalopélvica & 8 & 14,2 \\
Alteração dos batimentos cardíacos fetais & 5 & 8,9 \\
Distocia funcional & 5 & 8,9 \\
Distocia de rotação & 4 & 7,1 \\
Líquido amniótico meconial & 3 & 5,4 \\
Parada de progressão do trabalho de parto & 3 & 5,4 \\
Distocia óssea & 2 & 3,6 \\
Período expulsivo prolongado & 2 & 3,6 \\
Apresentação pélvica & 2 & 3,6 \\
Laterocedência ou prolapso de cordão & 1 & 1,8 \\
Descolamento prematuro de placenta & & 8,9 \\
Fórceps & 5 & 3,6 \\
Abreviação do período expulsivo & & $\mathbf{1 0 0}$ \\
Vácuo extrator & 2 & \\
Abreviação do período expulsivo & $\mathbf{5 6}$ & \\
\hline Total & &
\end{tabular}

Observa-se que entre as cesarianas a maioria das indicações ocorreu em razão de problemas maternos (32/49; 65,3\%), seguidas por motivos referentes ao bebê $(16 / 49 ; 32,7 \%)$. Aproximadamente, $6 \%$ das mulheres transferidas necessitaram de partos instrumentais para abreviar o período expulsivo $(7 / 111 ; 6,3 \%)$.

Quanto à alta hospitalar, a maioria das puérperas teve alta em torno de 48 horas, após o parto vaginal e 72 horas, após a cesariana.

\section{Dados dos bebês nascidos no hospital}

Do total dos bebês que nasceram no hospital, tiveram Apgar menor que 7 nos $1^{\circ}$ e $5^{\circ}$ minutos de vida $(28 / 111 ; 25,2 \%)$ e $(5 / 111 ; 4,5 \%)$, respectivamente.

As análises de subgrupo indicaram que a maioria das mulheres, cujos filhos nasceram com índice de Apgar menor que 7 no $1^{\circ}$ minuto de vida, era nulípara (24/28; $85,7 \%$ ), e que também $100 \%$ dos RN com Apgar menor que 7 no $5^{\circ}$ minuto de vida eram filhos de nulíparas (5/5).

Cerca de $20 \%$ dos RNs que nasceram de parto normal (10/55; $18,2 \%)$ tiveram Apgar menor que 7 no $1^{\circ}$ minuto de vida e um RN (1/55; 
1,8\%) apresentou escore Apgar menor que 7 no $5^{\circ}$ minuto de vida. Entre os neonatos de parto cesariana, um terço $(15 / 49 ; 30,6 \%)$ obteve pontuação no Apgar menor que 7 no $1^{\circ}$ minuto e quatro RN $(4 / 49 ; 8,2 \%)$ menor que 7 no $5^{\circ}$ minuto de vida.

Entre os RNs que nasceram de parto fórceps, a maioria teve Apgar menor que 7 no $1^{\circ}$ minuto de vida $(3 / 5 ; 60 \%)$, porém nenhum mostrou Apgar menor que 7 no $5^{\circ}$ minuto de vida. Os dois bebês cujo parto necessitou de vácuo extrator, apresentaram escores de Apgar superior a 7 nos $1^{\circ}$ e $5^{\circ}$ minutos de vida.

Em relação às manobras de reanimação neonatal, $27 \%$ (30/111) dos RN nascidos no hospital necessitaram de aspiração das vias aéreas superiores, 54\% (60/111) de oxigênio, 17 (15,3\%) de ventilação com pressão positiva e 9,0\% de intubação orotraqueal (10/111). Doze RN (12/111; 10,8\%) foram encaminhados para a UTI neonatal, 10 (10/111; $9,0 \%)$ à unidade de cuidados intermediários e 1 (1/111; 0,9\%) ao setor de observação da unidade neonatal. A maioria dos RN (88/111; 79,3\%) foi encaminhada ao alojamento conjunto. A média de peso dos RN de mães transferidas intraparto foi $3.203,8 \mathrm{~g}$ (desvio-padrão 391,7; peso mínimo $2.300 \mathrm{~g}$ e máximo $4.600 \mathrm{~g}$ ).

\section{Casos de óbito entre os recém-nascidos das mulheres transferidas}

A mortalidade neonatal entre as mulheres admitidas na CPS no período do estudo foi de 0,73/1.000 nascidos vivos (2/2.736 x 1.000). Koiffman et al. (2010) encontraram uma taxa de mortalidade neonatal de 1,0/1.000 nascidos vivos, em estudo caso-controle sobre transferências neonatais realizadas na mesma CPS, entre 1998 e 2005.

A descrição dos dois casos de óbitos de $\mathrm{RN}$ de parturientes transferidas da CPS para o hospital é apresentada a seguir. 
Óbito de RN com 28 h55 de vida, em março de 2004, por síndrome de aspiração meconial e hipertensão pulmonar.

Parturiente primigesta de 28 anos, admitida às 00h50 de 27/03/2004, 40 semanas de idade gestacional pela data da última menstrução (DUM) e ultrassom (US), altura uterina de $34 \mathrm{~cm}$, com companheiro, com trabalho remunerado, pertencente à área de abrangência da CPS, duas consultas de pré-natal e duas na CPS, não tabagista, teve infecção do trato urinário tratada na gestação. Não há registro da cervicodilatação na admissão nem da condição das membranas amnióticas, contudo a rotura das membranas foi espontânea durante o trabalho de parto, aos $5 \mathrm{~cm}$ de dilatação. Não há registro de cardiotocografia ou amnioscopia. A parturiente foi transferida para o hospital às $8 \mathrm{~h} 30$ do mesmo dia, com colo pérvio para $5 \mathrm{~cm}$, por apresentar cardiotocografia com padrão comprimido e líquido amniótico meconial. Foi admitida na maternidade do HEVA às 9h40, onde foram realizados cardiotocografia e registro do acompanhamento do trabalho do parto em partograma. Como medidas de conforto, utilizaram-se banho de aspersão e deambulação. Não foi administrada ocitocina intravenosa. A cesariana foi indicada por distocia funcional e sofrimento fetal. O RN obteve Apgar 4 e $8,3.430 \mathrm{~g}$, às $13 \mathrm{~h} 45$ de 27/03/04. O RN foi submetido à intubação orotraqueal aos 20 minutos de vida e internado na UTI neonatal. Recebeu dobutamina, dopamina, fentanil, nitroprussiato de sódio e permaneceu em ventilação mecânica. Ao exame de raios-x, apresentou infiltrado bilateral sugestivo de síndrome de aspiração de mecônio. Faleceu às $19 \mathrm{~h} 10$ de 28/03/04 (com 28h55 de vida). A causa do óbito foi síndrome de aspiração meconial e hipertensão pulmonar.

Óbito de RN com 11 dias de vida, em setembro de 2006, por sindrome de aspiração meconial.

Parturiente primigesta, com 30 anos, admitida às 8 h30 horas de 02/09/2006, 39 semanas pela DUM e US, altura uterina de $35 \mathrm{~cm}$, colo cervical pérvio para $2,0 \mathrm{~cm}$, realizada amnioscopia com líquido amniótico claro e monitorização fetal. A mulher tinha companheiro, trabalho remunerado, não era fumante e pertencia à área de abrangência da CPS. Havia realizado uma 
consulta na CPS, sem registro do número de consultas na UBS. Foi utilizada infusão de ocitocina e realizada rotura artificial das membranas amnióticas (observada saída de líquido amniótico claro com grumos) com $6 \mathrm{~cm}$ de dilatação cervical. A parturiente foi transferida para o HEVA às $23 \mathrm{~h} 50$, por parada de progressão e líquido amniótico meconial fluido, com dilatação de $8,0 \mathrm{~cm}$. Observou-se taquicardia fetal na cardiotocografia. Foi admitida na maternidade aos 20 minutos do dia 03/09/2006 com a mesma dilatação e não foi visualizado líquido amniótico no exame vaginal. Realizada cardiotocografia. Foi indicada cesariana por desproporção cefalopélvica e líquido amniótico meconial. Nasce RN vivo, às $13 \mathrm{~h} 25 \mathrm{~h}$ de 03/09/2006, com $3.610 \mathrm{~g}$ e Apgar 2 e 2. Realizada entubação orotraqueal, cateterização umbilical e encaminhado à UTI neonatal. O RN evoluiu com síndrome de aspiração meconial, anasarca e crise convulsiva. Foram realizados diálise peritoneal e exame de tomografia, que demonstraram isquemia cerebral. Faleceu aos 50 minutos do dia 16/10/2006, com diagnóstico de falência de múltiplos órgãos, septicemia e encefalopatia hipóxico-isquêmica.

\subsubsection{Desfechos das transferências maternas no período pós-parto}

Houve 13 casos de transferência materna pós-parto, que corresponderam a uma taxa de transferência de 0,5\% (13×100/2.625). Os motivos das transferências pós-parto foram agrupados nas seguintes categorias:

1 - retenção placentária;

2 - sangramento vaginal aumentado;

3 - febre materna; e

4 - Outros: motivos relativos à condição clínica desfavorável ou não prevista no protocolo de admissão na CPS, como ausência de colostro, loquiação fétida e tontura. 
Tabela 8 - Número e frequência dos motivos para transferência materna pós-parto. São Paulo, 2002 a 2009.

\begin{tabular}{lcc}
\hline Motivos de transferência materna pós-parto & N & \% \\
\hline Retenção placentária & 5 & 38,5 \\
Outros problemas & 4 & 30,8 \\
Sangramento vaginal aumentado & 2 & 15,4 \\
Febre materna & 2 & 15,4 \\
\hline Total & $\mathbf{1 3}$ & $\mathbf{1 0 0}$ \\
\hline
\end{tabular}

A categoria outros problemas incluiu casos de mulheres que apresentaram astenia (1), sinais de estado emocional incompatível com autocuidado (1) e hipertensão arterial materna (2). A maioria das mulheres era primigesta (8/13; 61,5\%), tinha média de 26,2 anos (desvio-padrão 9,1, mínimo 16 e máximo 42 anos), tinha companheiro (10/13; 76,9\%), não possuía trabalho remunerado (10/13; 76,9\%), era da área de abrangência da CPS $(7 / 13 ; 53,8 \%)$, tinha feito três ou mais consultas na CPS (10/13; 76,9\%) e mais de quatro consultas de pré-natal (12/13; 92,3\%). Em 46,2\% das transferidas, após o parto (6/13), foram realizadas curetagem; e $38,4 \%$ necessitaram de transfusão sanguínea (5/13).

Entre os casos de retenção placentária, $60 \%$ (3/5) eram nulíparas e $40 \%(2 / 5)$ multíparas. Todos os RN de mães que foram transferidas no período pós-parto tiveram escore Apgar maior que 7 nos $1^{\circ} \mathrm{e}$ $5^{\circ}$ minutos de vida. Todos esses RN acompanharam suas mães na transferência para o hospital. A média de peso dos bebês foi $3.406,2 \mathrm{~g}$, desvio-padrão $493,9 \mathrm{~g}$, o peso mínimo $2.670 \mathrm{~g}$ e máximo $4.370 \mathrm{~g}$. Um RN foi encaminhado à UTI neonatal por ter apresentado sepse tardia onde permaneceu em antibioticoterapia por 14 dias. Outro RN ficou na unidade de cuidados intermediários por cerca de 22 horas, por ter apresentado desconforto respiratório. Ambos os $\mathrm{RN}$ receberam alta em bom estado geral. 
Este é um estudo caso-controle que procurou identificar os fatores de risco para transferências maternas de um centro de parto extrahospitalar (CPS) para o hospital, com a finalidade de ressaltar as características sociodemográficas, assistenciais e clínico-obstétricas relacionadas a esses eventos.

A identificação dos fatores de risco é primordial na avaliação de mulheres em centros de parto, sobretudo nos centros de parto autônomos. Mulheres que dão à luz nesses serviços, não devem apresentar condições clínicas que impliquem riscos, tais como: diabetes, hipertensão arterial e problemas cardíacos (Stapleton, 2011). Ter uma cesariana anterior pode ser considerado um fator de risco para essas mulheres, mas a questão é controversa. Um estudo prospectivo foi conduzido com 1.453 mulheres americanas admitidas em centros de parto autônomos, após terem uma ou mais cesarianas. Houve seis casos de rotura uterina $(0,4 \%)$ e sete de óbito perinatal $(0,5 \%)$. Mulheres com mais de uma cesariana prévia e idade gestacional superior a 42 semanas tiveram maior risco para rotura uterina ou outra complicação séria, como histerectomia, escore de Apgar de $5^{\circ}$ minuto inferior a 7, óbito materno ou perinatal. Os autores concluíram que mulheres com uma cesariana anterior deveriam ser encaminhadas aos hospitais para dar à luz, onde teriam pronto acesso ao parto operatório de emergência (Lieberman et al., 2004).

Nesse estudo, merece destacar que, entre os casos de rotura uterina, três mulheres tinham duas cesarianas anteriores ou idade gestacional de 42 semanas ou mais, portanto, não deveriam ser assistidas em centro de parto. Se apenas mulheres com uma cesariana anterior tivessem sido incluídas na pesquisa, a taxa de rotura uterina seria de 2/1.000 nascidos vivos (Albers, 2005). Este resultado é inferior ao do estudo de coorte retrospectiva realizado com 20.000 mulheres que deram à luz, após uma cesariana em hospitais no qual foi verificada taxa de rotura uterina de 5,2/1.000 entre mulheres que entraram em trabalho de parto espontaneamente (Lydon-Rochelle et al., 2001).

Estudo alemão com 6.812 mulheres assistidas em centros de parto autônomos, 306 mulheres tinham cesariana anterior e apresentaram 
risco seis vezes maiores de serem transferidas para o hospital e 13 vezes maiores de serem submetidas à cesariana. No entanto, não houve aumento do risco para escore de Apgar menor que 7 no $5^{\circ}$ minuto de vida ou admissão do recém-nascido em unidade neonatal. Mas, mulheres com cesariana prévia tiveram maior indicação de transferência para o hospital para reparo perineal que mulheres sem cesariana prévia $(2,5 \%$ versus $0,5 \%$, respectivamente), embora os autores não tivessem esclarecido o tipo de laceração ocorrida. Não houve casos de rotura uterina, contudo o reduzido número de mulheres com cesariana prévia não permite estimar o risco para esta morbidade. Os autores destacaram que a cooperação entre os centros de parto e o hospital permitiu a intervenção oportuna nos casos de transferências emergenciais (David et al., 2009).

Estes achados sugerem que mulheres que dão à luz em centros de parto após uma cesariana, não têm risco de rotura uterina superior àquelas em hospitais. Não há estudos randomizados que avaliem os resultados de partos vaginais planejados, após cesariana (Dodd et al., 2004). Na CPS, a gestante que teve uma cesariana prévia é considerada como de baixo risco caso tenha tido um parto normal após essa cirurgia.

A nuliparidade tem sido apontada em vários estudos como fator de risco para transferência do centro de parto ou do domicílio para o hospital, no período intraparto. Estudo de coorte prospectiva realizado na Dinamarca comparou os resultados de dois centros de parto autônomos e duas unidades obstétricas hospitalares. A taxa de transferência intraparto foi de $11,5 \%$, mas mulheres primíparas foram transferidas em maior número $(36,7 \%)$ comparadas às multíparas $(7,2 \%)$ (Overgaard et al., 2011). Estudo americano com 84 centros de parto reportou taxa de transferência intraparto cerca de quatro vezes maiores entre as nulíparas, quando comparadas com as multíparas (Rooks, Weatherby, Ernst., 1992). Achados similares foram encontrados em ensaio clínico randomizado em centro de parto intrahospitalar sueco, que verificou taxas de transferência intraparto de nulíparas $(29,4 \%)$ quase cinco vezes maiores que entre as multíparas $(4,2 \%)$ (Waldenstrom, Nilsson, Winbladh, 1997) Estudo em centros de parto 
alemães relatou a taxa de transferência de 14,4\% entre nulíparas e de 5,4\% entre multíparas (David et al., 2006).

Pesquisa norueguesa citou menor proporção de nulíparas entre as mulheres transferidas $(36,2 \%)$ de centros de parto para hospitais, porém nesses locais elas eram admitidas em menor proporção $(11,2 \%)$ que as multíparas (88,8\%) (Schmidt et al., 2002). Em um estudo que avaliou as transferências de centros de parto nos EUA, ser primípara representou risco duas vezes maior de ser transferida, considerando os períodos anteparto e intraparto (Nguyen et al., 2009). Esse resultado foi inferior ao do presente estudo, no qual ser nulípara representou risco quase seis vezes maior de ser transferida que ser multípara.

Nesta investigação, ter idade materna igual ou superior a 35 anos representou um risco cinco vezes maior de a mulher ser transferida no período intraparto. A gestação, em idade superior a 35 anos, tem sido relacionada a maus resultados obstétricos, como o aumento de infertilidade, abortamentos, anomalias cromossômicas, complicações hipertensivas e óbito fetal (Heffner, 2004), além de maior risco para cesariana, em razão de suposta deterioração da função miometrial (Jolly et al., 2000). No entanto, estudo suíço de base populacional não encontrou associação entre ter mais de 39 anos e ser transferida para o hospital, em partos domiciliares planejados (Lindgren et al., 2008).

Neste estudo, não ter companheiro foi fator de risco independente para transferência intraparto. Ter um companheiro pode indicar estrutura familiar e segurança à mulher, embora um estudo casocontrole em Israel não tenha detectado diferenças nos resultados de partos entre mulheres casadas e solteiras (Lurie et al., 2010). Por outro lado, estudo finlandês verificou que mulheres solteiras tinham maior probabilidade de resultados adversos, como mortes perinatais e fetos com baixo peso ao nascer e prematuros (Manderbacka et al., 1992). No entanto, estudo que comparou o impacto da qualidade de relacionamento das gestantes solteiras no comportamento delas e nos resultados obstétricos observou que mulheres que relataram a condição do relacionamento como ruim tinham mais sintomas depressivos (razão de prevalência - RP: 1,93; IC 95\% 1,65; 
2,25), estresse (RP 1,24; IC 95\% Cl: 1,14; 1,35), uso de drogas (RP 1,34; IC 95\%: 1,11; 1,61) e tabagismo (RP 1,28; IC 95\% 1,10; 1,49) (Bloch et al., 2010). Estes achados indicam que não apenas o estado marital, mas também a qualidade do relacionamento pode ter impacto nas condições de saúde da mulher.

A adequação entre altura uterina e idade gestacional, quando sugestiva de RN grande para a idade gestacional (adequação alta) não representou risco aumentado para transferência materna intraparto no atual estudo, ao contrário do peso fetal superior a $4.000 \mathrm{~g}$, que representou risco quase quatro vezes maior. Estudo de base populacional sueco sobre parto domiciliar planejado encontrou risco aumentado para transferência intraparto entre mulheres que tiveram bebês com peso superior a $4.500 \mathrm{~g}$, (OR 2,1, IC $95 \% 1,4 ; 2,5)$, porém apenas entre as multíparas (Lindgren et al., 2008). Pesquisa em centro de parto alemão não encontrou diferença entre o peso de $\mathrm{RN}$ de mulheres que deram à luz em centros de parto ou foram transferidas para o hospital (David et al., 2006). Em estudo norueguês, o peso médio dos bebês de mulheres que foram transferidas intraparto foi menor que os daquelas que deram à luz em centros de parto autônomos (3.495 g versus $3.640 \mathrm{~g}$, respectivamente) (Schmidt, Abelsen, Oian, 2002). A adequação entre altura uterina e idade gestacional baixa pode sugerir feto com restrição de crescimento intrauterino, que está associada a complicações como baixos escores de Apgar. Essa restrição está associada também a maior incidência de convulsões no segundo dia de vida, sobretudo para fetos com peso abaixo do percentil 75 (Mcintire et al., 1999), além de risco para aspiração meconial (Bernstein et al., 2000). Entretanto, no presente estudo esta adequação baixa representou proteção para transferência intraparto.

A admissão da parturiente na CPS com dilatação cervical de até $3 \mathrm{~cm}$ implicou um risco duas vezes maior de transferência durante o trabalho de parto. Mulheres que procuram a CPS nesta fase do parto poderiam ter idade gestacional superior a 41 semanas ou rotura das membranas amnióticas, mas a idade gestacional e a condição das membranas amnióticas não foram fatores de risco independentes para 
transferência intraparto. A CPS utiliza algumas práticas para protelar a admissão da mulher, tais como a reavaliação. Este é um procedimento usual na CPN, quando o exame obstétrico inicial apresenta achados limítrofes. Pode-se usar, como exemplo, o caso de uma parturiente primigesta com colo pérvio para $3 \mathrm{~cm}$, pouco esvaecido e contrações uterinas esporádicas, que não permitiram determinar se era período prodrômico ou fase inicial do trabalho de parto. Assim, esta mulher pôde se beneficiar da permanência na CPS por algumas horas para a realização de novo exame, procedimento usual em diversos serviços obstétricos (Austin, 1996). Além das orientações feitas às gestantes nas consultas, contatos telefônicos também podem ser utilizados para esclarecimento de dúvidas na fase inicial do parto (Barnes e Dossey, 1999).

Revisão sistemática que incluiu um estudo com 209 mulheres demonstrou que programas que procuraram protelar a admissão da parturiente para cuidado intraparto até a fase ativa do trabalho, resultaram em menor permanência no setor de pré-parto (OR 5,20 horas, IC 95\% 7,06; 3,34 ), menor uso de ocitocina durante o parto (OR 0,45, IC 95\% 0,25; 0,80) e de analgesia (OR 0,36, IC 95\% 0,16; 0,78) (Lauzon, Hodnett, 2004). A admissão das mulheres em fase precoce do parto pode indicar preocupação da mulher e de seus familiares com relação ao desfecho do parto.

Mulheres que realizaram cinco ou mais consultas na CPS apresentaram maior risco para transferência intraparto. Este elevado número de consultas, assim como a internação em período precoce podem indicar receio quanto aos resultados do parto.

A identificação dos fatores de risco mencionados anteriormente possibilitou a elaboração de um modelo de risco para transferência intraparto da CPS para o hospital. Modelos de risco são processos estatísticos que estimam a probabilidade de ocorrência de eventos de risco em determinado período de tempo. Estes têm sido utilizados para avaliar resultados clínicos de indivíduos com determinadas condições (Whittemore, 2010), tais como, a ocorrência de crises de eclampsia (Phaloprakarn, Tangjitgamol, 2009) (von Dadelszen et al., 2009). 
Existem duas abordagens estatísticas básicas para avaliar os fatores de risco associados à determinada condição: na primeira, a probabilidade do evento é função dos fatores de risco (ou preditores), de acordo com a regressão logística. O valor de um fator de risco é mensurado por seus efeitos no risco, condicionado a outros preditores. A segunda sintetiza o desempenho do preditor, de acordo com medidas como sensibilidade, especificidade, valores preditivos e curvas ROC (receiver operating characteristics ou características operacionais do operador) (Huang, Pepe, 2010). O estudo caso-controle é usualmente utilizado para a investigação de fatores preditivos de determinado evento, na fase inicial do estudo (Huang, Pepe, 2010).

No presente estudo, observa-se que a transferência, embora possa ser determinada por um único fator durante o trabalho de parto, é também influenciada por um conjunto de fatores já presentes na admissão da mulher no serviço. A decisão clínica é complexa e, frequentemente, determinada por uma combinação de complicações, como a presença de líquido meconial e alteração dos batimentos cardíacos fetais (Rooks, Weatherby, Ernst., 1992) e a fase em que se encontra o trabalho de parto. Conhecer os fatores anteriores ao trabalho de parto pode auxiliar os profissionais na decisão clínica sobre a transferência intraparto e na discussão com a mulher e seus familiares sobre o local mais adequado para dar à luz.

A taxa de transferência materna intraparto entre as 2.736 mulheres admitidas na CPS, de 2002 a 2009, foi de 4,1\%. Esta taxa é definida como a porcentagem de mulheres admitidas na unidade que foram transferidas para o hospital durante o trabalho de parto (Hall, 2003). Resultado semelhante foi encontrado no estudo prospectivo norueguês que incluiu todas as mulheres que planejaram dar à luz nos dez centros de parto extra-hospitalares do país. Quatro e meio por cento das mulheres foram transferidas para o hospital no período intraparto (Schmidt, Abelsen, Oian, 2002). No entanto, as autoridades de saúde da Noruega recomendam que os centros de parto prestem cuidados a mulheres com, pelo menos, um parto normal prévio, embora em algumas unidades a obstetriz possa admitir 
também parturientes nulíparas. $\mathrm{O}$ fato pode ter contribuído para as menores taxas de remoção intraparto.

A taxa de transferência materna em centros de parto varia amplamente entre os serviços. Ensaio clínico randomizado irlandês comparou os resultados maternos e neonatais de gestantes de baixo risco atendidas em serviços sob a coordenação de obstetrizes e de médicos, sendo ambos localizados no hospital. No grupo de mulheres alocadas para o cuidado com as obstetrizes, $13,1 \%$ delas foram transferidas para o cuidado médico por causa de intercorrências (Begley et al., 2011). Taxas maiores de transferência foram encontradas na revisão sistemática da Biblioteca Cochrane que incluiu 10.684 mulheres de nove ensaios clínicos em centros de parto intra-hospitalares e encontrou taxas de $22 \%$ a $63 \%$ (Hodnett et al., 2010). No entanto, não foi possível distinguir o efeito do local do parto sobre os resultados maternos e neonatais do efeito de outras variáveis, tais como continuidade no cuidado ou profissional prestador de serviço.

Estudo retrospectivo realizado na Casa do Parto Davi Capistrano em Belo Horizonte, um centro de parto peri-hospitalar, encontrou uma taxa de transferência intraparto de 10,5\%, entre 2.117 mulheres admitidas no serviço (Campos e Lana, 2007), similares às taxas encontradas em estudo americano que reportou taxa de transferência intraparto entre 2.002 mulheres admitidas (8,0\%) em 16 centros de parto autônomos nos Estados Unidos da América (Eakins, 1989).

Em uma revisão estruturada sobre resultados de centros de parto autônomos, nos três estudos foram relatadas taxas de transferência intraparto que variaram de $14,6 \%$ a $22 \%$. A principal indicação para transferir a mulher foi falha no progresso do primeiro estágio do parto (Walsh, Downe, 2004).

Em um estudo que investigou os resultados de 35 centros de parto autônomos (free-standing maternity units) ingleses, em 1998, a taxa de transferência variou de 0 a 31,1\% (média de 15,8\%) (Hall, 2003), similares aos achados do estudo prospectivo que avaliou os resultados de sete centros de parto extra-hospitalares em Berlim, com taxa de transferência de 14,2\% (David et al., 2006), entre as 3.060 mulheres assistidas nesses 
serviços. Estudo italiano com 1.484 mulheres em centro de parto perihospitalar encontrou taxa de transferência intraparto de 14,1\%. No entanto, $32 \%$ das mulheres foram transferidas por requisitarem analgesia peridural. Assim, a taxa de transferência devido por razões clínicas foi em torno de 10\% (Morano et al., 2007), semelhantes às do estudo dinamarquês já citado, que encontrou 11,5\% (Overgaard et al., 2011). Frequências similares foram observadas em estudo australiano que descreveu os resultados de 16 centros de parto (13 eram intra ou peri-hospitalares, três eram extrahospitalares) e relatou taxas de transferência intraparto de $7 \%$ a $29 \%$ e média de 16,4\% (Laws et al., 2009).

Um estudo de coorte prospectivo realizado nos EUA incluiu 84 centros de parto e 17.856 mulheres, das quais um terço (11.814) recebeu assistência nesses locais. Dentre estas, $12,4 \%$ foram transferidas no período intraparto (15\% destas transferências foram de emergência). Os centros de parto estavam localizados fora dos hospitais, embora a distância entre os serviços não tenha sido descrita no estudo (Rooks, Weatherby, Ernst, 1992) A frequência de cesariana foi de $4,4 \%$, sem nenhum caso de morte materna, sendo a taxa de mortalidade perinatal de 1,3/1.000 nascidos vivos, similar à encontrada em outros estudos sobre nascimentos em hospitais. No entanto, este estudo apresentou os resultados de CPN intra-hospitalares e autônomos de maneira conjunta. Outro estudo americano verificou uma taxa de transferência intraparto de 19,6\% em centros de parto autônomos (Nguyen et al., 2009), similares aos achados do ensaio clínico randomizado que comparou os resultados maternos e neonatais em centro de parto alemão intra-hospitalar que relatou uma taxa de transferência intraparto de 19\% (Waldenstrom, Nilsson, Winbladh, 1997).

Observa-se que a taxa de transferência materna intraparto na CPS é menor que a de outros serviços. Isso se deve, provavelmente, aos estritos critérios de inclusão das parturientes no atendimento. Gestantes que a princípio não apresentam contraindicações (problemas clínicos ou obstétricos) para o atendimento nesse serviço, são orientadas a procurar o hospital para dar à luz, caso apresentem alguma intercorrência. 
Os centros de parto peri-hospitalares podem ter taxas de transferência intraparto maiores que as de centros de parto autônomos, pois nestes serviços as mulheres podem ter como motivo de transferência o desejo de receber analgesia. Morano et al., (2007), em estudo sobre centro de parto peri-hospitalar italiano, relataram que $32 \%$ das mulheres transferidas tiveram este motivo como indicação de transferência. Já Campos e Lana (2007), em um estudo em centro de parto peri-hospitalar em Belo Horizonte, observaram que $25,3 \%$ das mulheres foram transferidas por esta mesma razão. Na CPS, nenhuma mulher foi transferida por solicitação de analgesia. De modo geral, este procedimento não é realizado a pedido da parturiente no SUS. Embora a analgesia obstétrica esteja contemplada na tabela de pagamento da assistência ao parto (Brasil, 1998), de maneira geral as maternidades não dispõem de estrutura para oferecê-la.

A variação nas taxas de transferência na CPS reflete mudanças no serviço nos anos de 2002 a 2009. Em 2003, houve mudanças na direção técnica e na coordenação do Programa de Saúde da Família. Em 2004, exacerbou-se o posicionamento contrário da classe médica aos centros de parto extra-hospitalares (casas de parto), o que resultou em uma Resolução do Conselho Regional de Medicina de São Paulo que proibia médicos de prestarem assistência nesses serviços e exigia a notificação de casos de mulheres provenientes desses estabelecimentos (CREMESP, 2004). O Conselho Regional de Medicina do Estado de São Paulo, assim como fez o CRM do Rio de Janeiro (que se mobilizou para impedir o funcionamento da Casa do Parto de Realengo, sem sucesso), denunciou a CPS junto ao Ministério Público solicitando seu fechamento. Este pedido foi indeferido, conforme análise judicial (Koiffman, 2006). A FEBRASGO e outras entidades médicas seguem com posicionamento contrário aos centros de parto extra-hospitalares.

Este contexto político desfavorável refletiu-se na queda no número de atendimentos e nas taxas mais elevadas de transferência. Atualmente, a CPS segue em atividade, porém com número de atendimentos muito aquém de sua capacidade. Da mesma forma, a Casa de Maria, (centro de parto peri-hospitalar anexo ao Hospital Geral do Itaim 
Paulista) é pouco utilizada pela população, embora a região onde está localizada (extrema zona leste da capital paulista) seja carente de leitos obstétricos.

A Casa Ângela, outro centro de parto extra-hospitalar também localizado em São Paulo, iniciou o atendimento em 2009 e ainda procura meios de financiar seus custos, por meio de doações, campanhas e poucos atendimentos particulares. O processo de parceria com o SUS está em trâmite na Câmara Municipal de São Paulo, porém tem sido sistematicamente negada pelas autoridades de saúde ${ }^{3}$.

A demanda por atendimento alternativo, como o parto domiciliar, assistido por enfermeiras obstétricas, obstetrizes e médicos obstetras com o apoio de médicos pediatras e doulas, tem crescido na cidade de São Paulo. Este movimento foi reforçado pela busca de informação pelas usuárias em listas de discussão na internet e sites, como Amigas do Parto e Parto do Princípio, entre outros (Diniz, 2005). No entanto, as maternidades privadas de São Paulo seguem com taxas de cesariana superiores a $80 \%$ (Brasil, 2008).

Neste estudo, os motivos para a transferência materna foram, em sua maioria, referentes a distocias durante o trabalho de parto (quase $60 \%$ dos casos), sendo a parada de progressão na fase ativa o motivo mais frequente (cerca de um terço dos casos). Achados similares foram encontrados em estudo de coorte prospectiva na Dinamarca, no qual $44,4 \%$ das transferências no período intraparto foram feitas em razão da falha de progressão no trabalho de parto (Overgaard et al., 2011) e também no estudo com 11.814 mulheres em 84 centros de parto americanos (43,2\%) (Rooks, Weatherby, Ernst, 1992). Na coorte dinamarquesa (Overgaard et al., 2011), líquido amniótico meconial e anormalidades nos batimentos cardíacos fetais foram as razões para 11,3\% e 8,1\% das transferências intraparto, inferiores às frequências encontradas na CPS, $18 \%$ e cerca de $10 \%$, respectivamente. Estes achados são semelhantes aos resultados do ensaio clínico irlandês já mencionado, no qual as razões de transferência das

\footnotetext{
${ }^{3}$ Informação fornecida pela Dra. Anke Riedel, coordenadora geral do Centro de Parto Normal Casa Ângela - Associação Comunitária Monte Azul, em $1^{\circ}$ de novembro de 2011.
} 
mulheres do grupo das obstetrizes para o grupo de cuidados médicos foram: falha de progressão do trabalho de parto (41\%) e líquido amniótico meconial (18\%) (Begley et al., 2011).

Estudo comparativo sobre motivos de transferência intraparto em centros de parto na Alemanha relatou que, aproximadamente, um terço das mulheres foi transferida em razão de rotura prematura das membranas e em quase um quarto dos casos por distocia funcional (inércia uterina). Alterações na frequência dos batimentos cardíacos fetais e na parada de progressão foram as razões para transferência em 14,1\% e 12,6\%, respectivamente (David et al., 2006). No estudo americano, a segunda razão mais comum para transferências foi líquido amniótico meconial (10,5\%) e a seguir alterações nos batimentos cardíacos fetais (7,8\%) (Rooks, Weatherby, Ernst, 1992).

Houve alguns casos em que a transferência foi ocasionada por situações em que a parturiente apresentava condições que contraindicavam atendimento na CPS, como apresentação pélvica (não identificada na internação) e HPV. Duas parturientes com prolapso de cordão umbilical tiveram transferência de emergência e apresentaram resultados satisfatórios do concepto, o que vai ao encontro de resultados similares no centro de parto peri-hospitalar em Belo Horizonte (Campos, Lana, 2007). Há dúvidas sobre os resultados maternos e neonatais de complicações raras em parturientes de baixo risco em centros de parto, visto que comparar os resultados do manejo dessas complicações em hospitais e centros de parto, em mulheres de baixo risco, requerer pesquisas com tamanho de amostra com milhares de mulheres (Albers, Katz, 1991).

No presente estudo, não foi possível avaliar se houve modificação nos motivos de transferência ao longo dos anos. Estudo holandês de base populacional que analisou as transferências de mulheres atendidas por obstetrizes para serviços obstétricos em um período de 17 anos verificou que houve aumento contínuo do número de transferências. Ter cesariana em parto anterior, a presença de líquido amniótico meconial e a solicitação de analgesia foram os fatores mais influentes nestas taxas (Amelink-Verburg et al., 2009). Estudo australiano analisou motivos para 
transferência e recusa de admissão de mulheres em centros de parto (a maioria peri-hospitalares), em estudos feitos em 1997 e 2007. Os autores verificaram que houve aumento nas proporções de mulheres transferidas por líquido amniótico meconial e parada de progressão do trabalho de parto, assim como diminuição na admissão de mulheres com cesariana anterior (Laws et al., 2010).

Em relação aos desfechos das parturientes transferidas para o hospital, cerca de metade delas teve parto cesariana. Esta taxa é superior às encontradas nos estudos já citados, conduzidos em centros de parto alemães e que reportou taxa de cesariana de $28,7 \%$ para nulíparas e $30,6 \%$ para multíparas transferidas (David et al., 2006) e em centros de parto americano de $35,5 \%$ para mulheres transferidas (Rooks, Weatherby, Ernst, 1992). A taxa de transferência intraparto na CPS é, pelo menos, a metade dos serviços citados. É provavel que estas mulheres transferidas da CPS para o hospital fizessem parte de um grupo que incluísse maior número de mulheres com necessidade de resolução do parto por cesariana.

No Brasil, estudo de CPN em Belo Horizonte constatou taxas de cesariana entre mulheres transferidas de 20,8\% (Campos e Lana, 2007), similares às encontradas no estudo em centros de parto dinamarqueses $(19,6 \%)$ (Overgaard et al., 2011). Os menores índices de cesariana foram observados no estudo em centros de parto norueguês com $17,2 \%$ entre as mulheres transferidas para o hospital (Schmidt, Abelsen, Oian, 2002). As taxas de fórceps encontradas no estudo da Noruega foram inferiores àquelas verificadas na $\mathrm{CPS}(3,5 \%$ versus $5,0 \%$, respectivamente. Por outro lado, as proporções de partos por vácuo extrator $(10,0 \%)$ foram cerca de cinco vezes maiores que as da CPS.

Estudo em centros de parto alemães apontou frequência de $13,3 \%$ e $12,3 \%$ de partos instrumentais (fórceps e vácuo extrator) entre as mulheres nulíparas e multíparas transferidas para 0 hospital, respectivamente (David et al., 2006). No estudo da Dinamarca, a taxa de partos por vácuo extrator foi 3,0\% entre as mulheres do grupo dos centros de parto. Nesse país, as obstetrizes podem realizar a aplicação de vácuo extrator em caso de bradicardia fetal no período expulsivo, de acordo com a 
recomendação da International Confederation of Midwives (ICM) (Overgaard et al., 2011).

Entre as indicações das cesarianas das mulheres transferidas, a maioria foi decorrente de problemas maternos, como desproporção cefalopélvica e distocias ósseas e funcionais. Isto vai ao encontro dos motivos registrados para transferência, que foram em sua maioria, referentes à falha no progresso do trabalho de parto. Estes achados são similares aqueles do estudo de dois CPN alemães autônomos, no qual a maioria das mulheres $(61,3 \%)$ foi submetida a cesariana em razão de problemas na progressão do trabalho de parto. A segunda indicação mais frequente desta cirurgia foi por motivos fetais (alteração no traçado da cardiotocografia $37,1 \%$ e líquido amniótico meconial 6,5\%) (David et al., 1999).

Cerca de um quarto dos bebês de mães transferidas da CPS para o hospital teve Apgar menor que 7 no $1^{\circ}$ minuto de vida; mas, estudo realizado em centros de parto dinamarqueses encontrou proporção de $15,3 \%$ e 13,5\% em nulíparas e multíparas transferidas para o hospital, respectivamente (David et al., 2006). No $5^{\circ}$ minuto de vida, 4,5\% dos $\mathrm{RN}$ de mães transferidas tiveram Apgar menor que 7 na CPS, taxas inferiores àquelas reportadas por Overgaard et al. (2011), que foram 7,25\% (9/124) e similares às encontradas por David et al. (2006), que foram de 5,0 e 1,4\% para nulíparas e multíparas, respectivamente.

Os RN de parto cesariana apresentaram pior condição ao nascer do que os de parto fórceps ou vácuo extrator. Além disso, dois RN de cesariana morreram. No óbito ocorrido em 2004, a transferência mais precoce poderia ter melhorado o resultado perinatal. Mas, em ambos os casos, com a realização mais precoce de cesariana poderia ter sido benéfica para ambos os RN. Não está claro se os óbitos neonatais poderiam ter sido evitados, caso as mulheres tivessem sido admitidas no hospital sem receberem atendimento na CPS, visto que as transferências foram feitas horas antes da realização de cesariana, em ambos os casos.

Estudo realizado na mesma CPS encontrou uma taxa de mortalidade neonatal de 1,0/1.000 nascidos vivos, em estudo caso-controle sobre transferências neonatais, no período de 1998 a 2005 (Koiffman et al., 
2010), superior à taxa encontrada nesse estudo ( $0,73 / 1.000$ nascidos vivos). Essas taxas das CPS são inferiores às encontradas em estudo americano já mencionado, que constatou taxa de mortalidade perinatal de 1,3/1.000 (nascidos vivos e óbitos fetais) (Rooks et al., 1989). Em estudo norueguês, a taxa de mortalidade neonatal de 1,6/1.000 nascidos vivos (Schmidt et al., 2002). Já estudo realizado em Belo Horizonte encontrou taxa de mortalidade neonatal de 2/1.000 nascidos vivos (Campos, Lana, 2007).

Chama a atenção o fato de a paridade estar relacionada à mortalidade perinatal. Estudo suíço em centro de parto intra-hospitalar encontrou risco aumentado para mortalidade perinatal entre primíparas (OR 2,2, IC 95\% 1,3-3,9), porém, não entre multíparas (0,7, IC 95\% 0,3-1,9) (Gottvall et al., 2004). No entanto, estudo de base populacional australiano com 1.001.249 mulheres verificou mortalidade perinatal significantemente menor entre mulheres que deram à luz em centros de parto $(1,51 / 1.000$ nascidos vivos) que entre as que deram à luz no hospital $(10,03 / 1.000$ nascidos vivos). Entre primíparas de centros de parto e hospitais, a mortalidade perinatal foi 1,4 versus $1,9 / 1.000$ nascidos vivos, respectivamente. Os autores concluem que a mortalidade perinatal nos centros de parto foi inferior a encontrada em hospitais, a despeito da paridade (Tracy et al., 2007).

Merece comentar que a mortalidade perinatal em partos assistidos no domicílio apresenta resultados divergentes entre os estudos. Estudo de coorte de base populacional realizado na Holanda, com 529.688 mulheres de baixo risco, comparou os resultados de partos domiciliares e hospitalares. Mulheres que estavam sob o cuidado de obstetrizes no início do parto apresentaram risco relativo de 0,97 (IC 95\% 0,69-1,37) para morte fetal intraparto, comparadas àquelas assistidas em hospitais. De maneira similar, morte fetal intraparto e neonatal nas primeiras 24 horas de vida (RR 1,02; IC 95\% 0,77-1,36), morte fetal e neonatal até 7 dias de vida (RR 1,00; IC 95\% 0,78-1,27) e admissão em unidade de cuidado intensivo neonatal (RR 1,00; IC 95\% 0,86-1,16) não diferiram entre domicílios e hospitais (De Jonge et al., 2009). 
Metanálise sobre resultados maternos e neonatais de partos domiciliares nos EUA apontou risco para morte neonatal quase três vezes maior entre mulheres assistidas nesses locais (OR 2,9; IC 95\% 1,32-6,25) (Wax et al., 2010). No entanto, este estudo foi amplamente criticado por não relatar os estudos excluídos nem incluir o estudo de De Jonge et al. (2009) no cálculo de mortalidade neonatal, visto que o estudo excluído relatou somente morte neonatal precoce (até 24 horas de vida). Esta metanálise utilizou pesquisa baseada em declarações de nascidos vivos como a maior fonte de informação para o cálculo das taxas de mortalidade neonatal. Entretanto, este estudo não dispunha de critérios de qualidade para ser incluído no trabalho (Johnson, Daviss, 2011; Kirby, Frost, 2011; Sandall, Bewley, Newburn, 2011). Havia também outros problemas metodológicos, como ausência de avaliação de fatores de confusão (Gyte, Dodwell, MacFarlane, 2011). A despeito das inconsistências dessa metanálise, sua ampla divulgação acirrou o debate sobre a segurança de partos domiciliares, sem entretanto fornecer informações confiáveis (Sandall, Bewley, Newburn, 2011).

Embora o presente estudo não tenha sido desenhado para verificar a influência da paridade nos resultados maternos e neonatais das mulheres transferidas da CPN para o hospital, observou-se que as nulíparas tiveram piores resultados, como maior taxa de cesarianas e maiores proporções de RN com escore de Apgar menor que 7 nos $1^{\circ}$ e $5^{\circ}$ minutos de vida. Estes achados vão ao encontro dos resultados de transferências dos centros de parto alemães, que relataram escore de Apgar inferior a 7 no $5^{\circ}$ minuto de vida de 5,0\% e 1,4\% para multíparas e nulíparas, respectivamente (David et al., 2006).

Estudo dinamarquês relatou como primeira causa de transferências no período pós-parto a necessidade de reparo de laceração de $3^{\circ}$ grau $(16 / 27 ; 59,3 \%)$ seguida por retenção placentária $(9 / 27 ; 33,3 \%)$ e desconforto respiratório do recém-nascido $(2 / 27 ; 7,4 \%)$ (Overgaard et al., 2011). No presente estudo, a principal causa de transferência após o parto foi retenção placentária, responsável por quase $50 \%$ dos casos. Os fatores de risco para as transferências neonatais na CPS foram analisadas em outro 
estudo. Tabagismo, complicações durante o parto e escore Apgar $\leq$ no $1^{\circ}$ minuto de vida estiveram associados à transferência neonatal (Koiffman et al., 2010). Não foram registrados casos de rotura de $3^{\circ}$ grau na CPS, porém como não foi utilizada a classificação internacional de lacerações (NICE, 2007), esta intercorrência pode não ter sido detectada. Já David et al. (2006) reportaram prevalência de laceração perineal entre as mulheres transferidas de $14,4 \%$ e $2,4 \%$ para nulíparas e multíparas, respectivamente. Estes autores referem sangramento acima de $1.000 \mathrm{ml}$ após o parto em 1,9\% das nulíparas, porém não indicaram se essa foi a causa de transferência. Overgaard et al. (2011) também relataram sangramento pós-parto e retenção placentária aumentada como motivo de transferência para 33,3\% (9/27) das mulheres para o hospital, até 2 horas após o parto, enquanto na CPS $15,4 \%$ (2/13) das mulheres foram transferidas em razão de sangramento pós-parto aumentado. 
Este estudo permitiu as seguintes conclusões:

1. Fatores de risco para transferência materna

As seguintes variáveis foram identificadas como fatores de risco independentes para transferência intraparto:

- Nuliparidade (OR 5,6; IC 95\% 2,9; 10,9)

- Idade materna igual ou superior a 35 anos (OR 5,0; IC 95\% 2,0; 12,7)

- Não ter companheiro (OR 2,7; IC 95\% 1,4; 5,1)

- Ser admitida na CPS com cervicodilatação de até $3 \mathrm{~cm}$ (OR 2,0; IC $95 \% 1,1 ; 3,4)$

- Realizar de 5 a 12 consultas na CPS (OR 3,3; IC 95\% 1,6; 6,7)

- Ter recém-nascido com peso entre 4.000 e 4.600 g (OR 3,5; IC 95\% $1,1 ; 11,2)$

A seguinte variável foi fator de proteção para a transferência intraparto:

- Adequação entre altura uterina e idade e idade gestacional baixa (OR 0,3 ; IC 95\% 0,2; 0,6)

2. Modelo de risco

- Um modelo de risco foi apresentado, no qual a probabilidade de transferência foi estimada, de acordo com a resposta sim ou não para as variáveis identificadas, como fatores de risco independentes para transferência materna intraparto: paridade, adequação entre altura uterina e idade gestacional, dilatação cervical na admissão na CPS, ter companheiro, número de consultas na CPS, idade em anos e peso do RN em gramas.

3. Desfechos das transferências maternas

- A taxa de transferência materna no período intraparto foi $4,1 \%$.

- A taxa de transferência materna no período pós-parto foi $0,5 \%$.

- Não houve óbitos entre as mulheres admitidas na CPS que deram à luz no serviço ou que foram transferidas para o hospital.

- $\quad$ Não houve óbitos entre os RN de mulheres que deram à luz na CPS. 
- $\quad$ Entre as mulheres transferidas para o hospital, houve óbito de dois RN (taxa de mortalidade perinatal de 0,73/1.000 nascidos vivos).

- As causas de transferência intraparto foram:

- Maternas (57,6\% como falha no progresso do trabalho de parto);

- Fetais $(28 \%$ dos casos de líquido amniótico meconial e traçado cardiotocográfico alterado);

- Outras (hipertensão arterial, febre materna, líquido amniótico sanguinolento, NIC III, HPV, prolapso de cordão umbilical e estresse materno;

- Via de parto das mulheres transferidas: 49,5\% tiveram parto normal; $44,1 \%$ cesariana; $4,5 \%$ fórceps e $1,8 \%$ vácuo extrator;

- Indicação de parto cirúrgico entre as mulheres transferidas: problemas maternos $(65,3 \%)$, problemas referentes ao feto $(32,7 \%)$; parto vaginal instrumental para abreviação do período expulsivo (6,3\%);

- Escore de Apgar dos RN de mães transferidas: 25,2\% e 4,5\% tiveram Apgar menor que 7 nos $1^{\circ}$ e $5^{\circ}$ minutos de vida, respectivamente; e

- Unidade de internação dos bebês nascidos no hospital: 10,8\% na UTI neonatal, 9,0\% na unidade de cuidados intermediários, 0,9\% no setor de observação da unidade neonatal e 79,3\% foram encaminhados ao alojamento conjunto.

- $\quad$ As causas de transferência no período pós-parto foram:

- Retenção placentária (38,5\%);

- Outros problemas $(30,8 \%$ hipertensão, febre materna, ausência de colostro);

- Sangramento vaginal aumentado (30,8\%); e

- Febre materna $(15,4 \%)$;

- Entre as mulheres transferidas no período pós-parto, 46,1\% necessitaram de curetagem e 38,4\% de transfusão sanguínea. 
Este estudo teve como finalidade identificar fatores de risco associados à transferência materna em um centro de parto extra-hospitalar. O delineamento do estudo, do tipo caso-controle, mostrou-se adequado para a análise desses fatores de risco. $O$ fato de os casos tratarem-se de uma população claramente definida e os controles serem provenientes da mesma população dos casos, amenizou a possibilidade do viés de seleção, que consiste no maior problema associado a esse tipo de estudo.

Embora os resultados da presente pesquisa tenham apontado taxas de transferência materna e de mortalidade neonatal bastante baixas, aprimorar a colaboração entre as equipes do centro de parto e do hospital poderia melhorar tais resultados.

O modelo de risco proposto nesta pesquisa poderá ser utilizado pelos profissionais de centros de parto para estimar as probabilidades de transferência das mulheres. Embora o estudo tenha sido conduzido em um único serviço, proporcionou identificar fatores de risco que podem ser generalizados aos que dispõem do mesmo modelo de cuidado. Isto pode contribuir para aprimorar os critérios de admissão das mulheres atendidas em CPN, ao identificar os casos que podem resultar em complicações e diminuir as taxas de transferências maternas e neonatais. Estas informações poderão ser úteis às mulheres que procuram subsídios para a decisão sobre o local do parto.

A coleta retrospectiva dos dados foi dificultada pela precariedade dos registros e pode ter possibilitado a ocorrência de viés de aferição, sobretudo em variáveis como a mensuração da altura uterina e da dilatação do colo cervical, feitas por diferentes profissionais. No entanto, considerando-se a necessidade de incluir o maior número possível de casos de transferência, um estudo prospectivo seria inviável dentro do prazo disponível para realização da pesquisa, em razão da baixa frequência desses eventos de transferência. O baixo custo também é uma vantagem desse tipo de estudo.

Outras dificuldades metodológicas permeiam a investigação dos resultados de diferentes locais para dar à luz. O desenho de estudo que melhor determinaria os efeitos do local de parto nos resultados maternos e 
perinatais é o ensaio clínico randomizado (Albers, Katz, 1991). Entretanto, mulheres que escolhem dar à luz em ambientes alternativos (casas de parto ou no domicílio), geralmente, estão bastante convictas de sua decisão e poderiam não concordar com a possibilidade de serem designadas para dar à luz em ambiente hospitalar (Tracy et al., 2007). Questões relativas à ausência de aleatorização, amostras pequenas, autosseleção das mulheres e coletas de dados retrospectiva (Albers, Katz, 1991), além dos diferentes modelos de assistência ao parto, dificultam a consolidação de um corpo de conhecimentos sobre o melhor local para dar à luz. A questão da autosseleção das mulheres tem sido apontada em diversos trabalhos, pois o "efeito da mãe saudável" pode favorecer os resultados dos locais alternativos de parto (Hogberg, 2008). Mulheres que escolhem dar à luz nestes locais usualmente têm nível educacional mais elevado, com melhor condição socioeconômica, estrutura familiar mais estável e acesso precoce e regular aos serviços de saúde (Walderstrom, Nilsson, 1993).

O tamanho da amostra também exerce influência sobre os resultados desses estudos. Em geral, as pesquisas sobre CPN dispõem de poder estatístico adequado para demonstrar diferenças evidentes entre os resultados de mulheres atendidas nesses serviços e hospitais, como taxas de cesariana. No entanto, a detecção de eventos raros em partos de mulheres saudáveis, como prolapso de cordão e descolamento prematuro de placenta, usualmente necessita de grandes amostras (Albers, Katz, 1991).

Até o momento, foram feitas pesquisas descritivas sobre centros de parto que evidenciaram bons resultados maternos e perinatais, porém ensaios clínicos controlados e aleatorizados e estudos de coorte são necessários para avaliar os resultados do atendimento de parturientes de baixo risco em centros de parto e em hospitais em nosso meio. 
Albers LL. Safety of VBACs in birth centers: Choices and risks. Birth. 2005;32(3):229-31.

Albers LL, Katz VL. Birth setting for low-risk pregnancies. An analysis of the current literature. J Nurse-Midwifery. 1991;36(4):215-20.

Amelink-Verburg MP, Rijnders MEB, Buitendijk SE. A trend analysis in referrals during pregnancy and labour in Dutch midwifery care 1988-2004. BJOG. 2009;116(7):923-32.

American College of Nurse-Midwives (ACNM). American College of NurseMidwives Position Statement on Home Birth. Washington 2005. [Citado em 201107 Nov.]. Disponível em:

http://www.midwife.org/siteFiles/position/homeBirth.pdf

American College of Obstetricians and Gynecologists (ACOG). Committee Opinion No. 476: Planned Home Birth. Obstet Gynecol. 2011;117(2):425-8.

American Public Health Association (APHA). Increasing access to out-ofhospital maternity care services through state-regulated and nationallycertified direct-entry midwives. APHA Public Policy Statements. 2001. . [Citado em 2011 Nov. 07]. Disponível

em: http://mana.org/APHAformatted.pdf

Austin DA. The process of obstetric triage: management by certified nursemidwives. J Perinat Neonatal Nurs. 1996;10(1):1-9.

Barbosa GP, Giffin K, Angulo-Tuesta A, Gama AS, Chor D, D'Orsi E, dos Reis AC.. Cesarean sections: who wants them and under what circumstances? Cad saude publica. 2003;19(6), p. 1611-1620, 2003.

Barnes PM, Dossey MS. Triage issues in an out-of-hospital birth center. J Nurse-Midwifery. 1999; 44(5):458-470.

Barros FC, Victora CG, Barros AJD, Santos IS, Albernaz E, Matijasevich A et al. The challenge of reducing neonatal mortality in middle-income countries: findings from three Brazilian birth cohorts in 1982, 1993, and 2004. Lancet. 2005;365(9462):847-854.

Begley C, Devane D, Clarke M, McCann C, Hughes P, Reilly M et al. Comparison of midwife-led and consultant-led care of healthy women at low risk of childbirth complications in the Republic of Ireland: a randomised trial. BMC Pregnancy Childbirth. 2011;11(1):85.

Bernstein IM, Bernstein IM, Horbar JD, Badger GJ, Ohlsson A, Golan A. Morbidity and mortality among very-low-birth-weight neonates with intrauterine growth restriction. Am J Obstet Gynecol. 2000;182(1):198-206. 
Bloch JR, Webb DA, Mathews L, Dennis EF, Bennett IM, Culhane JF. et al. Beyond Marital Status: The Quality of the Mother-Father Relationship and Its Influence on Reproductive Health Behaviors and Outcomes Among Unmarried Low Income Pregnant Women. Matern Child Health J. 2010;14(5): 726-34.

Borquez HA, Wiegers TA. A comparison of labour and birth experiences of women delivering in a birthing centre and at home in the Netherlands. Midwifery. 2006;22(4):339-47.

Brasil. Ministério da Saúde. Portaria GM 2275/95 2.815 de 29 de maio de 1998. Inclui analgesia nos grupos de procedimentos Cirurgia Obstétrica II, IV e VI da Tabela do SIH-SUS. Brasília; 1998. [Citado em 10 Nov. 2011]. Disponível em: http://brasilsus.com.br/legislacoes/gm/8735-2815.html

Brasil. Ministério da Saúde. Portaria Portaria GM/MS n 985, de 05 de agosto de 1999. Cria o Centro de Parto Normal-CPN, no âmbito do Sistema Único de Saúde. Brasília; 1999. . [Citado em 10 Nov. 2011]. Disponível em: http://www.saude.mg.gov.br/atos_normativos/legislacaosanitaria/estabelecimentos-de-saude/parto-normal/Portaria_985.pdf

Brasil. Ministério da Saúde. Agência Nacional de Saúde Suplementar (ANS). O modelo de atenção obstétrica no setor de saúde suplementar no Brasil: Cenários e perspectivas. Brasília (DF): Ministério da Saúde 2008. [Citado em 10 Nov. 2011]. Disponível em:

http://bvsms.saude.gov.br/bvs/publicacoes/livro_parto_web.pdf

Campos SEV, Lana FCF. Results of childbirth care at a birthing center in Belo Horizonte, Minas Gerais, Brazil. Cad Saúde Publica. 2007;23(6): 1349-59.

Conselho Regional de Medicina de São Paulo (CREMESP). Resolução CREMESP - 111/2004. Dispõe quanto aos procedimentos que o médico deve cumprir em relação aos estabelecimentos denominados Casas de Parto. 2004. São Paulo; 2004. [Citado em 10 Nov. 2011]. Disponível em: http://www.cremesp.org.br/?siteAcao=Jornal\&id=429

David M, Berg G, Werth I, Pachaly J, Mansfeld A, Kentenich H. Intrapartum transfer from a birth centre to a hospital - reasons, procedures, and consequences. Acta Obstet Gynecol Scand. 2006;85(4):422-28.

David M, Gross MM, Wiemer A, Pachaly J, Vetter K. Prior cesarean section an acceptable risk for vaginal delivery at free-standing midwife-led birth centers? Results of the analysis of vaginal birth after cesarean section (VBAC) in German birth centers. Eur J Obstet Gynecol Reprod Biol. 2009;142(2):106-10. 
David M, von Schwarzenfeld HK, Dimer JA, Kentenich H. Perinatal outcome in hospital and birth center obstetric care. Int J Gynecol Obstet. 1999;65(2):149-56.

Davis-Floyd R. The technocratic, humanistic, and holistic paradigms of childbirth. Int J Gynecol Obstet. 2001;75(S1):S5-S23.

De Jonge A, van der Goes BY, Ravelli ACJ, Amelink-Verburg MP, Mol BW, Nijhuis J. Perinatal mortality and morbidity in a nationwide cohort of 529688 low-risk planned home and hospital births. BJOG 2009;116(9):177-84.

Diniz CSG. Humanização da assistência ao parto no Brasil: os muitos sentidos de um movimento. Ciênc Saúde Coletiva. 2005;10:627-37.

Dodd JM, Crowther CA, Huertas E, Guise JM, Horey D. Planned elective repeat caesarean section versus planned vaginal birth for women with a previous caesarean birth. Cochrane Database Syst Rev. 2004;(4):CD004224. DOI:10.1002/14651858.CD004224.pub2

Eakins PS. Free-standing birth centers in California. Program and medical outcome. J Reprod Med. 1989;34(12):960-70.

Esposito NW. Marginalized women's comparisons of their hospital and freestanding birth center experiences: a contrast of inner-city birthing systems. Health Care Women Int. 1999;20(2):111-26.

Federação Brasileira das Associações de Ginecologia e Obstetrícia (FEBRASGO). Comunicado da FEBRASGO em relação às casas de parto. 2009. [Citado em 10 Nov. 2011]. Disponível em: http://www.cremesp.com/?siteAcao=Noticias\&id=1714

Fernandes BM. Casa de parto: experiências e vivências orientam um novo pensar em saúde. Juiz de Fora: Ed.UFJF; 2006.

Fullerton JT, Jackson D, Snell BJ, Besser M, Dickinson C, Garite T. Transfer rates from freestanding birth centers. A comparison with the National Birth Center Study. J Nurse-Midwifery 1997;42(1):9-16.

Gail M, Williams R, Byar DP, Brown C. How many controls? J Chronic Dis. 1976;29(11):723-31.

Gottvall K, Grunewald C, Waldenstrom U. Safety of birth centre care: perinatal mortality over a 10-year period. BJOG. 2004;111(1):71-8.

Gyte GM, Dodwell MJ, Macfarlane AJ. Home birth metaanalysis: does it meet AJOG's reporting requirements? [letter] Am J Obstet Gynecol. 2011;204(4):e15. 
Hall J. Free-standing maternity units in England. In: Kirkham M., editor. Birth centres: a social model for maternity care. London: Books for Midwives, 2003. p. 3-10.

Heffner LJ. Advanced Maternal Age - How Old Is Too Old? N Engl J Med. 2004;351(19):1927-9.

Hennekens $\mathrm{CH}$, Buring JF. Case-control studies. London: Lippincott Williams \& Wilkins;1987. Epidemiology in medicine; p. 132-52.

Hodnett ED, Downe S, Walsh D, Weston J. Alternative versus conventional institutional settings for birth. Cochrane Database Syst Rev. 2010;(10):

CD000012. DOI: 10.1002/14651858.CD000012.pub3.

Hogberg U. Homebirths in a modern setting - a cautionary tale. Acta Obstet Gynecol Scand. 2008;87(8):797-9.

Hosmer DW, Lemeshow S. Assessing the fit of the model. New York: John Wiley \& Sons, 2000. Applied logistic regression; p. 135-75.

Huang Y, Pepe MS. Assessing risk prediction models in case-control studies using semiparametric and nonparametric methods. Stat Med.

2010;29(13):1391-410.

International Federation of Gynecology and Obstetrics (FIGO).

Recommendations accepted by the General Assembly at the XIII World Congress of Gynecology and Obstetrics. Int J Gynecol Obstet. 1992;38:S79S80. [Citado em 2011 Nov. 07]. Disponível em:

http://www.ijgo.org/article/0020-7292(92)90037-J/pdf.

Johnson KC, Daviss BA. International data demonstrate home birth safety. [letter]. Am J Obstet Gynecol. 2011;204(4):e16-7.

Jolly M, Sebire N, Harris J, Robinson S, Regan L. The risks associated with pregnancy in women aged 35 years or older. Hum Reprod. 2000;15(11): 2433-7.

Kirby RS, Frost J. Maternal and newborn outcomes in planned home birth vs planned hospital births: a metaanalysis. [letter]. Am J Obstet Gynecol. 2011;204(4):e16.

Koiffman MD. Fatores de risco para remoção neonatal na Casa do Parto de Sapopemba - São Paulo [dissertação]. Escola de Enfermagem, Universidade de São Paulo; 2006.

Koiffman MD, Schneck CA, Riesco MLG, Bonadio IC. Risk factors for neonatal transfers from the Sapopemba free-standing birth centre to a hospital in Sao Paulo, Brazil. Midwifery. 2010;26(6):e37-e43. 
Lauzon L, Hodnett ED. Labour assessment programs to delay admission to labour wards. Cochrane Database Syst Rev. 2004(10):CD000936. DOI: 10.1002/14651858.CD000936.pub4.

Laws PJ, Lim C, Tracy SK, Dahlen H, Sullivan EA. Changes to booking, transfer criteria and procedures in birth centres in Australia from 1997 to 2007: A national survey. J Clin Nurs. 2010;20(19-20):2812-21.

Laws PJ, Lim C, Tracy SK, Sullivan E. Characteristics and practices of birth centres in Australia. Aust N Z J Obstet Gynaecol. 2009;49(3):290-5.

Lieberman E, Ernst EK, Rooks JP, Stapleton S, Flamm B. Results of the National Study of vaginal birth after cesarean in Birth Centers. Obstet Gynecol. 2004;104(5):933-42.

Lindgren HE, Hildingsson IM, Christensson K, Radestad IJ. Transfers in planned home births related to midwife availability and continuity: A nationwide population-based study. Birth. 2008; 35(1):9-15.

Lurie S, Zalmanovitch A, Golan A, Sadan O. The effect of marital status on pregnancy outcome in Israel: A retrospective case-control study. J Obstet Gynaecol Res. 2010;36(6):1161-4.

Lydon-Rochelle M. Holt VL, Easterling TR, Martin DP. Risk of Uterine Rupture during Labor among Women with a Prior Cesarean Delivery. N Engl J Med. 2001; 345(1):3-8.

Manderbacka K, Merilainen J, Hemminki E, Rahkonen O, Teperi J. Maritalstatus as a predictor of perinatal outcome in Finland. J Marriage Fam. 1992;54(3):508-15.

Martinelli S, Bittar RE, Zugaib M. Proposta de Nova Curva de Altura Uterina para Gestações entre a 20a e a 42a semana. Rev Bras Ginecol Obstet. 2001;23:235-41.

McIntire DD, Bloom SL, Casey BM, Leveno KJ. Birth weight in relation to morbidity and mortality among newborn infants. N Engl J Med.

1999;340(16):1234-8.

Moore B. Appropriate technology for birth. Lancet. 1985;2(8452):436-7.

Moraes MS, Goldenberg P. Cesáreas: um perfil epidêmico. Cad Saúde Pública. 2001;17(3):509-19.

Morano S, Cerutti F, Mistrangelo E, Pastorino D, Benussi M, Costantini S. et al. Outcomes of the first midwife-led birth centre in Italy: 5 Years' experience. Arch Gynecol Obstet. 2007;276(4):333-7. 
Nguyen U, Rothman KJ, Demissie S, Jackson DJ, Lang JM, Ecker JL. Transfers Among Women Intending A Birth Center Delivery in the San Diego Birth Center Study. J Midwifery Womens Health. 2009;54(2):104-10.

National Institute for Health and Clinical Excellence (NICE). Intrapartum care. Care of healthy women and their babies during childbirth. London: RCOG Royal College of Obstetricians and Gynaecologists; 2007. [Citado em 2011 Nov. 07]. Disponível em: http://www.nice.org.uk/nicemedia/pdf/IPCNICEguidance.pdf.

Overgaard C, Møller AM, Fenger-Grøn M, Knudsen LB, Sandall J. Freestanding midwifery unit versus obstetric unit: a matched cohort study of outcomes in low-risk women. BMJ Open. 2011;1(2):1-12.

Phaloprakarn C, Tangjitgamol S. Risk assessment for preeclampsia in women with gestational diabetes mellitus. J Perinat Med. 2009;37(6):617-21.

Rooks JP, Weatherby NL, Ernst EK. The national birth center study. Part IIIIntrapartum and immediate postpartum and neonatal complications and transfers, postpartum and neonatal care, outcomes, and client satisfaction. J Nurse-midwifery. 1992;7(6):361-97.

Rooks JP, Weatherby NL, Enst EKM, Stapleton S, Rosen D, Rosenfield A. Outcomes of care in birth centers. The National Birth Center Study. N Engl J Med. 1989;321(26):1804-11.

Royal College of Obstetricians and Gynaecologists (RCOG)/ Royal College of Midwives (RCM). Home Births. Joint statement n.2. 2007. [Citado em 2011 Nov. 07]. Disponível em: http://www.rcog.org.uk/files/rcog-corp/uploadedfiles/JointStatmentHomeBirths2007.pdf.

Sandall J, Bewley S, Newburn M. "Home birth triples the neonatal death rate": public communication of bad science? [letter] Am J Obstet Gynecol. 2011;204(4):e17-8.

Schmidt N, Abelsen B, Oian P. Deliveries in maternity homes in Norway: results from a 2-year prospective study. Acta Obstet Gynecol Scand. 2002; 81(8):731-7.

Schneck CA, Riesco MLG. Intervenções no parto de mulheres atendidas em um centro de parto normal intra-hospitalar. REME Rev Min Enferm. 2006;10:240-6.

Stapleton SR. The birth centre as a place for normal birth. In: Donna S, editor. Promoting normal birth: research, reflections \& guidelines. London: Fresh Heart Publisher, 2011. p. 68-78. 
Stewart M, McCandlish R, Henderson J, Brockhurst P. Review of evidence about clinical, psychological and economic outcomes for women with straightforward pregnancies who plan to give birth in a medwife-led birth center, and outcomes for their babies. Report of a structured review of birth center outcomes. Oxford: National Perinatal Epidemiology Unit, 2005. [citado 2011 Nov. 07]. Disponível em:

https://www.npeu.ox.ac.uk/files/downloads/reports/Birth-Centre-Review.pdf.

Tracy SK, Dahlen H, Caplice S, Laws P, Wang YA, Tracy MB et al. Birth centers in Australia: A national population-based study of perinatal mortality associated with giving birth in a birth center. Birth. 2007;34(3):194-201.

Tuffnell D. Place of delivery and adverse outcomes [editorial]. BMJ. 2010; 341(5560):947-8.

von Dadelszen P, Menzies JM, Payne B, Magee LA, Piers Study Group. Predicting Adverse Outcomes in Women with Severe Pre-eclampsia. Semin Perinatol. 2009; 33(3):152-7.

Waldenstrom U, Nilsson CA, Winbladh B. The Stockholm Birth Centre Trial: Maternal and infant outcome. Br J Obstet Gynaecol. 1997;104(4):410-8.

Walderstrom U, Nilsson CA. Characteristics of women choosing birth center care. Acta Obstet Gynecol Scand. 1993;72(3):181-8.

Walsh D, Downe SM. Outcomes of free-standing, midwife-led birth centers: A structured review. Birth. 2004;31(3):222-9.

Wax JR, Lucas FL, Lamont M, Pinette MG, Cartin A, Blackstone J. Maternal and newborn outcomes in planned home birth vs planned hospital births: a metaanalysis. Am J Obstet Gynecol. 2010;203(3):e1-8.

Whittemore AS. Evaluating health risk models. Stat Med. 2010;29(23):243852.

World Health Organization (WHO ). Care in Normal Birth: A practical guide. Maternal and Newborn Health/Safe Motherhood Unit of the World Health Organization. Geneva; 1996. [citado 2011 Nov. 07]. Disponível em: http://whqlibdoc.who.int/hq/1996/WHO_FRH_MSM_96.24.pdf.

World Health Organization (WHO ). Making pregnancy safer : the critical role of the skilled attendant - a joint statement by WHO, ICM and FIGO. Geneva: WHO Library Cataloguing-in-Publication Data; 2004. [citado 2011 Nov. 07]. Disponível em: http://whqlibdoc.who.int/publications/2004/9241591692.pdf. 
World Health Organization (WHO ). Neonatal and perinatal mortality : country, regional and global estimates. Geneva: WHO Library Cataloguingin-Publication Data 2006. [citado 2011 Nov. 07]. Disponível em: http://whqlibdoc.who.int/publications/2006/9241563206_eng.pdf.

World Health Organization (WHO ). Managing Complications in Pregnancy and Childbirth: A guide for midwives and doctors. Geneva: Department of Reproductive Health and Research; 2007. [citado 2011 Nov. 07]. Disponível em:

http://www.who.int/making_pregnancy_safer/publications/archived_publicatio ns/mcpc.pdf. 


\section{Anexo 1}

\section{Protocolos assistenciais da Casa do Parto de Sapopemba}

\section{1 - INTRODUÇÃO}

Em linhas gerais, estes protocolos procuram demonstrar os princípios que norteiam a assistência prestada à mulher e ao recém-nascido na Casa do Parto de Sapopemba. Os protocolos fornecem limites para atuação na Casa do Parto e não contemplam todas as situações possíveis da assistência. Cada caso é avaliado individualmente.

\section{PROTOCOLO DE PLANO DE PARTO E CONSULTAS SUBSEQÜENTES}

As gestantes virão à Casa do Parto encaminhadas pelos profissionais das Unidades Básicas para abertura do Plano de Parto. Esta ficha é o primeiro passo do acompanhamento da mulher na Casa e contém um registro da história obstétrica, clínica, ginecológica e de amamentação. Tem como objetivo realizar uma triagem, selecionando as mulheres de baixo risco.

Para a abertura deste Plano, deverão ser observados os seguintes critérios:

- Gestação única;

- Apresentação cefálica;

- Idade gestacional igual ou superior a 37 semanas e inferior a 41 semanas;

- Ausência de intercorrências clínicas pregressas e atuais, tais como: cardiopatias, cirurgias uterinas, hipertensão, diabetes, anemias e outras hemoglobinopatias, doenças sexualmente transmissíveis e HIV, entre outras;

- Ausência de intercorrências obstétricas pregressas e atuais, como doença hipertensiva da gestação, apresentações anômalas, anormalidades do líquido amniótico, macrossomia, retardo de crescimento uterino, alterações da vitalidade fetal e da 
implantação placentária e resultado positivo para pesquisa de estreptococo do grupo $B$, entre outras; e

- Realização de exames laboratoriais, tais como: sorologias para sífilis, HIV, citomegalovírus, hepatites, toxoplasmose, rubéola, urina I e antibiograma, protoparasitológico, glicemia e exames ultrassonográficos e de primeiro e terceiro trimestres, com resultado normais.

Nesta consulta, a gestante conhecerá a filosofia de atendimento e poderá refletir sobre a opção de dar à luz na Casa do Parto.

O registro da consulta ficará arquivado em um prontuário com o nome da gestante, ao qual serão acrescentados os registros das consultas subsequentes. $\mathrm{O}$ acompanhamento pré-natal na unidade básica não será interrompido.

As consultas terão a seguinte frequência: semanal, até as 40 semanas e a cada 2 ou 3 dias, entre 40 e 41 semanas, intercaladas com as consultas de pré-natal. Caso seja detectada alguma intercorrência nos atendimentos, será feito contato com a unidade básica ou o encaminhamento para atendimento hospitalar.

Este agendamento não é realizado de maneira rígida, procura-se observar a necessidade de cada gestante.

\section{PROTOCOLO DE ADMISSÃO DURANTE O TRABALHO DE PARTO}

Os critérios para admissão de mulheres em trabalho de parto na Casa do Parto, em linhas gerais, são os seguintes:

- Franco trabalho de parto (dinâmica uterina efetiva na alteração da cervicodilatação, rotura das membranas ovulares inferior a 6 horas);

- Confirmação da idade gestacional (feto a termo), igual ou superior a 37 semanas e igual ou inferior a 41 semanas; 
- Parâmetros normais de batimentos fetais e movimentação fetal adequada;

- Pressão arterial normal;

- Ausência de febre materna;

- Apresentação cefálica fletida;

- Gestação única;

- Ausência de anormalidades na atividade uterina (taquissistolia, hipertonia);

- Ausências de intercorrências obstétricas pregressas e atuais (hemorragias graves, doença hipertensiva, descolamento prematuro da placenta, anormalidades da implantação placentária e do líquido amniótico, cirurgias uterinas pregressas, apresentação anômala, gestação múltipla, macrossomia, retardo de crescimento intrauterino, alterações da vitalidade fetal, entre outras);

- Ausências de intercorrências clínicas (hipertensão, infecção urinária, cardiopatias, sorologias positivas para quaisquer doenças infecto-contagiosas, nefropatias, etc.);

- Estar com todos os exames laboratoriais normais; e

- Realização de USG.

\section{PROTOCOLO DE ASSISTÊNCIA DURANTE O TRABALHO DE PARTO}

A assistência durante o trabalho de parto deverá observar os seguintes princípios;

- Todos os eventos e procedimentos relacionados ao cuidado serão explicados à mulher e seu acompanhante;

- O parto e nascimento serão valorizados como experiência positiva, com uma postura otimista e encorajadora por parte de toda a equipe;

- O conhecimento da mulher e seus questionamentos serão respeitados;

- A parturiente pode assumir as posições nas quais se sentir mais confortável, estimulando-se a livre deambulação e a postura ativa; 
- Serão utilizados os métodos não medicamentosos de alívio à dor, como banhos de aspersão e imersão, massagens e uso de bola suíça ou outros de preferência da parturiente;

- A parturiente poderá se alimentar normalmente e ingerir líquidos, em razão do alto gasto energético no trabalho de parto;

- O acompanhamento da vitalidade fetal será feito por meio da cardiotocografia (quando houver indicação), ausculta intermitente dos batimentos cardíacos fetais e vigilância do aspecto do líquido amniótico;

- A progressão do trabalho de parto será registrada no partograma;

- A posição no parto será de livre escolha da parturiente;

- Será oferecida ao acompanhante a possibilidade de seccionar o cordão umbilical;

- O uso de ocitocina, amniotomia e episiotomia será reservado aos casos em que houver necessidade;

- Será feito o manejo ativo do terceiro período do trabalho de parto, conforme orientação da OMS, que consiste em administração intramuscular de 10 unidades de ocitocina, clampeamento precoce do cordão umbilical e tração contínua e controlada do cordão até a dequitação (protocolo do ALSO - Advanced Life Support in Obstetrics);

- Será promovido o contato precoce pele a pele da mãe com o recém-nascido e a amamentação na primeira hora de vida, salvo em casos em que haja necessidade de intervenções de reanimação (protocolo da Sociedade Brasileira de Pediatria), após o que serão administradas as medicações de rotina, como Credê e vitamina $\mathrm{K}$;

- Com relação à dequitação, a mulher e seu acompanhante poderão ver a placenta e receberem informações sobre sua função;

- O banho do recém-nascido será realizado com o acompanhante, junto à mãe e sob a orientação do profissional de enfermagem; 
- A puérpera será orientada a respeito das cólicas uterinas (sobretudo durante a amamentação) e seu papel na diminuição do sangramento e involução uterina; e

- A puérpera será encaminhada ao puérpério para repouso após estar alimentada, ter amamentado e estar em estabilidade hemodinâmica. Ficará sempre com o recém-nascido.

\section{PROTOCOLO DE REMOÇÃO MATERNA INTRAPARTO}

Para se efetuar a remoção no período anteparto, a enfermeira obstétrica deverá fazer contato telefônico com o obstetra de plantão do hospital de referência para comunicar os detalhes do caso. Os seguintes passos devem ser observados: comunicar a auxiliar de enfermagem, comunicar ao motorista; orientar a mulher e seus familiares sobre a transferência; preencher a carta de encaminhamento com todos os detalhes do caso e anexar aos exames, documentos e cartão de acompanhamento pré-natal da parturiente; anotar na carta de encaminhamento e no prontuário o nome do médico contactado para a transferência, as medidas instituídas e os detalhes do motivo da remoção.

A transferência será acompanhada pela enfermeira obstetra.

Serão removidas as mulheres que apresentarem:

- Presença de líquido amniótico meconial ou fisometria;

- Anormalidades na atividade uterina (taquissistolia ou hipertonia);

- Parada de progressão no trabalho de parto, detectado no partograma;

- Anomalias de variedade de posição que comprometam a evolução do parto;

- Alterações cardiotocográficas sugestivas de alterações no bemestar fetal; e

- Crise hipertensiva materna ou outra alteração clínica que necessite de maiores cuidados. 


\section{PROTOCOLO DE REMOÇÃO MATERNA PERÍODO PÓS-PARTO}

Para se efetuar a remoção no período anteparto, a enfermeira obstétrica deverá fazer contato telefônico com o obstetra de plantão do hospital de referência para comunicar os detalhes do caso. Devem ser observados os seguintes passos: comunicar à auxiliar de enfermagem, comunicar ao motorista; orientar a mulher e seus familiares sobre a transferência; preencher a carta de encaminhamento com todos os detalhes do caso e anexar aos exames, documentos e cartão de acompanhamento pré-natal da puérpera; anotar na carta de encaminhamento e no prontuário o nome do médico contactado para a transferência, as medidas instituídas e os detalhes do motivo da remoção. A transferência será acompanhada pela enfermeira obstetra. Serão removidas as mulheres que apresentarem:

- Crise hipertensiva ou outra alteração clínica que necessite de maiores cuidados;

- Sangramento pós-parto aumentado;

- Presença de hematomas de parede vaginal ou episiotomia;

- Retenção placentária; e

- Suspeita de restos placentários.

\section{PROTOCOLO DE ALTA}

A mulher que der à luz na Casa do Parto de Sapopemba receberá alta em média 24 horas após o parto. Este tempo de observação poderá ser prolongado, caso haja intercorrências como dificuldades na amamentação ou sucção ou outras situações que demandem necessidade de maior observação da mãe ou do bebê.

O recém-nascido e a puérpera receberão alta estando em boas condições. O recém-nascido deverá apresentar eliminações urinárias e intestinais presentes e amamentação estabelecida com sucção efetiva.

A mãe receberá todas as orientações referentes a cuidados com o bebê, repouso, retorno à unidade básica de saúde, cuidados com a mama e amamentação e noções de planejamento familiar, entre outras orientações. 
Anexo 2

\section{PARECER DO COMITÊ DE ÉTICA EM PESQUISA}

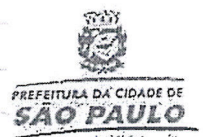
SECRETRRIA DA SAUUDO
Prefeitura do Município de São Paulo Secretaria Municipal da Saúde

Coordenação de Desenvolvimento de Programas e Politicas de Sátide - CODEPPS

Comitê de Ética em Pesquisa

São Paulo, 05 de Setembro de 2006

\section{Parecer $n^{\circ}: 223 / 2006 /$ CEP/SMS}

I. - Identificação:

1-Título do projeto: "REMOÇÓES MATERNAS E NEONATAIS NA CASA DE PARTO DE SAPOPEMBA - SÄO PAULO".

2-Pesquisador responsável: Isabel Cristina Bonadio

3-Projeto n': CAAE 098/06

II-Objetivos:

1. Geral:

Descrever â-analisar as remoçōes de:parturientes, puérperas e recém-nascidos ocorridos na Casa de Parto Sapopemba

2- Específicos:

Descrever as características sociodemográficas, condiçōes clínico-obstétricas è a assistência ao parto de mulheres admitidas na Casa de Parto de Sapopemba e removidas para outros serviços ou'cujos recém nascidos tenham sido removidos.

Identificar os motivos de remoções maternas e neonatais

Descrever os desfechos das remoçōes maternas e neonatais

III - Sumário do Projeto:

Desenho geral do projeto: Estudo quantitativo, epidemiológico transversal. O estudo será feito na Casa de Parto, integrada ao Programa de Saúde da Familia da SMS, em parceria com a Fundação Zerbini do InCor da FMUSP. A população atendida é encaminhada pelas UBS da região, ou atraidas pelo modelo dè atenção oferecido. No atendimento inicial $\left(37^{\mathrm{a}}\right.$ semana) verifica-se a possibilidade de atendimento, isto é, se é um parto de baixo risco. A partir dai a gestante é acompanhada o que não exclui o pré-natal na UBS. A assistência obstétrica é prestada somente por enfermeiras. Quando ocorrem complicações as gestantes são removidas para serviços de emergência.

Serão avalıados os prontuários das mulheres e recém removidos. Os registros das remoções serão analısados um a um. As variáveis a serem analisadas foram apresentadas no projeto. Será feita análise descritiva das informaçōes utilizando pacotes estatisticos.

Procedimentos

Coleta de dados dos prontuários das mulheres e recém nascidos

Adequação da metodologia: Adequada

IV - Comentários do relator, frente à Resolução CNS 196/96 e complementares em particular sobre:

1-Estrutura do protocolo: Justificativa de uso de placebo: não se aplica

2-Justificativa de suspensão terapêutica (Wash - out.): não se aplica.

3-Análise de riscós e benefícios: não há riscos e os beneficios são significativos para a Casa de Parto e instituiçõés em que as mulheres e recém nascidos ficarem internados. 
Prefeitura do Municipio de São Paulo

Secretaria Municipal da Saúde

PREFETUZA OA CIDADE DE

SARO PAULO

secretartadoA saudoe

Coordenäção de Desenvolvimento de Programas Comitê de Éticia em Pesquisa

benefícios para sujeito elou para comunidade e para a Secretaria Municipal de Saúde: o trabalho está direcionado para um diagnóstico do perfil dos

pacientes

5-TCLE: adequado

6-Informaçăo adequada quanto ao financiamento: foi apresentada declaração do pesquisador assumindo os custos da pesquisa

V-Parecer do CEP: APROVADO Como procedimento adotado por este Comitê de Etica em Pesquisa, solicitánón dúvida, esclarecimento ou de Consentımento Livre e Esclarecido do seguinte: qualquer questa contato com: Comitê de Ética reclamacão sobre os aspectos éticos dessa pesquisa, Paulo - Rua General Jardim, $36-2^{\circ}$ andar em Pesquisás da Secretaria Municipal da Sacide de Sa pov.br

Telefone: 3218-4043 - e-mail: smscep@prefeitura.sp.gov.br. possa se realizar dentro da unidade, $\dot{e}$ Lembramos que este parecer nấo basta para que seu estudo possa séria.

necessária também a permissão administrativa da autoridade sanitaria. o sujeito da:pesquisa tem a liberdade de recusar-se a participar ou de retirar seu cuidado (Res. CNS qualquer fase da pesquisa, sem penalização alguma ou sem prejuizo ao seu cuida e Esclarecido, na $196 / 96$ - item IV. 1f) e deve receber

integra, por ele assinado(item IV.2.d).

uisa conforme delineada no protocolo aprovado.

er Eventuais modificaçöes ou emendas ao protocolo devem ser apresentaficativas. O relatório final deve sucinta, identificando a parte do protocolo a ser modificada e

ser apresentado ao CEP, logo que o estudo estiver concluido.

Atenciosamente,

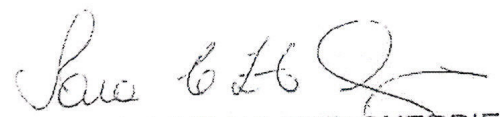

Dra. IARA COELHO ZITO GUEBRIERO

Coordenadora do Comitê de Ética em Pesquisa da

Secretaria Municipal da Saúde - CEP/SMS

llustríssimo(a) Senhor(a) Doutor(a)

ISABEL CRISTINA BONADIO

NESTA

Rua Generat Jardim, 36 - $2^{\circ}$ andar - Vila Buarque - São Paulo, SP - CEP 01223-010 Telefone: (11) 3218-4043

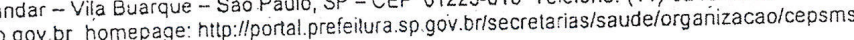




\section{Anexo 3}

\section{PARECER DO COMITÊ DE ÉTICA EM PESQUISA}

Protocolo CEP no 03/2010.

n Nome do projeto: "Remoções Maternas da Casa do Parto de Sapopemba, São Paulo"

- Pesquisador Responsável: Flora Maria Barbosa da Silva.

- Nome do (da) Orientador (a): Prof.a Dr. - Sonia Maria Junqueira Vasconcellos de Oliveira.

* Instituição Responsável: Escola de Enfermagem da Universidade de São Paulo.

- Área do Conhecimento e Código: 4.04.

" Justificativa do projeto: esclarecida.

- Objetivos do projeto: esclarecido.

a Desenho do estudo: esclarecido.

- Obtenção da amostra: esclarecida.

" Critérios de inclusão e exclusão dos participantes: esclarecidos.

- Instrumentos de coleta de dados: apresentados.

* Cronograma do estudo: apresentado.

* Execução e financiamento: apresentados.

"Termo de Consentimento Livre e Esclarecido: apresentado.

Conclusão:

Com base nos aspectos acima relatados, este projeto foi Aprovado por este Comitê de Ética em Pesquisa.

Relatório(s) do Pesquisador Responsável previsto(s) para: Abril e Outubro de 2011.

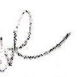

Maria Rosa Logiodice Cardoso Presidente do CEP

Data: $07 / 04 / 2010$.

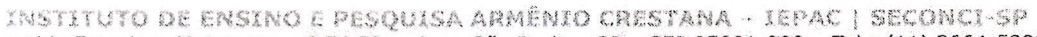
Avenida Francisco Matarazzo, no 7470 andar - São Paulo - SP - CEP 05001-000 - Tel.: (11) 3664-5900 MIC 642 v. 0 Fax: (11) 4081-8678 - e-mail: iepacáseconci-sp.ora.br 


\section{Apêndice 1}

FORMULÁRIO DE COLETA DE DADOS - Não Removida - CONTROLE 0

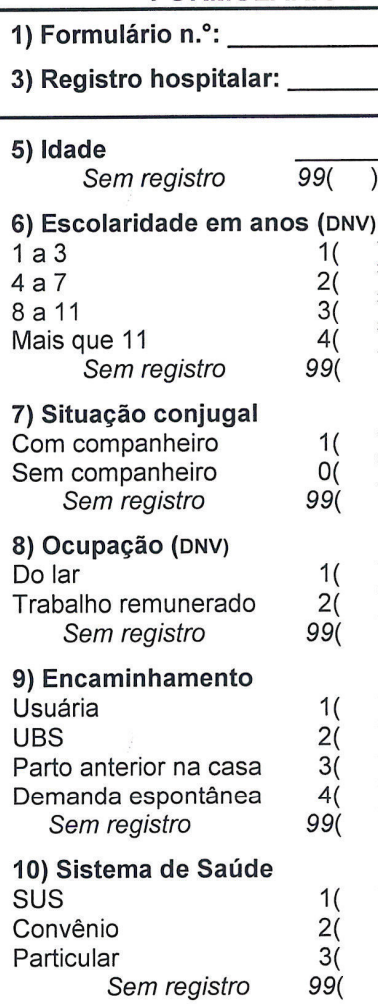

11) Residência/Distrito

Nome do bairro

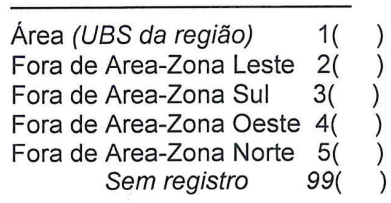

12) Consultas Pré-natal (DNV)

1 a 3

4 a 6

7 ou mais

1()

Sem registro

2( )

13) Consultas na casa Sem registro $\overline{99(\text { ) }}$

14) Tabagismo

Sim

Não

Parou na gestação

Sem registro

$1(\quad)$
0()
$2(\quad)$
99()

Não se aplica: 88

2) Não transferida

$0(1)$

4) Iniciais:

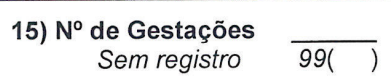

16) Paridade

Primigesta

Sem registro

$88($ )
99()

17) N. ${ }^{\circ}$ de Partos anteriores

(pode ser mais de 1 alternativa)

17) A Normal

17) B Fórceps

17) C Cesariana

17) D Vácuo-extrator

Não se aplica Sem registro

18) Aborto anterior

Sim

Não

Não se aplica

Sem registro

19) Natimorto anterior

Sim

Não

Não se aplica

Sem registro

20) Neomorto anterior

Sim

Não

Não se aplica

Sem registro

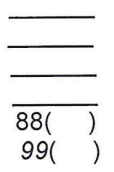

99()

$\begin{array}{ll}1( & ) \\ 0( & )\end{array}$

88()

99()

$1(\quad)$

88

88()

$99(\quad)$

Intercorrência clínica ou obstétrica na gestação

Sim

Não

Sem registro

22) Se sim, descrever

\begin{tabular}{cc}
\hline Não se aplica & 88( \\
Sem registro & 99(
\end{tabular}

\section{ADMISSÃO NA CPS}

23) Data admissão

24) Hora admissão

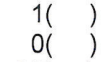

25) Idade gestacional (DUM) semanas completas Sem registro $99($ )

26) Idade gestacional (US)

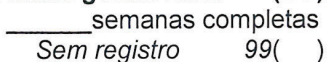

27) $\mathrm{AU}$ SU registro $\mathrm{cm}$
28) Dilatação $\quad \mathrm{cm}$ Sem registro

29) Estado das membranas Integras.

Rotas

Sem registro

1( )

Sim

Não

Não se aplica

Sem registro

99()

31) Condição líquido amniótico

Claro

Meconial

Sanguinolento Sem registro

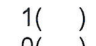

88(

99()

32) Tempo de bolsa rota

(em horas e minutos)

$$
\begin{array}{cc}
\text { Não se aplica } & : \\
\text { Sem registro } & 99(\quad)
\end{array}
$$

33) Monitorização fetal

$\begin{array}{ll}\text { Sim } & 1( \\ \text { Não } & 0(\end{array}$

Sem registro 99()

34) Dinâmica uterina

Pronte

Ausente

1( )

Sem registro 99()

ASSISTÊNCIA NA CPS

35) Monitorização fetal

Sim

Não

$\begin{array}{rr} & 1 \\ & 0() \\ \text { Sem registro } & 99()\end{array}$

36) Uso de ocitocina

Sim

Não

$\begin{array}{rr} & 1() \\ \text { Sem registro } & \left.0()^{\prime}\right)\end{array}$

37) Se uso de ocitocina sim, com dilatação de

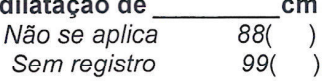

38) Ocitocina (período de uso)

Dilatação

Expulsivo

Dequitação

1. ' hora pós-parto

Não se aplica

Sem registro 
39) Rotura das membranas Artificial

Espontânea no TP

BR na internação

Sem registro

40) Dilatação na rotura

das membranas Sem registro 99(

41) Controles BCF Sem registro $99(\overline{\quad)}$

42) Controles DU Sem registro $\overline{99(\quad)}$

43) Toques vaginais Sem registro $\overline{99()}$

44) Conforto (práticas)

Banho imersão

Banho aspersão

Bola suíça

Massagem

Deambulação

Outro

Sem registro

\section{PARTO NA CPS}

45) Posição no parto

Semi sentada

Sims (Lateral)

Cócoras

Em pé

Quatro apoios

Outro

Sem registro

46) Data do nascimento

47) Hora do nascimento

48) Condições do períneo

Íntegro

I Grau

II Grau

III Grau

IV Grau

EMLD

Episiotomia mediana Sem registro

$\begin{array}{ll}1( & ) \\ 2( & ) \\ 3( & ) \\ 4( & ) \\ 5( & ) \\ 6( & ) \\ 99(\quad)\end{array}$

99( )

49) Dequitação

Espontânea

Manual

$$
\text { Sem registro }
$$

$\begin{array}{cc}1( & ) \\ 2( & ) \\ 3( & ) \\ 4( & ) \\ 5( & ) \\ 6( & ) \\ 99( & )\end{array}$

99( )

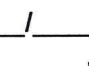

50) Presença acompanhante

$\begin{array}{lr}\text { Sim } & 1() \\ \text { Não } & 0()^{\prime} \\ \text { Sem registro } & 99()\end{array}$

51)Intercorrência no TP e parto Sim

Não

Sem registro

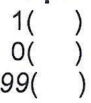

52) Se sim, descrever

\begin{tabular}{cc}
\hline & \\
\hline Não se aplica & $88(\quad)$ \\
Sem registro & $99(\quad)$ \\
ASSISTÊNCIA RN &
\end{tabular}

53) Peso RN Sem registro

$99($ )

54) Apgar $1^{\circ} \mathrm{min}$ Sem registro

55) Apgar $5^{\circ} \mathrm{min}$ Sem registro

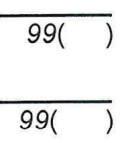

56) Aspiração de VAS

Sim

Não

Sem registro

1( )

O( )

57) Aspiração gástrica

Sim

Não

Sem registro

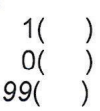

58) Lavagem gástrica

Sim

Não

Sem registro

59) Uso $\mathrm{O}_{2}$ nasal

Sim

Não

Sem registro

60) Uso VPP

Sim

Não

Sem registro

$\begin{array}{rr}1( & ) \\ 0( & ) \\ 99( & )\end{array}$

61) Outras manobras de

reanimação

Sim

Não

Sem registro

62) Se sim, qual

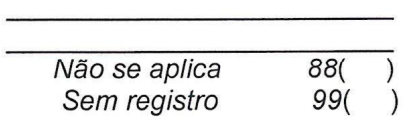

63) Intercorrência neonatal

Sim

Não

Sem registro
64) Se sim, descrever

\begin{tabular}{cc}
\hline Não se aplica & $88(\quad)$ \\
Sem registro & $99(\quad)$ \\
PÓS-PARTO NA CPS &
\end{tabular}

65) Intercorrência no pós-parto

Sim

Não

Sem registro

1( )

66) Se sim, descrever

$\begin{array}{cc}\text { Não se aplica } & 88(\quad) \\ \text { Sem registro } & 99(\quad)\end{array}$

67) Data da alta ___

68) Hora da alta

69) ANOTAÇÕES SOBRE

INTERCORRÊNCIAS NO CASO

DE PARTURIENTE NÃO

REMOVIDA 
Apêndice 2

FORMULÁRIO DE COLETA DE DADOS - Remoção Intra-Parto - CASO 1

$\begin{array}{lll}\text { 1) Formulário } .^{\circ}: & \text { 2) Removida Intra-Parto } \\ \text { 3) Registro hospitalar: } & \text { 4) Iniciais: }\end{array}$

5) Idade Sem registro

$\overline{99()}$

6) Escolaridade em anos (DNV)

1 a 3

4 a 7

8 a 11

Mais que 11 Sem registro

7) Situação conjugal

Com companheiro

Sem companheiro

Sem registro

8) Ocupação (DNV)

Do lar

Trabalho remunerado Sem registro

9) Encaminhamento

Usuária

UBS

Parto anterior na casa

Demanda espontânea Sem registro

$\begin{array}{cc}\text { (DNV) } \\ 1( & \text { ) } \\ 2( & ) \\ 3( & ) \\ 4( & ) \\ 99( & )\end{array}$

$\begin{array}{rr}1( & \text { ) } \\ 0( & \text { ) } \\ 99( & )\end{array}$

99(

$\begin{array}{rr}1( & ) \\ 2( & ) \\ 99( & )\end{array}$

99(

10) Sistema de Saúde

SUS

Convênio

Particular

$$
\text { Sem registro }
$$

$\begin{array}{rr}1( & ) \\ 2( & ) \\ 3( & ) \\ 4( & ) \\ 99( & )\end{array}$

11) Residência/Distrito Nome do bairro

Área (UBS da região) 1( )

Fora de Area-Zona Leste 2( ) Fora de Area-Zona Sul 3( )

Fora de Area-Zona Oeste 4( )

Fora de Area-Zona Norte 5( Sem registro $99(\quad)$

12) Consultas Pré-natal (DNV)

1 a 3

4 a 6

7 ou mais

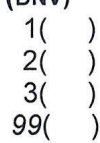

13) Consultas na casa

$$
\text { Sem registro } \overline{99(})
$$

14) Tabagismo

Sim

Não

Parou na gestação

Sem registro
15) $N^{\circ}$ de Gestações Sem registro

16) Paridade

Primigesta

$$
\text { Sem registro }
$$

17) $\mathrm{N} .^{\circ}$ de Partos anteriores

(pode ser mais de 1 alternativa)

17) A Normal

17) B Fórceps

17) C Cesariana

17) D Vácuo-extrator

Não se aplica

Sem registro

18) Aborto anterior

Sim

Não

Não se aplica

Sem registro

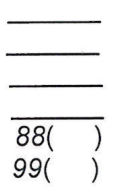

99()

$\begin{array}{ll}1( & \\ 0( & ()\end{array}$

88()

88( )

19) Natimorto anterior

Sim

Não

Não se aplica
Sem registro

20) Neomorto anterior

Sim

Não

$$
\begin{aligned}
& \text { Não se aplica } \\
& \text { Sem registro }
\end{aligned}
$$

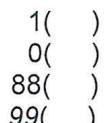

21) Intercorrência clínica ou obstétrica na gestação

Sim

Não

$$
\text { Sem registro }
$$

$1(\quad)$

22) Se sim, descrever

$\begin{array}{ccc}\text { Não se aplica } & 88( & \text { ) } \\ \text { Sem registro } & 99( & \text { ) } \\ \text { ADMISSÃO NA CPS } & \end{array}$

23) Data admissão

24) Hora admissão

1

25) Idade gestacional DUM) semanas completas Sem registro 99( )

26) Idade gestacional (US) semanas completas Sem registro 99( )

27) $\mathrm{AU}$ Sem registro
28) Dilatação Sem registro $99($ )

29) Estado das membranas Íntegras.

Rotas

Sem registro

$1(\quad)$

30) Amnioscopia

Sim

Não

Não se aplica Sem registro

31) Condição líquido amniótico

Claro

Meconial

Sanguinolento

Não visualizado

$$
\text { Sem registro }
$$

1( )

0(

99()

32) Tempo de bolsa rota

(em horas e minutos)

$$
\begin{aligned}
& \text { Há } \\
& \text { Não se aplica } \\
& \text { Sem registro }
\end{aligned}
$$

1()
2()

$3(\quad)$

4()

33) Monitorização fetal

Sim

Não

Sem registro

34) Dinâmica uterina

Presente

Ausente

Sem registro

$1(\quad)$

\section{ASSISTÊNCIA NA CPS}

35) Monitorização fetal

Sim

Sem registro

$1(\quad)$

$0($ )

36) Uso de ocitocina

Sim

Não

Sem registro

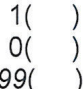

37) Se uso de ocitocina sim, com dilatação de

$\begin{array}{cc}\text { Não se aplica } & 88\left(\begin{array}{l}\mathrm{cm} \\ \text { Sem registro }\end{array}\right)\end{array}$

38) Ocitocina (período de uso)

Dilatação

Expulsivo

Não se aplica

1()

Sem registro 
39) Rotura das membranas

Artificial

Espontânea no TP

BR na internação Não se aplica Sem registro

40) Dilatação na rotura

das membranas)

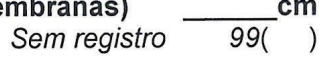

41) Controles BCF Sem registro $99 \overline{(\quad)}$

42) Controles DU Sem registro

43) Toques vaginais Sem registro

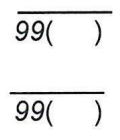

44) Conforto (práticas)

Banho imersão

Banho aspersão

Bola suiça

Massagem

Deambulação

Outro

Sem registro

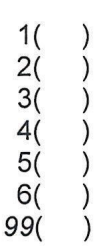

REMOCÃ̃O INTRA-PARTO

70) Motivo da remoção

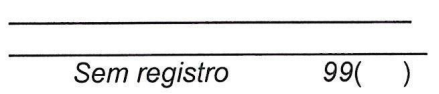

71) Data remoção Sem registro

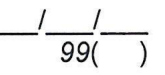

72) Hora remoção Sem registro

73) Dilatação Sem registro

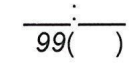

74) BCF

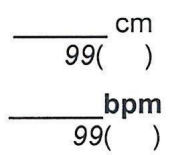

75) Estado das membranas Íntegras.

Rotas

Não se aplica Sem registro

$1(\quad)$
$2(\quad)$
$88(\quad)$
$99(\quad)$

76)Condição líquido amniótico Claro

Meconial

Sanguinolento

Não visualizado

Sem registro

$1(\quad)$
2()

77) Alteração no estado materno

Sim
Sem registro

3( )

4( ) $1(\quad)$
$0(\quad)$
$99(\quad)$
78) Se sim, descrever

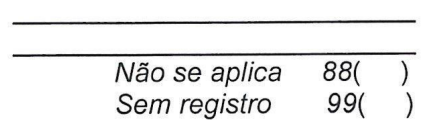

79) Alteração no estado fetal

Sim

Não

Sem registro

80) Se sim, descrever

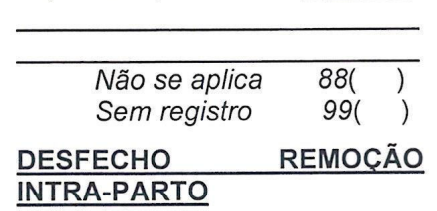

\section{INTRA-PARTO}

81) Data internação Sem registro

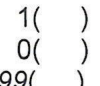

82) Hora internação Sem registro

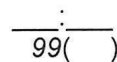

83) Uso partograma

Sim Sem registro

84) Monitorização fetal

Sim

Não

Sem registro

85) Uso de ocitocina

Sim

Não

Sem registro

$\begin{array}{cc}1( & ) \\ 2( & ) \\ 99( & )\end{array}$

86) Se uso de ocitocina sim com dilatação de $\begin{array}{lll}\text { Não se aplica } & 88(\quad) \\ \text { Sem registro } & 99(\quad)\end{array}$

87) Ocitocina (período de uso)

Dilatação

Expulsivo

Dequitação

$1{ }^{\text {a }}$ hora pós-parto Não se aplica Sem registro

$1(\quad)$
$2(\quad)$
$3(\quad)$
$4(\quad)$
$88(\quad)$
$99(\quad)$

88) Rotura das membranas

Artificial

Espontânea

BR na internação

Sem registro

$1(\quad)$
$2(\quad)$
$99(\quad)$

88A) Dilatação na rotura

das membranas) Sem registro $\left.{ }_{99(}^{\mathrm{cm}}\right)$
89) Líquido amniótico

Claro

Meconial

Sanguinolento

Não visualizado

Sem registro

90) Controles BCF

Sem registro

91) Controles DU

Sem registro

1()

92) Toques vaginais Sem registro

93) Conforto (práticas)

Banho imersão

Banho aspersão

Bola suiça

Massagem

Deambulação

Outro

Sem registro

4) Data do parto

Sem registro $\frac{1}{9} \overline{9()}$

95) Hora do parto

Sem registro

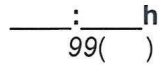

96) Tipo de parto

Normal

Fórceps

Cesariana

Vácuo extrator Sem registro

97) Se parto cirúrgico ou instrumental, qual indicação

\begin{tabular}{ll}
\hline Não se aplica & $88(\quad)$ \\
Sem registro & $99(\quad)$
\end{tabular}

98) Posição no parto

Semi sentada

Sims (Lateral)

Cócoras

Em pé

Quatro apoios

Outro

Não se aplica

Sem registro 


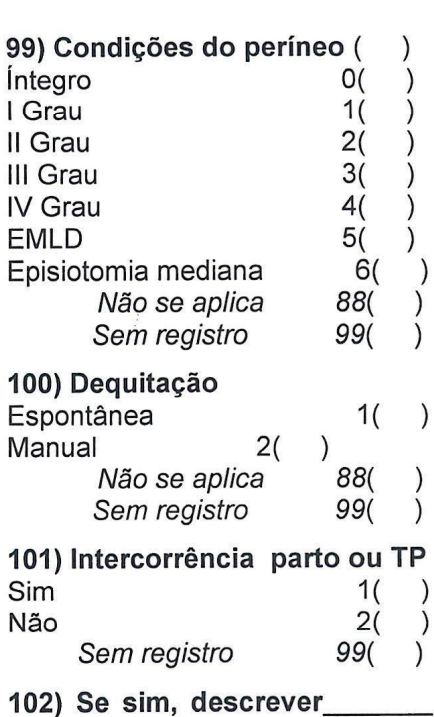

$\begin{array}{ll}\text { Não se aplica } & 88( \\ \text { Sem registro } & 99(\text { ) }\end{array}$

103) Unidade de internação materna

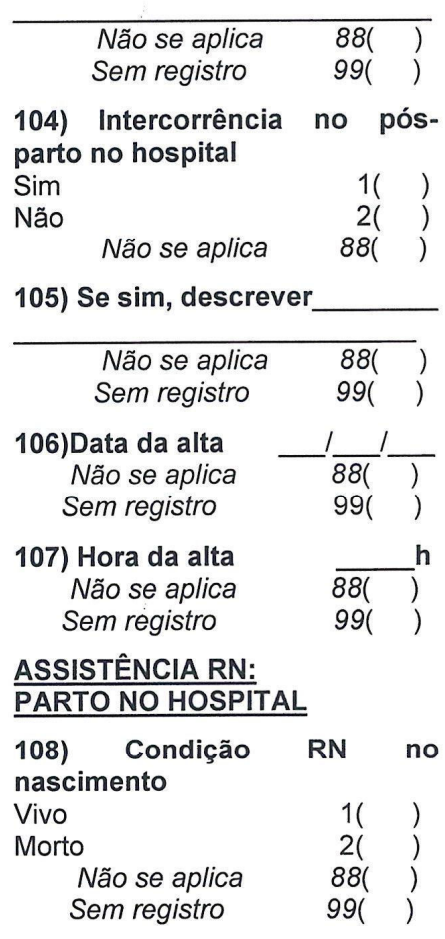

109) Se óbito RN, qual causa$$
\text { - }
$$$$
\text { ( }
$$$$
\begin{array}{ll}
\text { Não se aplica } & 88(\quad) \\
\text { Sem registro } & 99(\quad)
\end{array}
$$

110) Se óbito RN, com quantas horas de vida

Não se aplica Sem registro

111) Peso RN Sem registro $88\left({ }^{h}\right)$ 99()

112) Apgar $1^{\circ} \mathrm{min}$ Sem registro

113) Apgar $5^{\circ} \mathrm{min}$ Sem registro

114) Aspiração de VAS

Sim

Não

Sem registro

$99($ )

115) Aspiração gástrica

Sim

Não

Sem registro

$\overline{99(\quad)}$

116) Lavagem gástrica

Sim

Não

Sem registro

117) Uso $\mathrm{O}_{2}$ nasal

Sim

Não

Sem registro

118) Uso VPP

Sim

Não

Sem registro

99()

2()

99( )

$1(\quad)$
$0(\quad)$
$99(\quad)$

$\begin{array}{ll}1( & \\ 0 & ()\end{array}$

99( )

19) Outras manobras

reanimação

Sim

Não

Sem registro

$$
\begin{aligned}
& 1(\quad) \\
& 2()
\end{aligned}
$$

2( )

$1(\quad)$

1
0()
99()

120) Se sim, qual

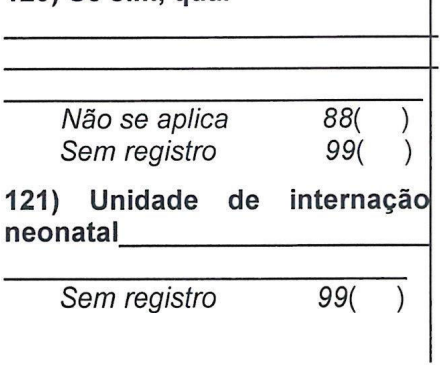

122) Data alta $R N$

$$
\text { Sem registro }
$$

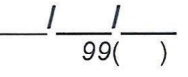

123) Hora alta RN

Sem registro

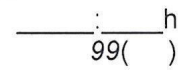

124) ANOTAÇÕES SOBRE

INTERCORRÊNCIAS NO CASO DE REMOÇÃO INTRA-PARTO 


\section{Apêndice 3}

FORMULÁRIO DE COLETA DE DADOS - Removida Pós-parto - CASO 2

1) Formulário $n .{ }^{\circ}$ :

3) Registro hospitalar: 2) Transferida após o parto

$2(1)$

5) Idade Sem registro $\overline{99()}$

6) Escolaridade em anos (DNV)

1 a 3

4 a 7

8 a 11

Mais que 11 Sem registro

7) Situação conjugal

Com companheiro

Sem companheiro Sem registro

8) Ocupação (DNV)

Do lar

Trabalho remunerado Sem registro

9) Encaminhamento Usuária

UBS

Parto anterior na casa Demanda espontânea Sem registro

10) Sistema de Saúde SUS

Convênio

Particular Sem registro

11) Residência/Distrito Nome do bairro

Área (UBS da região) 1( Fora de Area-Zona Leste 2( ) Fora de Area-Zona Sul 3( )

Fora de Area-Zona Oeste 4( $\begin{array}{ccc}\text { Fora de Area-Zona Norte } & 5(\quad) \\ \text { Sem registro } & 9(\quad)\end{array}$

$1(\quad)$
$2(\quad)$
$3(\quad)$
$4(\quad)$
$99(\quad)$

12) Consultas Pré-natal (DNV)

1 a 3

4 a 6

7 ou mais Sem registro

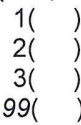

13) Consultas na casa Sem registro $\overline{99()}$

14) Tabagismo

Sim

Não

Parou na gestação Sem registro

Não se aplica: 88 4) Iniciais:

15) $N^{\circ}$ de Gestações Sem registro

16) Paridade......

Primigesta

$$
\text { Sem registro }
$$

17) $N .^{\circ}$ de Partos anteriores

(pode ser mais de 1 alternativa)

17) A Normal

17) B Fórceps

17) C Cesariana

17) D Vácuo-extrator

Não se aplica Sem registro

18) Aborto anterior

Sim

Não Não se aplica
Sem registro

19) Natimorto anterior

Sim

Não

Não se aplica Sem registro

20) Neomorto anterior

Sim

Não

Não se aplica

Sem registro

21) Intercorrência clínica ou obstétrica na gestação

Sim

Não

Sem registro

22) Se sim, descrever

\begin{tabular}{cc}
\hline Não se aplica & 88( \\
Sem registro & 99(
\end{tabular}

\section{ADMISSÃO NA CPS}

23) Data admissão

24) Hora admissão

$1-\frac{1}{\mathrm{~h}}$

25) Idade gestacional DUM) semanas completas Sem registro 99( )

26) Idade gestacional (US) semanas completas

Sem registro 99( )

27) $\mathrm{AU}$ Sem registro
28) Dilatação $\mathrm{cm}$ Sem registro 99()

29) Estado das membranas

Íntegras.

Rotas

Sem registro

30) Amnioscopia

Sim

Não

Não se aplica

Sem registro

1(
2()

99()

31) Condição líquido amniótico

Claro 1(

Meconial

Sanguinolento

$\begin{array}{cr}3(\text { ) } \\ \text { Sem registro } & 99()\end{array}$

1( )

$0(\quad)$

88()

32) Tempo de bolsa rota

(em horas e minutos)

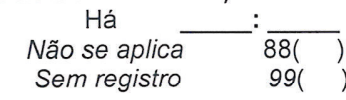

33) Monitorização fetal

$\begin{array}{ll}\text { Sim } & 1( \\ \text { Não } & 0(\end{array}$

Sem registro $99($ )

34) Dinâmica uterina

Ausente

1( )

Sem registro 99()

\section{ASSISTÊNCIA NA CPS}

35) Monitorização fetal

Sim

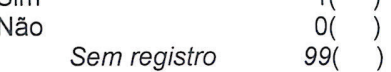

36) Uso de ocitocina

Sim

Não

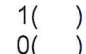

Sem registro

0()

37) Se uso de ocitocina sim,

com dilatação de

$\begin{array}{cc}\text { Não se aplica } & 88( \\ \text { Sem registro } & 99()\end{array}$

38) Ocitocina (período de uso)

Dilatação

Expulsivo

Dequitação

1. ${ }^{\text {a }}$ hora pós-parto Não se aplica Sem registro 
39) Rotura das membranas

Artificial

Espontânea no TP

BR na internação

$$
\text { Sem registro }
$$

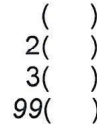

40) Dilatação na rotura

das membranas

$$
\text { Sem registro } 99\left(^{\mathrm{cm}}\right. \text { ) }
$$

41) Controles BCF Sem registro $99 \overline{\quad \text { ) }}$

42) Controles DU

$$
\text { Sem registro } \overline{99(\quad)}
$$

43) Toques vaginais Sem registro $\overline{99()}$

44) Conforto (práticas)

Banho imersão

Banho aspersão

Bola suíça

Massagem

Deambulação

Outro

Sem registro

PARTO NA CPS

45) Posição no parto

Semi sentada

Sims (Lateral)

Cócoras

Em pé

Quatro apoios

Outro

Sem registro

46) Data do nascimento

47) Hora do nascimento

$\begin{aligned} 1( & \text { ) } \\ 2( & ) \\ 3( & ) \\ 4( & ) \\ 5( & ) \\ 6( & ) \\ 99( & )\end{aligned}$

48) Condições do períneo Íntegro

I Grau

II Grau

III Grau

IV Grau

EMLD

Episiotomia mediana Sem registro

49) Dequitação

Espontânea

Manual

Sem registro

50) Presença acompanhante

Sim

Não

Sem registro

99(

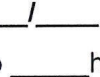

51) Intercorrência no TP e parto

Sim

Não

Sem registro

0()

52) Se sim, descrever

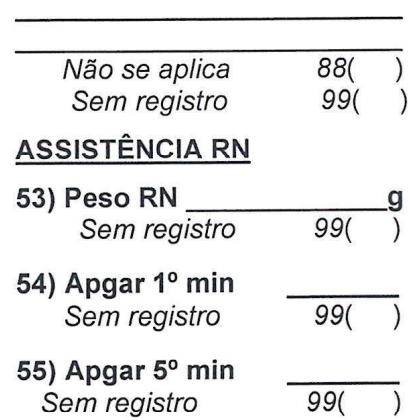

56) Aspiração de VAS

Sim

Não

Sem registro

$1(\quad)$
$0(\quad)$

7) Aspiração gástrica

Sim

Não

Sem registro

99()

$1(\quad)$

99()

58) Lavagem gástrica

Sim

Não

Sem registro

59) Uso $\mathrm{O}_{2}$ nasal

Sim

Não

Sem registro

$1(\quad)$

O( )

60) Uso VPP

Sim

Não

Sem registro

1( )

$0(\quad)$

) Outras manobras de

reanimação

Sim

Não

Sem registro

0( )

62) Se sim, qual

\begin{tabular}{cc}
\hline & \\
\hline Não se aplica & 88( \\
Sem registro & $99(\quad)$
\end{tabular}

63) Intercorrência neonatal

Sim

Não

Sem registro
64) Se sim, descrever

\begin{tabular}{cc}
\hline Não se aplica & $88(\quad)$ \\
Sem registro & $99(\quad)$
\end{tabular}

\section{PÓS-PARTO NA CPS}

65) Intercorrência no pós-parto

Sim

Não

$1(\quad)$

Sem registro 99()

66) Se sim, descrever

$\begin{array}{cc}\text { Não se aplica } & 88(\quad) \\ \text { Sem registro } & 99(\quad)\end{array}$

REMOCÃO PÓS-PARTO

125) Motivo da remoção

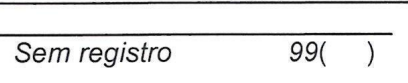

126) Data remoção

Sem registro

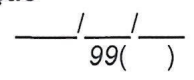

127) Hora remoção

Sem registro

$9 \overline{9()}$

128) Manobras antes remoçao

Ocitocina $1($ )

Curagem 2( )

Hidratação EV 3( )

$\begin{array}{ll}\text { Não se aplica } & 88(\quad) \\ \text { Sem registro } & 99(\quad)\end{array}$

DESFECHO REMOCÃO PÓSPARTO

129) Data internação

$\begin{array}{lll}\text { Não se aplica } & \frac{1}{88}\left(\begin{array}{l}) \\ \text { Sem registro }\end{array}\right. & 99(\quad)\end{array}$

130) Hora internação Não se aplica $88(\quad)$ Sem registro 99()

\begin{tabular}{|c|c|c|}
\hline & $\begin{array}{l}\text { Não se aplica } \\
\text { Sem registro }\end{array}$ & $\begin{array}{l}881 \\
99(\end{array}$ \\
\hline $\begin{array}{l}\text { 132) } \\
\text { parto }\end{array}$ & Intercorrência & no \\
\hline Sim & & 1( \\
\hline Não & & 0( \\
\hline & Não & 881 \\
\hline & Sem registro & 99( \\
\hline
\end{tabular}

131) Unidade de internação materna 
133) Se sim, descrever

\begin{tabular}{|c|c|}
\hline $\begin{array}{l}\text { Não se aplica } \\
\text { Sem registro }\end{array}$ & $\begin{array}{l}88( \\
99(\end{array}$ \\
\hline \multicolumn{2}{|c|}{ 134) Intervenções no hospital } \\
\hline Observação & 0 \\
\hline Curagem & 1( \\
\hline Curetagem & 2( \\
\hline Transfusão sanguinea & 3( \\
\hline Não se aplica & 88( \\
\hline Sem registro & 99( \\
\hline
\end{tabular}

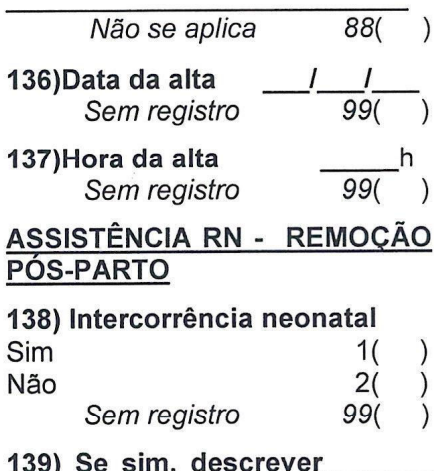

139) Se sim, descrever

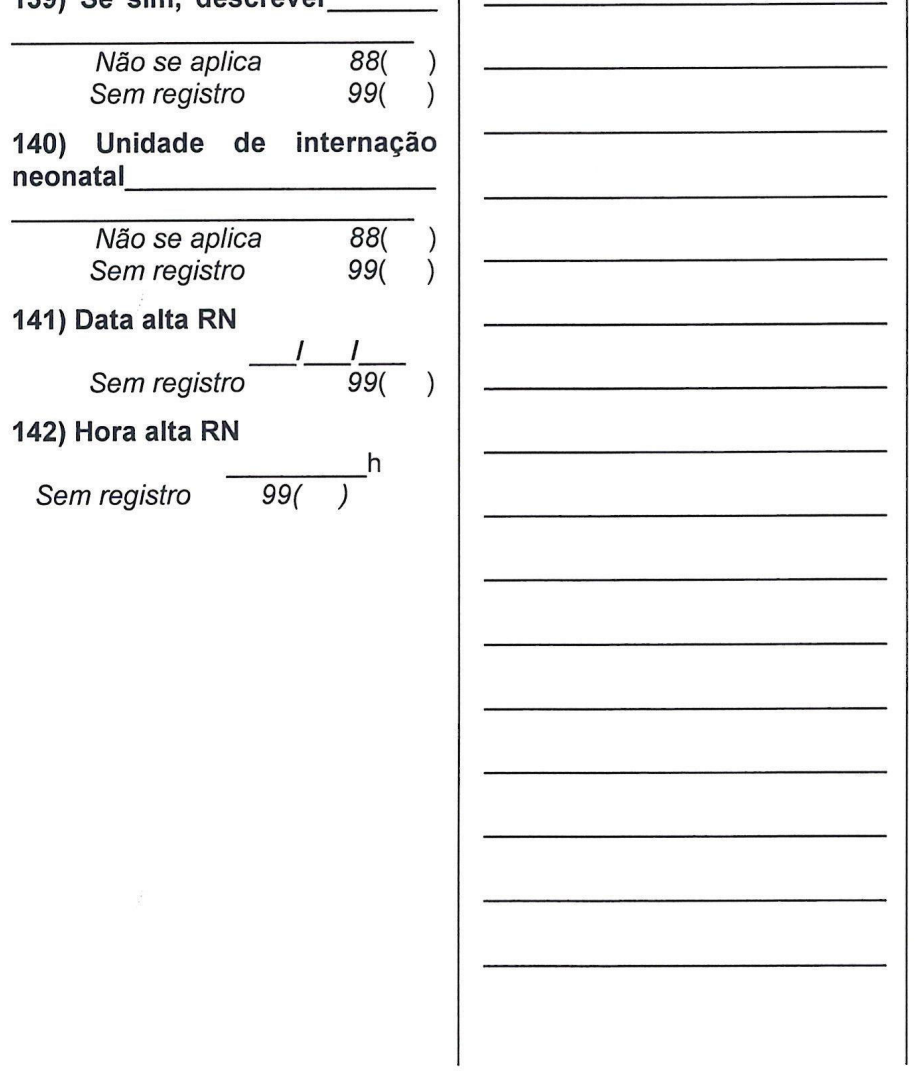
INTERCORRÊNCIAS NO CASO DE REMOÇÃO PÓS-PARTO

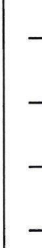

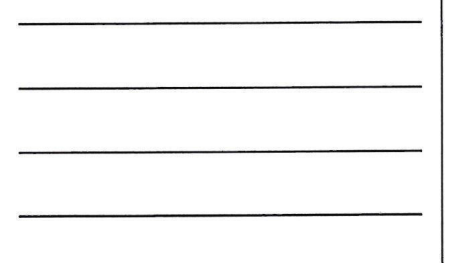

(1)

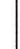

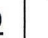

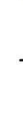

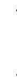
)

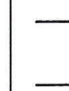
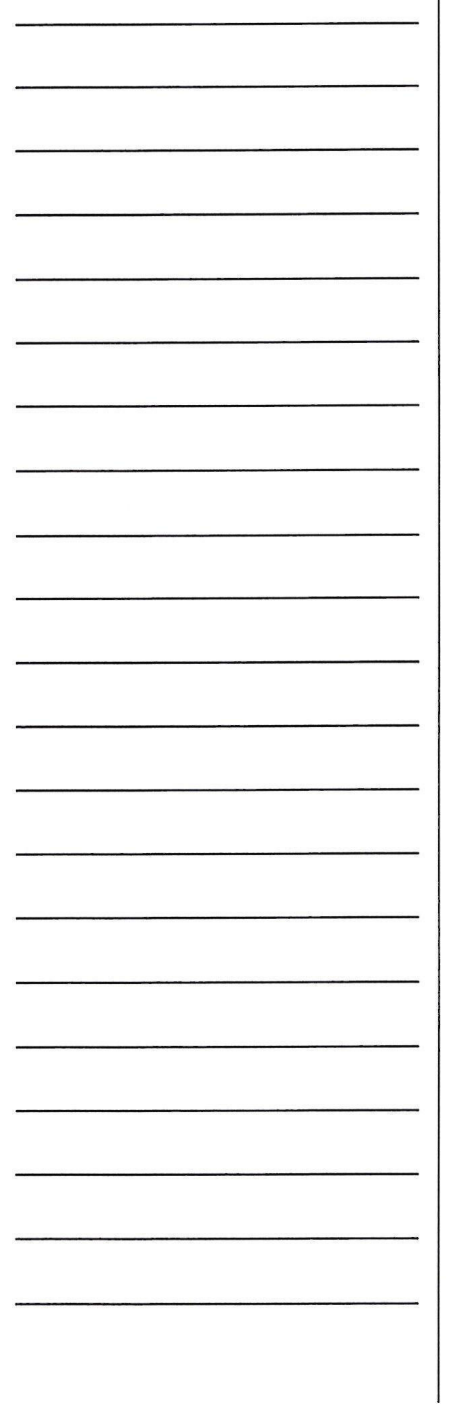

143) ANOTAÇÕES SOBRE 